U.S. Department of Transportation

National Highway

Traffic Safety

Administration

Final Report

\title{
Why People Drink and Drive: The Bases of Drinking-and-Driving Decisions
}


This publication is distributed by the U.S. Department of Transportation, National Highway Traffic Safety Administration, in the interest of information exchange. The opinions, findings and conclusions expressed in this publication are those of the author(s) and not necessarily those of the Department of Transportation or the National Highway Traffic Safety Administration. The United States Government assumes no liability for its contents or use thereof. If trade or manufacturers' name or products are mentioned, it is because they are considered essential to the object of the publication and should not be construed as an endorsement. The United States Government does not endorse products or manufacturers. 


\begin{tabular}{|l|l|l|}
\hline 1. Report No. & 2. Govemment Accession No. & 3. Recipient's Catalog No. \\
DOT HS 808251 & & \\
\hline $\begin{array}{l}\text { 4. Title and Subtitle } \\
\text { Why People Drink and Drive: - The Bases of Drinking-and- }\end{array}$ & 5. Report Date \\
$\begin{array}{l}\text { Driving Decisions } \\
\text { 7. Author(s) } \\
\text { McKnight, A.J; Langston, E.A.; McKnight, A.S.; Resnick, J.A.; Lange, J.E. }\end{array}$ & \begin{tabular}{c} 
8. Performing Organization Report No. \\
\hline $\begin{array}{l}\text { 9. Periorming Organization Name and Address } \\
\text { National Public Services Research Institute, 8201 Corporate Drive, Suite 220, } \\
\text { Landover, MD 20745 }\end{array}$
\end{tabular} & $\begin{array}{c}\text { 10. Work Unit No. (TRAIS) } \\
\text { DTNH22-91-C-07128 }\end{array}$ \\
\hline $\begin{array}{l}\text { 12. Sponsoring Agency Name and Address } \\
\text { U.S. Department of TransportationNational Highway Traffic Safety } \\
\text { Administration }\end{array}$ & $\begin{array}{c}\text { 13. Type of Report and Period Covered } \\
\text { Final Report 9/91-7/94 }\end{array}$ \\
\cline { 2 - 3 }
\end{tabular}

Ms. Amy Berning served as Contracting Officer's Technical Representative

16. Abstract

Using a Critical Incidents approach, 600 drivers were called upon to identify the bases of decisions to drink and drive. In an unstructured interview, each driver described the bases for decisions leading to specific instances of impaired driving, including decisions regarding participation in drinking events, transportation to events, plans prior to and following initiation of drinking, activities while drinking, leaving the drinking event, and transportation following drinking. Over 12,000 individual decision bases were described. While the bases were highly specific to the individual decisions, those involving the social environment exerted the strongest influence, followed in decreasing order by influences of a personal nature, the occasion giving rise to drinking, economic considerations, plans already made, and usual patterns of behavior. Results evidenced the need for 1) friends, hosts and sellers of alcohol to avoid inadvertent encouragement to over-consumption of alcohol and driving while impaired, 2) better planning in providing alternatives to drinking as well as driving, and 3) helping drinkers and those around them to redefine what they perceive as their "responsibilities" with respect to situations leading to alcohol impaired driving.

\begin{tabular}{|l|l|l|l|}
\hline $\begin{array}{l}\text { 17. Key Words } \\
\text { Drinking, Drinking and Driving, }\end{array}$ & $\begin{array}{l}\text { 18. Distribution Statement } \\
\text { Document is available to the } \\
\text { public through the National } \\
\text { Alcohol Impaired Driving } \\
\text { Springfield, Virginia 22l61 }\end{array}$ \\
\hline $\begin{array}{l}\text { 19. Security Classif. (of this report) } \\
\text { Unclassified }\end{array}$ & $\begin{array}{l}\text { 20. Security Classif. (of this pagol } \\
\text { Unclassified }\end{array}$ & $\begin{array}{l}\text { 21. No. of Pages } \\
\text { 22. Price }\end{array}$ & 123 \\
\hline
\end{tabular}

Form DOT F 1700.7 (8-72) Reproduction of completed page authorized . 
INTRODUCTION $\ldots \ldots \ldots \ldots \ldots \ldots \ldots \ldots \ldots \ldots \ldots \ldots \ldots \ldots \ldots \ldots \ldots \ldots \ldots$

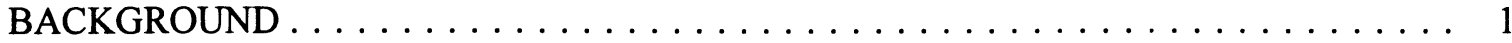

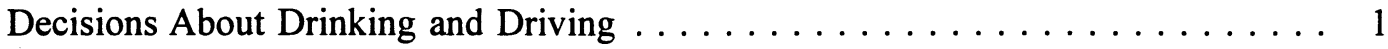

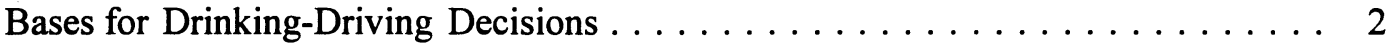

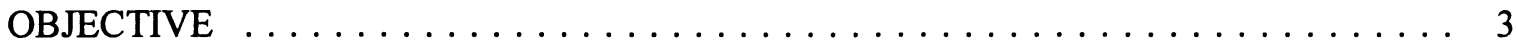

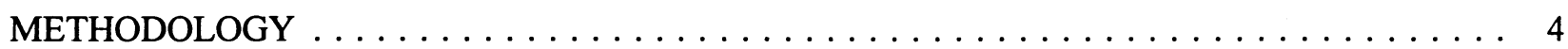

CRITICAL INCIDENT APPROACH $\ldots \ldots \ldots \ldots \ldots \ldots \ldots \ldots \ldots$

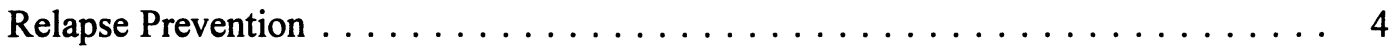

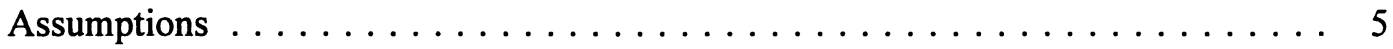

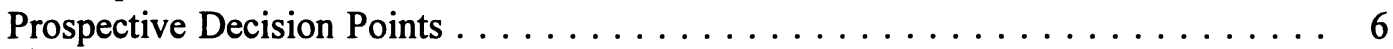

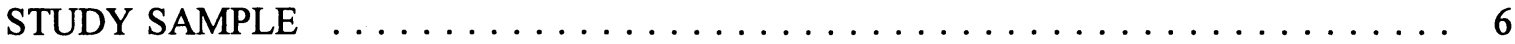

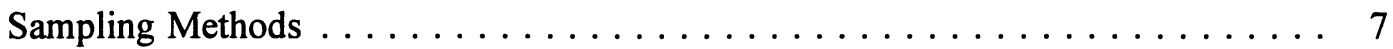

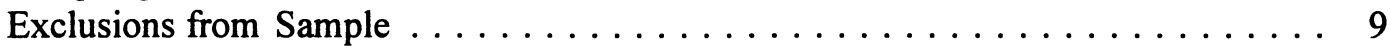

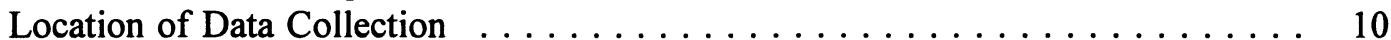

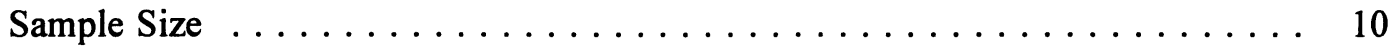

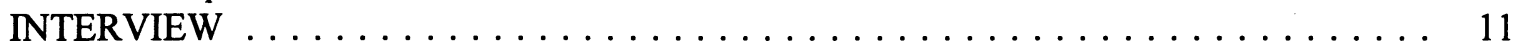

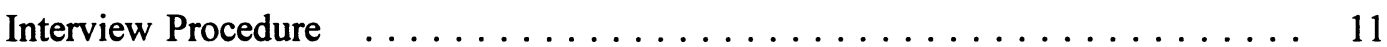

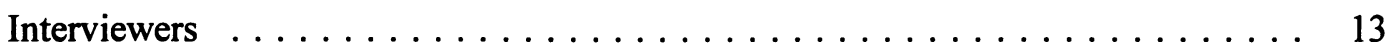

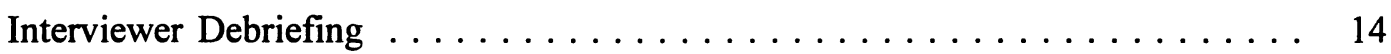

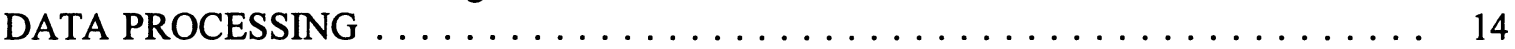

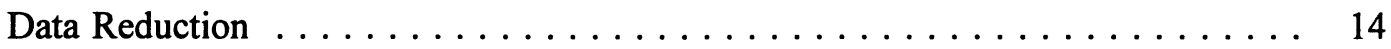

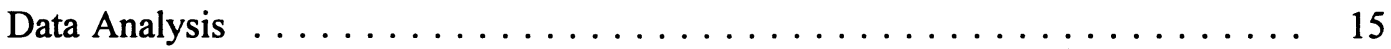

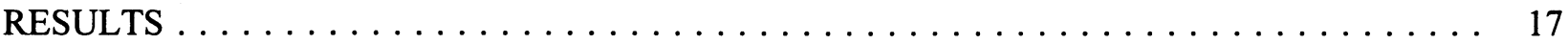

SAMPLE CHARACTERISTICS $\ldots \ldots \ldots \ldots \ldots \ldots \ldots \ldots \ldots \ldots \ldots \ldots$

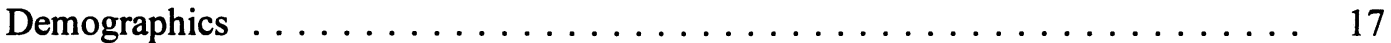

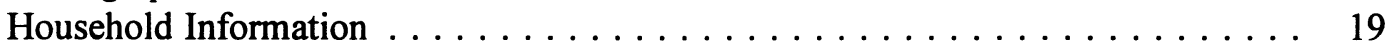

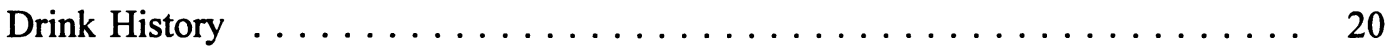

DEMOGRAPHIC GROUPS USED FOR ANALYSIS $\ldots \ldots \ldots \ldots \ldots \ldots \ldots \ldots \ldots$

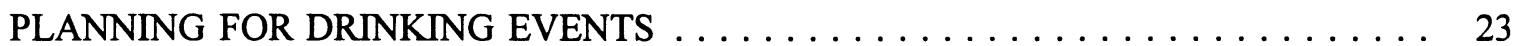

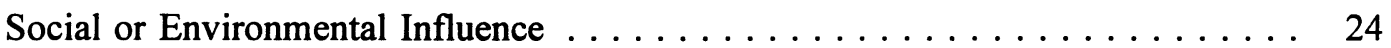

Personal Influence . . . . . . . . . . . . . . . . . . . . . . . . 27

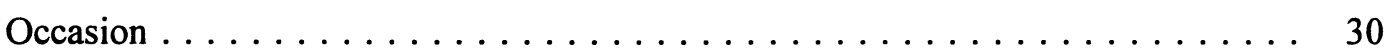

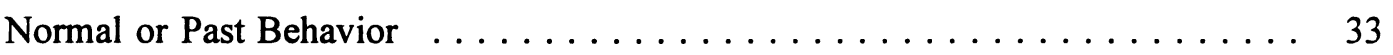

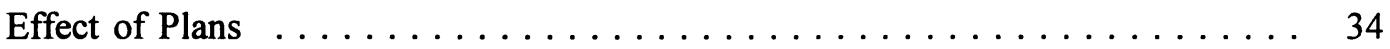

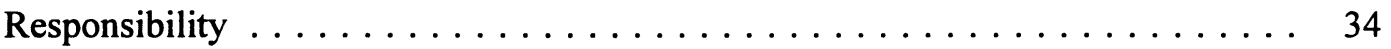

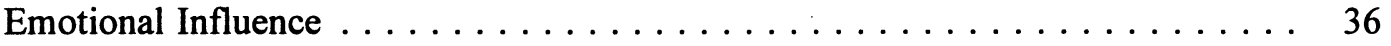

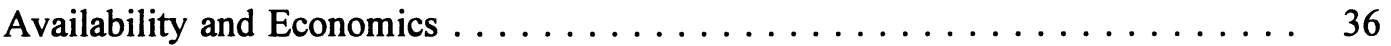

TRANSPORTATION DECISIONS $\ldots \ldots \ldots \ldots \ldots \ldots \ldots \ldots \ldots \ldots \ldots \ldots \ldots$

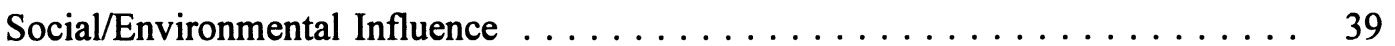

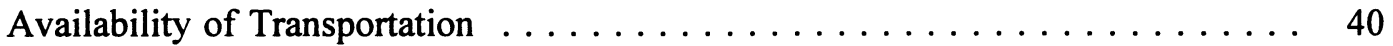

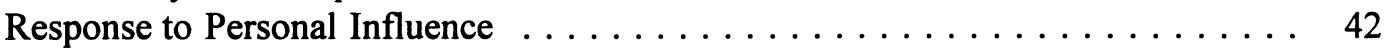

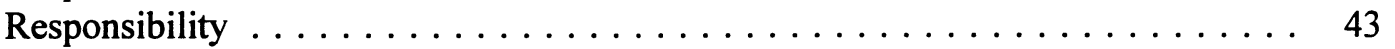

Vehicle-Related Factors $\ldots \ldots \ldots \ldots \ldots \ldots \ldots \ldots \ldots$. . . . . . . . . . . 44

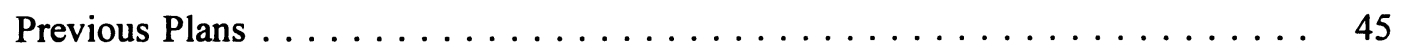

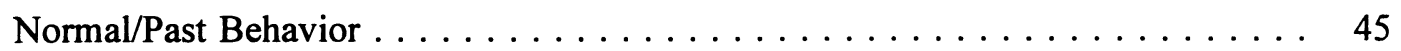


PLANNING FOR DRINKING $\ldots \ldots \ldots \ldots \ldots \ldots \ldots \ldots \ldots \ldots \ldots \ldots \ldots$

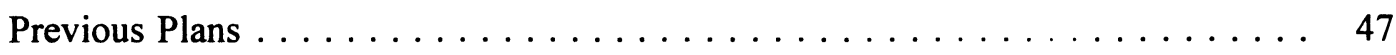

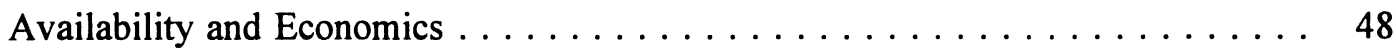

Normal Drinking Pattern $\ldots \ldots \ldots \ldots \ldots \ldots \ldots \ldots \ldots \ldots$

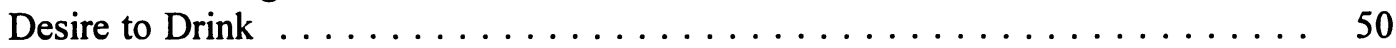

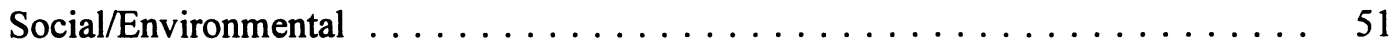

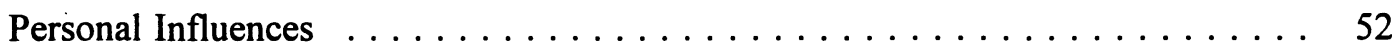

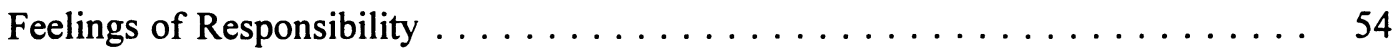

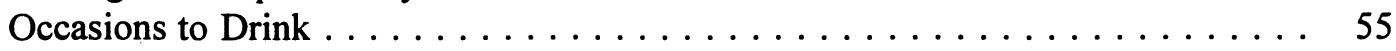

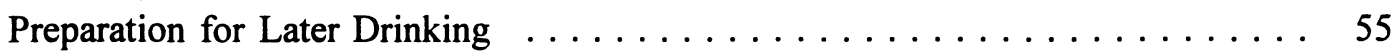

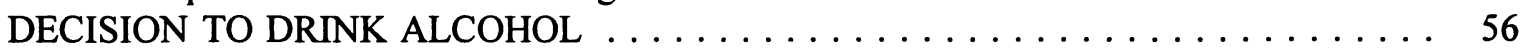

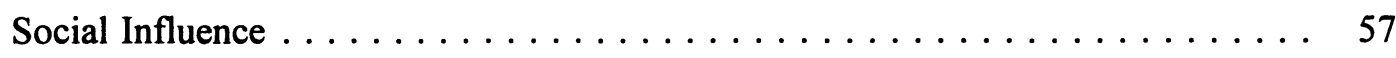

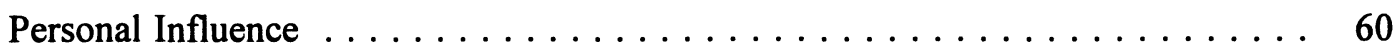

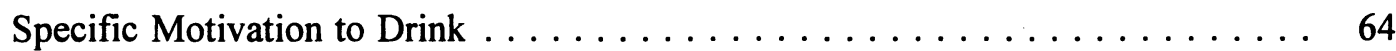

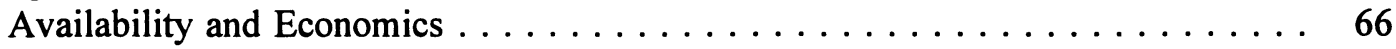

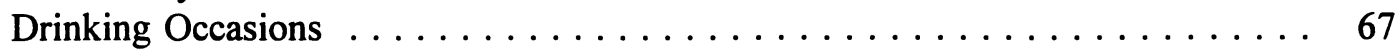

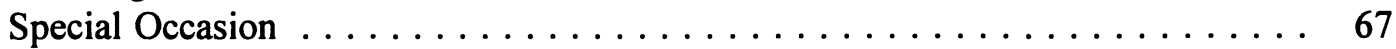

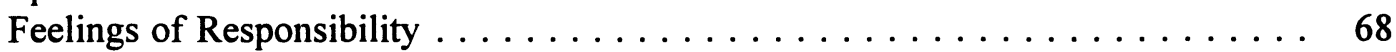

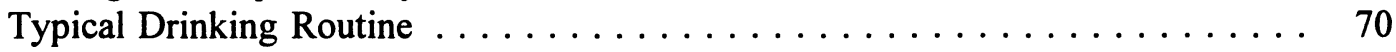

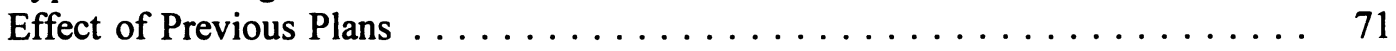

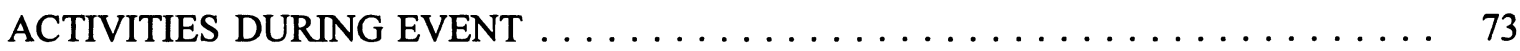

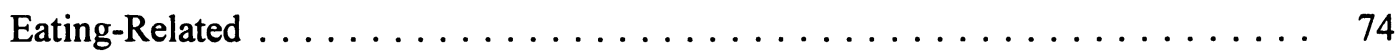

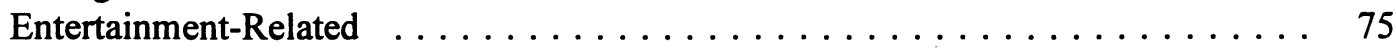

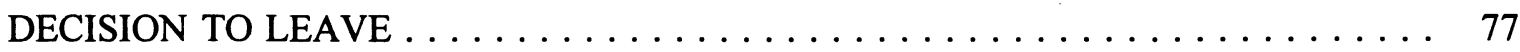

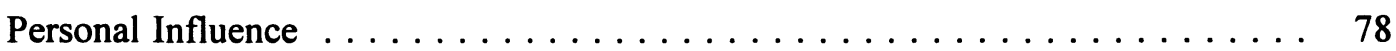

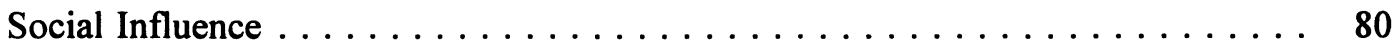

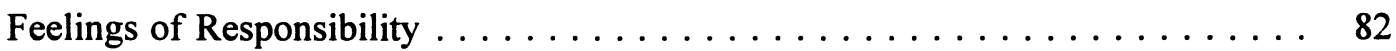

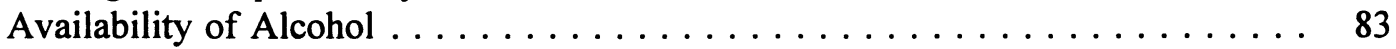

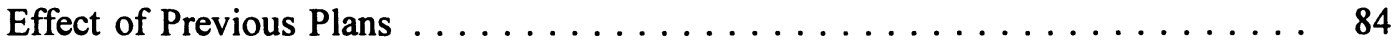

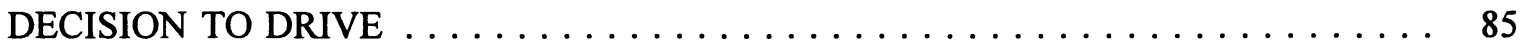

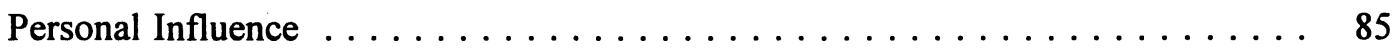

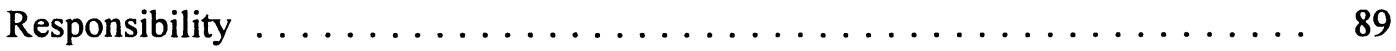

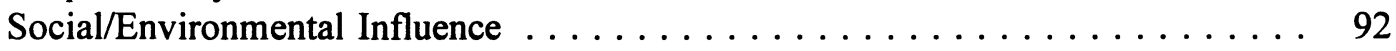

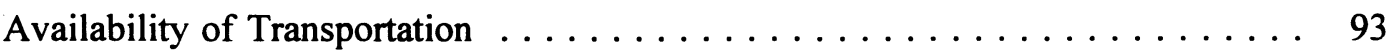

Vehicle-Related Factors . . . . . . . . . . . . . . . . . . 94

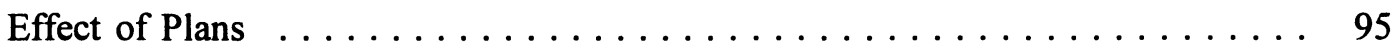

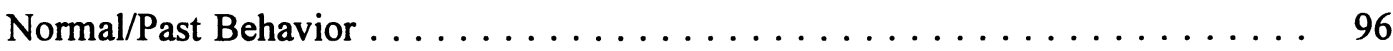

DEMOGRAPHICS AND DECISION BASES $\ldots \ldots \ldots \ldots \ldots \ldots \ldots \ldots \ldots \ldots$

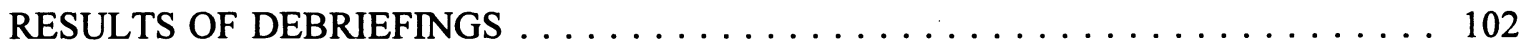

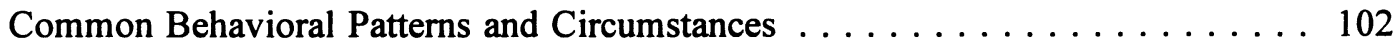

Suggested Countermeasures . . . . . . . . . . . . . . . . . . . . . . . 109

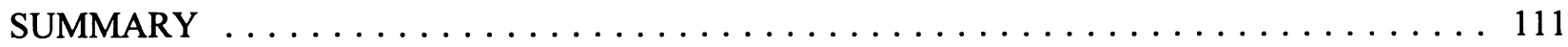

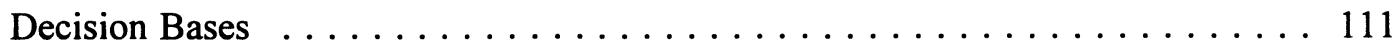

Implications for Action $\ldots \ldots \ldots \ldots \ldots \ldots \ldots \ldots \ldots \ldots \ldots \ldots \ldots$

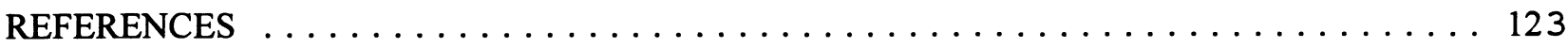




\section{INTRODUCTION}

\section{BACKGROUND}

The role of alcohol in highway deaths and injuries is too well documented to require elaboration here. Although the proportion of highway fatalities attributable to alcohol is diminishing, 1992 figures show that $21.9 \%$ of fatally injured drivers had a blood alcohol concentration (BAC) in excess of the $.10 \%$ that defines illegal intoxication in most States (NHTSA, 1993). While the involvement of alcohol in non-fatal automobile accidents is less well known, it is estimated that many drivers in such accidents had been drinking. A recent roadside survey disclosed that, in prime drinking hours, approximately $29.9 \%$ of drivers had measurable amounts of alcohol in their system, with $3.1 \%$ over .10\% BAC (Lund \& Wolfe, 1989).

\section{Decisions About Drinking and Driving}

Very few people set out to become drunk drivers; at least very few admit to it. However, they do set out to drink when they know they are going to drive, and they do set out to drive when they know they are going to drink. The variables that underlie these decisions have been among the more extensively studied aspects of the drinking-driving problem. Youth have been the primary subjects of inquiry. Efforts to uncover the basis for drinking and driving decisions by youth are found in studies by Grey Advertising (1975); Biddle, Biddle, and Bank (1980); Khron, Ackers, and Radosevich (1982); Nusbamer and Zussman (1981); Millgram (1982); Smith-Donals, Smith, and Klitzner (1985); Klitzner, Rossaper, Gruenewald (1987); Vegega and Klitzner (1989); Basch, Decicco, and Malfetti (1989); Basch (1987); and Biddle, Bank, and DeMarlin (1980) and Quint, Jackson and Zhao (1993). A "Compendium of Highway Safety Questionnaire Items" by the National Highway Traffic Safety Administration (NHTSA, 1987) reports on the surveys carried out in several states through interviews, mailouts, and telephone surveys.

From the various reports cited, the following statements concerning drinking and driving may be offered:

- Many people who drink and drive do so with other intoxicated passengers.

- One-quarter of the people who take steps to avoid drinking and driving do so to avoid legal penalties and one-quarter do so out of the fear of an accident.

- Among young people, about half of them do not believe that it is risky to drink and drive.

- For youth, parents were seen as having a significant effect on drinking and driving. 
- Many youth are hesitant to ask parents for rides in a drinking situation due to fear of the parent's response.

- When describing a person who is "drunk," often the only the signs of intoxication mentioned are those that arise at the extreme end of the drinking continuum.

- Many people believe in some of the fallacies concerning drinking and driving (e.g., coffee sobers people up, people can relax and drive better after a few drinks or that some alcoholic drinks are much more intoxicating than others).

- For young people, religion does not appear to be a discouraging factor for drinking and driving.

- One of the most frequently given reasons for driving after drinking is to avoid leaving the car.

- Among youth who drink and drive, many list the need to get somewhere - most commonly home or to get a passenger home - as the motivating factor.

- One of the alternatives to drinking and driving most commonly listed by youth is to wait to sober up. Other alternatives are just not going, calling someone other than a parent, calling a parent, or taking a bus or cab.

- Reasons for not using the above alternatives include the belief that they are not feasible, that driving presented no real danger, that the driver was the most sober possible person available, or that it was necessary to get somewhere.

\section{Bases for Drinking-Driving Decisions}

Extensive research has provided an abundance of information about the basis of decisions to drink, to drive, to drink and drive, or to intervene in any of these. However, insofar as providing a picture of the bases for drinking and driving, the results of this are not highly informative. One reason is the nature of the information that drinkers are called upon to provide, primarily answers to specific questions about particular decision bases. While these structured surveys yield valuable information, it is limited by the questions that are asked. Whatever researchers failed to anticipate, those surveyed could not provide. A second limitation of the surveys that have been conducted is that they call upon drinking drivers to extract generalities from a number of different experiences, covering a broad period of time. Valid generalizations require subjects to recall incidents related to drinking and driving, recollect or reconstruct the bases for decisions that occurred, and synthesize the results of such reminisces into some set of generalities - all in a few seconds. Without faulting previous research, it seems reasonable to suggest that more might be gained from an approach which called upon drinking drivers to explain their own decision bases rather than reacting to lists prepared by others, and which calls 
upon subjects only to recall recent incidents of drinking and driving rather than expecting them to generalize across experiences that encompass a broad range of time and place.

\section{OBJECTIVE}

The objective of the effort described in this report was to identify:

- The decisions leading up to instances of alcohol-impaired driving.

- The bases of drinking-and-driving decisions.

- The individual characteristics associated with riving decisions and their bases.

- Implications for action. 


\section{METHODOLOGY}

In order to fulfill the stated project objectives, it was necessary to develop an analytic process capable of identifying the basis of DWI decisions more precisely and more validly than the processes employed thus far. One can see a parallel between the current status of inquiry into the sources of drinking and driving and that which prevailed with respect to highway crashes 25 years ago. Until that time, the primary route of access to the antecedents of automobile accidents was people - police officers, insurance representatives, and others who visited accident scenes or talked with accident victims. While the information gathered from these sources was interesting, and provided the grist for popular articles on how to "stop senseless slaughter on the highways," it was too superficial to serve as a basis for concrete measures to improve highway safety.

The inadequacy of available safety information became evident when passage of the Highway Safety Act of 1966 gave both impetus and funding to highway safety countermeasures. A need for accurate information as to the causes of traffic accidents, information that could be used to prioritized safety effects, was quickly recognized. The response to this need was not to compile generalities about accident causes, but rather to collect information about specific accidents. This took place through a series of multi-disciplinary in-depth accident investigations. In time, the various independent efforts were welded into a continuous, ongoing, in-depth accident investigation program.

\section{CRITICAL INCIDENT APPROACH}

The application of accident analysis to the improvements in the highway transportation system can be viewed as an extension of what has been called the "critical incident technique." This approach to seeking improvement in human performance, originally formalized almost 50 years ago, identified specific incidents that are critical to the functioning of the system under study. The incidents could be critical to either success or failure of the system. Historically, it is failures that have been the most frequently and most extensively analyzed. The reason is primarily that successful functioning of most systems, such as the highway transportation system, involves normal operation of the system rather than specific instances of "critical" performance. From a research viewpoint, it is the system failures which produce the documentation needed to identify causes. For example, in automobile travel, success in reaching one's destination safely and expeditiously is more or less expected and neither claims the attention nor generates the documentation that an accident does.

\section{Relapse Prevention}

Returning to the subject of drinking and driving, the literature reveals no attempt to study drinking and driving decisions through a large-scale analysis of critical incidents. Probably the closest application of the critical incidence technique in alcohol safety is the use of the technique in "relapse prevention," that is preventing people who were once dependent upon alcohol from relapsing into such a condition. Marlatt and Gordon (1983) have attempted to identify the 
specific incidents that most often lead to relapse with the hope of helping recovering alcoholics to better deal with such incidents. While alcohol dependency itself is too insidious to be traced to any specific events, relapses are acute and associated with the same kinds of bad decisions that produce driving while intoxicated.

Relapse analysis involves the step-by-step examination of events leading up to a relapse with a focus upon decisions arising in choices made. Relapses, like drinking and driving, are typically the result of several bad decisions, any one of which if altered could have changed the outcome. In summaries of relapse episodes studied by Marlatt and his associates, the first incident of drinking, the one that "breaks the streak" of sober days, can be an event that crops up unexpectedly, as the last link in a clear chain of events.

\section{Assumptions}

Application of the critical incident approach to the discovery of influences upon drinkingdriving decisions is based upon the following assumptions:

1. A chain of events leading to an incident of drinking and driving can be identified.

2. Along the chain of events, there are decision points, the response to which can have a crucial impact upon drinking and driving.

3. Analyzing specific incidents of drinking and driving can provide a valid means of identifying the bases of decisions leading to alcohol-impaired driving.

4. Identifying the bases of drinking-driving decisions will help lead to countermeasures which could be introduced to...

a. Anticipate and avoid the situations that give rise to decision situations associated with high risk of drinking and driving.

b. Alter the decision bases to reduce the likelihood of drinking and driving.

Use of the critical incidence technique in achieving the objectives of the study involved analyzing the events leading up to specific incidents of driving while impaired in order to identify the decision situations arising, the decisions made, the bases for the decisions, and the alternatives that were available. When aggregated across large numbers of incidents, such a systematic process should lead to a more precise, more valid identification of drinking-driving decisions than can be achieved through processes that call upon drivers to generalize from drinking-driving experiences through questionnaires, interviews, or focus groups. 


\section{Prospective Decision Points}

At least seven possible decision points can be identified along the path to driving while intoxicated. These include:

Planning for Drinking Events - Decisions about participating in the events that lead to drinking and driving (e.g., whether to go, where to go, etc.).

Transportation Decisions - Decisions about transportation to the events (e.g., whether to drive or ride, whether to turn over keys).

Planning for Drinking - Decisions about drinking made prior to the event (e.g., whether to bring alcohol, whether to drink before starting out).

Decisions to Drink - Decisions about drinking made at the event (e.g., when to start, setting a limit, slowing down, stopping, switching drinks).

Activities During the Event - Decisions regarding participation in other activities which may affect the level of alcohol impairment (e.g., eating, dancing, drinking games).

Decisions to Leave - Decisions regarding leaving the drinking location (e.g., whether to leave, where to go).

Decisions to Drive - Decisions regarding driving after drinking (e.g., whether to drive or ride).

Initially, some consideration was given to broadening the scope of the critical incident analysis to include decisions on the part of those who might have intervened in the various decisions leading up to an incident of drinking and driving. However, during exploratory applications of the analysis, two obstacles to the inclusion of intervenors quickly appeared. First, each incident spanned a range of places, times, and perspective intervenors. Comprehensive analysis of intervention decisions underlying any one incident could involve several people. A more formidable obstacle was, however, the reluctance of drinkers to identify potential intervenors, much less agree to and secure their participation in review of the drinking-driving events. While some may have been influenced into accepting involvement of intervenors, the result would have been a highly biased selection of both drinkers and intervenors and less than candid accounts of decision bases. Clearly, the objectives of the study were best served by confining its scope to drinkers, and leaving the study of intervention to another project.

\section{STUDY SAMPLE}

In order to reveal accurately the decisions that lead to alcohol impaired driving, and the bases for these decisions, the sample of drivers from whom information was to be obtained had to be generally representative of the impaired driving population at large. Since the objective of 
the study was one of discovery rather than parameter estimation, the sample did not need to duplicate exactly the characteristics of the impaired driving population. Yet, if the information is to serve as a basis for prioritizing countermeasures, then the relative frequency with which the various decisions and bases are reported should be generally proportional to their frequency within the impaired population.

\section{Sampling Methods}

Generally speaking, there are two ways of securing a representative sample. One is to sample randomly from within a large population, trusting to random processes to assure that each individual within the population has an equal chance of being sampled and that target groups will be sampled in numbers that are proportional to their numbers in the population. The limitation of such proportional sampling is that lightly populated subgroups become represented by numbers that are too small to furnish reliable information. The alternative is disproportional sampling, that is basing the numbers of subjects in each target group on other than their relative numbers in the population, then differentially weighting the results in proportion to population numbers in order to obtain accurate estimates of what would be results for the population at large.

While interest in certain subcategories of alcohol impaired drivers certainly existed, disproportional sampling of target groups was precluded by inability to identify characteristics of alcohol-impaired drivers in advance in order to single out individuals for inclusion in the study. The only way to have obtained adequate numbers of under-represented groups would have been to contact extremely large numbers of individuals, obtaining sufficient information concerning their drinking, driving and other characteristics to permit adequate numbers within each individual target group to be recruited for the final sample. The cost of such a sampling scheme greatly exceeded any benefits of being able to sample disproportionately within target groups. The approach taken was therefore to identify sampling methods that would come as close as possible to yielding representative cross-sections of alcohol impaired drivers. Three parallel sources of subjects were employed: random surveys, DWI service providers, and roadside survey.

\section{Random Solicitation}

The most representative sample of any population is one drawn at random from that population. Since no defined population of people who have driven while alcohol impaired exists, no truly random sample is available. The most common approach is to identify people at random from some list, such as telephone directory or driver license file, and collect information from those who have acknowledged driving while alcohol impaired. Since data would be collected through interviews, as will be discussed, the solicitation of participants was confined to the metropolitan area surrounding each of the data collection sites employing this sampling method. Within each site, names were selected at random from the list of residential telephone numbers (for several reasons, random-digit dialing did not provide an efficient means of soliciting subjects in this application). 
While the sampling method described yielded a sample of households which is highly representative of those within the area, and likely to be acceptably representative of the country at large, the sample of subjects obtained through the process would not be representative of that initially solicited. Sources of sample losses were the following:

Failure to Contact - Even with repeated call backs, only $42 \%$ of those solicited were eventually contacted. It is likely that many calls were being screened by answering machines.

Lack of Cooperation - Many of the subjects contacted (30\%) were not willing to participate, or even to be solicited (they hung up immediately).

Failure to Qualify - Of those contacted, 64\% were either non-drivers, non-drinkers or did not acknowledge drinking and driving.

Misinformation - Among those not cooperating were undoubtedly some who had driven while impaired but were unwilling to admit it. Their absence from the sample may have introduced a bias that simple non-participation did not.

Because of these losses, the subjects ultimately obtained through telephone solicitation represent only $10.5 \%$ of the sample selected on a random basis from telephone lists.

\section{DWI Service Providers}

Agencies providing services to DWIs can furnish access to drivers known to have operated vehicles while impaired. In some jurisdictions, the clientele of DWI programs includes a very large proportion of those apprehended for alcohol impaired driving, including both those convicted and those diverted into various programs in lieu of conviction. One characteristic that makes DWIs a particularly attractive source is the high participation rate of those solicited. By arranging data collection through service providers, close to $100 \%$ participation was achieved. Second, the fact that data collection could take place as part of the DWI program itself minimized the size of the financial inducement required to gain participation. Finally, a sample recruited from the ranks of DWIs is known for certain to have driven while alcohol impaired and under conditions that are likely to have made circumstances surrounding the event particularly memorable. For all these reasons, a sample obtained through DWI service providers appeared likely to be more representative of alcohol impaired drivers in general than one secured through what were initially random processes.

\section{Roadside Surveys}

There is little doubt that the most representative sample of alcohol-impaired drivers is that secured through roadside surveys. Drivers pulled out of the traffic stream at randomly selected locations constitute as close to a random sample of drivers on the road at that particular time as is obtainable. Given the high participation rates that typically prevail at roadside surveys, 
in the neighborhood of $95 \%$, and the fact that the blood alcohol concentration of each participant is accurately measured, a driver identified as impaired through roadside surveys is likely to be highly representative of alcohol impaired drivers in general.

A challenge to use of roadside surveys as a source of information concerning drinkingdriving decisions in the present study was the length of time required to secure the information sought, which greatly exceeded the time people were generally willing to make available during a roadside survey. While surveys can provide an opportunity to identify and contact alcoholimpaired drivers, the task of obtaining participation is similar to that encountered with drivers contacted by telephone. A second challenge to use of roadside surveys is the cost of conducting such surveys, which would have been prohibitive in the present study.

Fortunately, it was possible to take advantage of a roadside survey as part of followup interviews being conducted by the Vermont Alcohol Research Center (VARC) in Canton, Ohio. With the aid of local police, drivers were stopped on a random basis, at varying locations, during prime drinking hours, $10 \mathrm{pm}-2 \mathrm{am}$. Those found to have BACs in excess of $.08 \%$ were invited to participate in a later interview. Approximately two-thirds of the drivers stopped agreed to participate in the interview. Through an arrangement with VARC, drivers responding favorably to the interview solicitation were offered an opportunity to extend the duration of their interview in order to take part in the study of their decision bases. Of those taking part in the VARC interview program, nearly all accepted the offer to participate in the study of their decision bases. This relatively high participation rate and known blood alcohol levels of participants, along with the likelihood that decisions leading up to such a recent and salient event would be clearly recalled, made the availability of the VARC sample well worth exploiting.

\section{Exclusions from Sample}

A category of alcohol impaired drivers excluded from the sample consisted of people who were dependent upon alcohol to the point that they maintained positive blood alcohol levels continuously and were likely to be over the limit most or all the time. Generally referred to as alcoholics, drivers in this group are largely beyond making decisions about their drinking.

Exclusion of alcoholics from the sample was complicated to some extent by the difficulty in identifying them prior to collection of data. Where subjects were recruited from the ranks of convicted DWIs, information secured through available documentation often identified certain individuals as being chemically dependent. For those not identifiable in this manner, two exclusion criteria were imposed:

Prior Record - Anyone with a prior conviction for alcohol impaired driving was excluded on the grounds that such a record indicated repeated drinking symptomatic of chemical dependency.

High Blood Alcohol Level - Anyone known in advance of having a BAC in excess of $.20 \%$ was excluded on the grounds that individuals at this level who are capable of 
functioning well enough to operate an automobile also come primarily from the ranks of the chemically dependent.

Because purchase, possession, and/or consumption of alcohol is illegal throughout the U.S., one might consider youth admitting having driven while alcohol impaired to be incriminating themselves. This issue only concerned subjects obtained through the random survey; any youth appearing among convicted DWIs and the roadside surveys had already revealed themselves as having violated the law. For those obtained from the random solicitations, special procedures were instituted to protect identities, even though they were in no jeopardy for acknowledging consumption of alcohol some time in the past. When subjects revealed their ages and were found to be under age 21 , no identifying information was collected.

\section{Location of Data Collection}

The face-to-face contact required in collecting data from the various groups of drinking drivers precluded representative sampling from across the entire country. Nevertheless, it was important that the data collection effort be carried out at more than one site in order to assure that the results were not biased by location-specific characteristics, such as DWI laws, drinking customs, the availability of alcohol or other variables.

For each of the two primary data collection methods, random telephone solicitation and DWI Service providers, two sites were selected; one urban and one rural. The four sites, plus the site added to take advantage of the roadside survey, were as follows:

\begin{tabular}{||l|l|l|l|c||}
\hline Solicitation & \multicolumn{1}{|c|}{ Location } & \multicolumn{1}{|c|}{ Organization } & \multicolumn{1}{|c|}{ Setting } & $\begin{array}{c}\text { No. of } \\
\text { Interviews }\end{array}$ \\
\hline Telephone & North Carolina & Mid-America Research, Inc. & Rural & 125 \\
\hline DWI & Mississippi & Mississippi State University & Rural & 125 \\
\hline Telephone & $\begin{array}{l}\text { Metro Washington, } \\
\text { D.C. }\end{array}$ & $\begin{array}{l}\text { National Public Services } \\
\text { Research }\end{array}$ & Urban & 125 \\
\hline DWI & California & $\begin{array}{l}\text { Occupational Health } \\
\text { Services }\end{array}$ & Urban & 125 \\
\hline Roadside & Ohio & $\begin{array}{l}\text { Vermont Alcohol Research } \\
\text { Center }\end{array}$ & $\begin{array}{l}\text { Urban/ } \\
\text { Rural }\end{array}$ & 100 \\
\hline
\end{tabular}

\section{Sample Size}

Because the objective of the study was primarily one of description rather than hypothesis testing, and the variables under study were largely qualitative - decision bases, alternatives, influences upon choice - the use of statistical power as a means of setting sample sizes was not appropriate. The original sampling plan called for a total of 150 subjects to be interviewed at 
each of the four sites. The result would be a total of 600 subjects, equally divided between rural and urban settings, and between telephone solicitations and DWIs. When the opportunity arose to interview 100 DWIs identified through a roadside survey, the quotas for each of the four remaining sites was reduced to 125 .

\section{INTERVIEW}

All information on drinking subjects was obtained through interviews.

\section{Interview Procedure}

The interview process was basically the same for all sites. Subjects were given some basic information on the purpose of the study and assured that the interview would be confidential. Subjects were asked to recall the details surrounding one incident in which the subject drove after drinking. Interviews generally lasted from 30 to 60 minutes. The interviews were all audio-recorded and the tapes sent to project offices in Landover, Maryland. Tapes were reviewed to make certain that proper procedures were being followed (e.g., avoiding leading questions, sticking to the events of one incident and making certain that subjects discussed the incident in sufficient depth). Interviewers continued to receive feedback on their interviews throughout the interview period.

During the interviews, subjects were first asked to recall one specific incident that occurred within the previous twelve months that resulted in their alcohol impaired driving. In the case of the DWI offenders and drivers obtained through roadside surveys, the incident was the one that resulted in the contact. Drivers reached through random telephone solicitation were asked to recall the most recent episode of impaired driving. Subjects were then asked to describe the general details concerning that incident including the amount of alcohol consumed and the distances driven. They were then asked to go back and describe in detail the specific decisions, and motivation underlying those decisions, for each of the decision points of interest, i.e., plans to attend, transportation plans, drinking plans made prior to attending, drinking behavior during the incident, decisions to eat or take part in activities, when to leave, whether to drive after drinking and whether to take advantage of alternatives to drinking or driving.

As much as possible, subjects were allowed to tell their stories without interference from interviewers. It was generally necessary to ask questions regarding decision points and alternatives not mentioned by the subject. It was also often necessary for the interviewer to keep subjects from digressing into generalities regarding drinking and driving or other information not related to the incident in question.

After all of the decision points were identified, interviewers reviewed each in turn, querying the subject as to what alternative choices were available, what alternatives might have worked to avoid having the drinking-driving situation occur, and what alternatives they may have been willing to use. In generating the possible influences on alternative choices, subjects were encouraged to think both of immediate and long-term influences. Alternatives were specifically 
investigated for decisions regarding attending the event, drinking at the event, leaving while impaired, and driving while impaired. For decisions regarding the choice of transportation to the event, the availability and practicality of alternatives was integrally related to the decision bases, so no separate discussion of those alternatives was warranted.

Since the objective of the interview was to discover what was unknown about drinkingdriving decisions, rather than to quantify what is already known, the process focused upon drawing information out of subjects rather than having them answer questions. It was often necessary to let lengthy periods pass in silence, or to go over the same ground on more than one occasion, in order to encourage and enable subjects to recall relevant information.

\section{Recording Information}

Because of the open-ended, subjective nature of the information provided, the "results" of the interview consisted of everything that subjects said. Exploratory interviews revealed that it was impossible to guide the interview effectively while recording in written form the information provided by subjects. Interviews were therefore tape recorded for later data reduction. Subjects were, of course, asked for their permission to record the discussion prior to recording it.

Prior to the interview process, interviewers recorded the following information on a printed checklist:
a) gender
b) age
c) weight
d) occupation
e) current employment
f) education
g) marital status
h) living arrangements
i) income
j) type of residence

k) racial/ethnic background,

l) number of DWI arrests (if any),

m) frequency of alcohol consumption,

n) frequency of driving after drinking,

o) whether they believed if they should cut down on drinking,

p) whether others are annoyed by their drinking,

q) whether they felt guilty about their drinking,

r) whether they have ever had a drink as an eye-opener in the morning.

The last four items are known as the CAGE index of drinking.

As a protection to subjects, all information was maintained by code number, which served only to collate written and tape recorded information. A separate key identifying individuals by code number was maintained only until the results of the interview had been reviewed and considered acceptable. It was then destroyed, thus rendering anonymous all maintained data. 


\section{$\underline{\text { Subject Fees }}$}

To obtain a high rate of participation by subjects solicited for the interview, a fee was offered for completing the interview. The size of the fee varied as a function of the degree of inconvenience involved. Subjects responding to a telephone solicitation and having to travel to the interview site received a higher fee than those whose participation in the interview occurred as a part of another activity.

\section{Telephone Interviews}

A number of subjects responding to the telephone solicitation declined to travel to the interview site but were willing to participate in a telephone interview. Where the telephone interview provided the only access to a subject, the advantages of minimizing any bias due to sample self-selection seemed to exceed any disadvantage that might be suffered from lack of direct contact with interviewees. Indeed, to minimize the chance of losing a subject, interviews were carried out at the point of initial contact wherever it was agreeable to subjects.

\section{Interviewers}

At each site, the services of several interviewers were engaged. All participated in a 4hour training program. In addition, the tape recorded interviews were reviewed and critiqued until their ability to carry out interviews according to the prescribed process was assured.

\section{Selection of Interviewers}

At the two sites where subjects were obtained through DWI service providers, interviewers were selected from the staff providing those services. All were experienced alcohol counselors, knowledgeable in the conditions surrounding drinking and driving. Their backgrounds were expected to give them insight into the possible origins of drinking-driving episodes, insight that would help them formulate probing questions. While this expectation was generally realized, some of the counselors were initially handicapped by an inclination to give advice rather than to ask question. For most interviewers, this problem was eventually overcome. Those interviewers who were unable to provide high quality interviews were terminated.

At the site where drivers were identified through a roadside survey, interviews were carried out by the staff performing interviews for the project through which the subjects were obtained. Most had behavioral science backgrounds and each had already been interviewing drinking drivers for over a year. These interviewers adhered uniformly to the prescribed procedures and their interviews were among the most probing and informative conducted.

Interviewers responsible for collecting information from those responding to telephone solicitations were primarily research assistants with behavioral science backgrounds, including research involving drinking and driving. Initially, solicitations and interviews were carried out 
by different individuals. However, the need to couple telephone interviews with initial contact led to having interviewers carry out the telephone solicitations.

\section{Interviewer Training}

All interviewers participated in a 4-hour training program administered on-site by a member of the project staff. The program involved a) a review of objectives and methods, b) review and discussion of decision points involved in drinking-driving events, c) an explanation of the unstructured interview procedure, and d) practice interviews. The bulk of the time was devoted to the practice interviews, which were initiated by having one pair of interviewers conduct a mock interview, one of the pair playing the part of a subject. The interview was then critiqued by the instructor, with the participation of other interviewers (e.g., asking them "What would you have done when the subject said ..."). Next, the "subject" became the "interviewer", and another "subject" was selected. The process of mock interview and critique were repeated until all interviewers had an opportunity to conduct at least one interview. Another cycle was then conducted with those interviewers having the most difficulty in the first round being given the most opportunity to play the role of an interviewer during the second round.

\section{Interviewer Debriefing}

At each site, interviewers were gathered together after all interviews were completed for that site for a debriefing session. This was done to take advantage of any insights the interviewers might have into major trends in drinking-driving decisions and what countermeasures might prove successful, based on impressions made during the interview process.

\section{DATA PROCESSING}

The processing of interview data was complicated by the fact that it consisted almost entirely of narrative - descriptions of decision bases. In all, the combination of almost 600 subjects describing the many considerations leading up to each of seven decision points yielded 12,540 individual decision bases.

\section{Data Reduction}

The data reduction process included the following stages:

- Data entry

- Data coding

- Data verification

Data Entry - Staff members listened to the recordings of interviews and entered verbal descriptions of drinking-related and driving-related decisions that were made, as well as the bases 
for those decisions, into a personal computer. The descriptions of decisions and bases were made as concise as possible so as to allow a reasonably accurate description to be recorded without dedicating too much space to the description in the computer file. The length of each description (decision or basis) was limited to 40 characters. A spreadsheet was created to facilitate data entry. Brief descriptions of each decision and up to six bases for each decision were entered into the spreadsheet along with a unique identification number for each subject.

Data Coding - In order to meaningfully analyze the large amount of data that had been collected, it was necessary to create a system for coding the verbal descriptions of decisions and bases. Descriptions of decisions and bases were initially coded in terms of the seven major decision points subdivided into individual decisions, and any classification of decision bases awaited development of a classification scheme capable of putting together those decisions and bases that were functionally similar. As desirable as it might be to create such a classification in advance, a truly efficient classification scheme could not be generated without an opportunity to review its constituent elements. The coding system was therefore developed only after a large number of interviews had been auditioned and recorded. Although this made it necessary to code most of the decisions and bases in a second pass, after the descriptions had been entered into the computer, it also made it possible to base the coding schemes on actual decisions and bases rather than speculating as to the types of decisions and bases that might be encountered and end up using a system that could not accommodate large portions of data. Appendix A.

\section{Data Verification}

After all data had been entered, the database was sorted by decision codes and basis codes to facilitate the process of checking the coding of data. In some cases data had been miscoded due to typographical errors. In some cases like-bases were identified that had been coded differently by different coders. In these cases it was not generally because coders coded bases incorrectly but because the bases were such that they might have reasonably been coded either way. In some cases trends were noticed when the data were viewed in their entirety that suggested improvements that could be made to the coding system to better represent those trends. Where necessary, the data were recoded to make all coding as consistent and accurate as possible.

\section{Data Analysis}

All data analyses involved tabulation of frequencies of decision bases, and crosstabulations of decision bases and associated demographics. The objective of the study is entirely descriptive; it is not to seek relationships among decision-related variables. The only use of inferential statistics occurs when decision bases are subdivided by other variables - primarily demographics and drinking history. Since these are nominal data, non-parametric statistics are appropriate. However, an overall test of differences, such as the chi-squared, would not offer the level of detail needed to determine whether differences among specific subgroups exist. To determine whether differences among subgroups are statistically significant, standard residuals were calculated for each frequency. The adjusted standardized residual in a contingency table, computed as the residual of a cell divided by an estimate of its standard deviation, can be used 
to determine where, within a contingency table, observed cell frequencies are significantly higher or lower than expected, based upon marginal frequencies. The magnitude (and direction) of this statistic can be interpreted in the same manner as a z-score, i.e., greater than 1.96 indicates a cell whose observed frequency is significantly greater than expected at the .05 level. An adjusted standardized residual less than -1.96 indicates the observed cell frequency is significantly less than expected. 


\section{RESULTS}

The following discussion of results will first address characteristics of the participating sample and then the bases for decisions at each stage of the drinking-driving problem. The discussions of each phase will first describe frequencies of various decisions related to that phase (e.g., decisions to go to private homes, under Planning for Drinking Events) as well as demographic characteristics of subjects making those decisions. The discussion will then identify the various decision bases, their relative frequencies, and the extent to which various decision bases vary across categories of drinking drivers. All those, and only those differences associated with standard residuals in excess of $2.0(p<.05)$ are noted in the discussion of results.

\section{SAMPLE CHARACTERISTICS}

Of the 600 drinking drivers interviewed, 581 yielded usable results. The shortfall of 19 subjects came entirely from the DWI category, where interviews by some of the alcohol counselors simply did not follow the prescribed procedure. Neither time nor funds permitted the deficient interviews to be replaced. The loss of 19 subjects should not seriously compromise the reliability of results. And, since the loss was associated with characteristics of interviewers rather than subjects, it should not introduce a significant bias.

\section{Demographics}

Table 1 (on the following page) displays the demographic characteristics of the sample by source: phone (telephone solicitation), DWI (DWI service providers), and roadside (roadside survey).

Any group of drinking drivers identified at random in a roadside survey is likely to be more representative of drinking drivers in general than DWIs or the rather selected group emerging from a telephone solicitation. The characteristics of the roadside group are reasonably similar to those found by Voas (1990) in roadside surveys of 2,800 Minnesota drivers. A BACmatched sample of Minnesota drivers included $71 \%$ males, $20 \%$ under age 21 , and $53 \%$ with college-level education.

As anticipated, the DWI subjects appear to resemble more closely the drinking drivers in general (as represented by the roadside group) than the phone group. Compared to the roadside and DWI groups, those solicited by telephone tended to include a larger number of females, relatively young, employed in white-collar occupations, and on a less than full-time basis, to have had college-level education, and to be single. The one characteristic in which the DWI and roadside surveys were not similar was with respect to racial/ethnic background, where subjects of African-American background were represented in three times the proportion within the DWI group than in the roadside group. Except for race, subjects obtained from DWI and roadside sources were relatively similar to one another and dissimilar to subjects responding to the phone solicitation. Compared to the other two groups, those responding to the phone 
Table 1. Demographic Characteristics of Sample, Subdivided by Source of Subjects

\begin{tabular}{|c|c|c|c|c|}
\hline Characteristic & Phone & DWI & Roadside & Total Sample \\
\hline \multicolumn{5}{|l|}{ Gender } \\
\hline Male & $62 \%$ & $78 \%$ & $73 \%$ & $71 \%$ \\
\hline Female & $38 \%$ & $20 \%$ & $27 \%$ & $29 \%$ \\
\hline \multicolumn{5}{|l|}{ Age Group } \\
\hline Under 20 & $10 \%$ & $11 \%$ & $6 \%$ & $10 \%$ \\
\hline $20-25$ & $44 \%$ & $17 \%$ & $23 \%$ & $30 \%$ \\
\hline $26-39$ & $38 \%$ & $49 \%$ & $49 \%$ & $44 \%$ \\
\hline Over 39 & $8 \%$ & $23 \%$ & $22 \%$ & $17 \%$ \\
\hline \multicolumn{5}{|l|}{ Racial/Ethnic } \\
\hline Caucasian & $86 \%$ & $56 \%$ & $97 \%$ & $76 \%$ \\
\hline African-American & $10 \%$ & $36 \%$ & $3 \%$ & $19 \%$ \\
\hline Hispanic & $1 \%$ & $5 \%$ & $0 \%$ & $2 \%$ \\
\hline Other & $3 \%$ & $8 \%$ & $0 \%$ & $2 \%$ \\
\hline \multicolumn{5}{|l|}{ Occupation } \\
\hline Blue-Collar & $30 \%$ & $72 \%$ & $67 \%$ & $54 \%$ \\
\hline White-Collar & $71 \%$ & $28 \%$ & $33 \%$ & $46 \%$ \\
\hline \multicolumn{5}{|l|}{ Employment } \\
\hline Full-Time & $50 \%$ & $64 \%$ & $78 \%$ & $60 \%$ \\
\hline School & $36 \%$ & $11 \%$ & $3 \%$ & $20 \%$ \\
\hline Other & $15 \%$ & $25 \%$ & $19 \%$ & $19 \%$ \\
\hline \multicolumn{5}{|l|}{ Education } \\
\hline High School or Less & $16 \%$ & $46 \%$ & $58 \%$ & $38 \%$ \\
\hline College-level & $68 \%$ & $50 \%$ & $41 \%$ & $56 \%$ \\
\hline Grad School & $17 \%$ & $4 \%$ & $1 \%$ & $6 \%$ \\
\hline \multicolumn{5}{|l|}{ Marital Status } \\
\hline Single & $66 \%$ & $40 \%$ & $36 \%$ & $51 \%$ \\
\hline Married & $16 \%$ & $26 \%$ & $28 \%$ & $22 \%$ \\
\hline Other & $8 \%$ & $34 \%$ & $23 \%$ & $27 \%$ \\
\hline \multicolumn{5}{|l|}{ Income } \\
\hline$<25,000$ & $62 \%$ & $57 \%$ & $47 \%$ & $57 \%$ \\
\hline $25,000+$ & $38 \%$ & $43 \%$ & $53 \%$ & $43 \%$ \\
\hline
\end{tabular}


solicitation tended to be young, single, blue-collar, still in school, and drawn from the lower income brackets. As pointed out earlier, this group was highly self-selective and it is likely that the offer of a fee played a significant role in the responsiveness of this group.

Taken as a whole, the sample seems reasonably representative of the drinking and driving population at large.

\section{Household Information}

Information concerning the households of subjects, including type of residence, living arrangements, and household income is shown in Table 2.

Table 2. Household Information, by Source of Subjects

\begin{tabular}{|c|c|c|c|c|}
\hline Characteristic & Phone & DWI & Roadside & Total Sample \\
\hline \multicolumn{5}{|l|}{ Living With } \\
\hline Alone & $17 \%$ & $22 \%$ & $15 \%$ & $18 \%$ \\
\hline Spouse & $15 \%$ & $25 \%$ & $26 \%$ & $21 \%$ \\
\hline Parents & $9 \%$ & $21 \%$ & $29 \%$ & $18 \%$ \\
\hline Children & $14 \%$ & $21 \%$ & $36 \%$ & $20 \%$ \\
\hline Siblings & $4 \%$ & $7 \%$ & $8 \%$ & $6 \%$ \\
\hline Roommates & $39 \%$ & $11 \%$ & $6 \%$ & $22 \%$ \\
\hline Significant Other & $8 \%$ & $11 \%$ & $16 \%$ & $11 \%$ \\
\hline Other Relative & $2 \%$ & $7 \%$ & $6 \%$ & $5 \%$ \\
\hline \multicolumn{5}{|l|}{ Household Income } \\
\hline$\$ 0-\$ 9.9 \mathrm{~K}$ & $37 \%$ & $22 \%$ & $13 \%$ & $26 \%$ \\
\hline$\$ 10-\$ 24.9 \mathrm{~K}$. & $25 \%$ & $35 \%$ & $38 \%$ & $22 \%$ \\
\hline$\$ 25-\$ 49.9 \mathrm{~K}$ & $24 \%$ & $27 \%$ & $34 \%$ & $26 \%$ \\
\hline$>\$ 50 \mathrm{~K}$ & $15 \%$ & $16 \%$ & $18 \%$ & $16 \%$ \\
\hline \multicolumn{5}{|l|}{ Housing } \\
\hline House & $43 \%$ & $57 \%$ & $73 \%$ & $54 \%$ \\
\hline Apartment & $40 \%$ & $29 \%$ & $13 \%$ & $31 \%$ \\
\hline Condo/Townhouse & $12 \%$ & $3 \%$ & $9 \%$ & $8 \%$ \\
\hline Other & $5 \%$ & $11 \%$ & $5 \%$ & $8 \%$ \\
\hline
\end{tabular}


In keeping with the demographics described in the preceding section, those obtained through phone solicitation were over-represented in groups living in apartments with roommates.

\section{Drink History}

The amount of drinking by each group, expressed in number of drinks per week, appears in Table 3. Subjects expressed their alcohol consumption in anything from drinks per day to drinks per year. These figures were calculated into a drinks-per-week value. The total population was then divided into five groups, roughly equal in size. This explains why drinksper-week categories contain fractions of drinks.

Table 3. Drinks Consumed per Week, by Source

\begin{tabular}{||l|c|c|c|c||}
\hline Mean drinks/wk. & Phone & DWI & Roadside & Total \\
\hline $0-3.5$ & $26 \%$ & $19 \%$ & $18 \%$ & $22 \%$ \\
\hline $3.6-6.5$ & $20 \%$ & $21 \%$ & $20 \%$ & $20 \%$ \\
\hline $6.6-12.5$ & $19 \%$ & $19 \%$ & $22 \%$ & $19 \%$ \\
\hline $12.6-22$ & $20 \%$ & $18 \%$ & $18 \%$ & $19 \%$ \\
\hline$>22$ & $16 \%$ & $23 \%$ & $24 \%$ & $20 \%$ \\
\hline
\end{tabular}

Since all three groups were selected on the basis of their drinking while driving, a pattern of rather heavy drinking is not surprising. What is perhaps surprising is the parity across sources. The DWI group would certainly have evidenced a higher frequency of alcohol consumption but for the effort to exclude the chemically dependent.

The frequency with which subjects reported having driven after drinking was annualized in Table 4. The number of episodes are based on answers to the question "how often do you drive after drinking alcohol (not necessarily to the point of intoxication)?"

Table 4. Number of Drinking-driving Instances per Year, by Source

\begin{tabular}{||c|c|c|c|c|}
\hline \hline Episodes & Phone & DWI & Roadside & Total \\
\hline$\leq 10$ & $22 \%$ & $24 \%$ & $13 \%$ & $21 \%$ \\
\hline $11-24$ & $37 \%$ & $27 \%$ & $28 \%$ & $31 \%$ \\
\hline $25-59$ & $22 \%$ & $19 \%$ & $22 \%$ & $17 \%$ \\
\hline$>59$ & $19 \%$ & $30 \%$ & $37 \%$ & $26 \%$ \\
\hline
\end{tabular}

Although all subjects had to have engaged in at least one instance of drinking and driving in order to qualify for inclusion in the sample, it is evident that instances of such behavior were 
common. Differences across the three subject sources were slight, with those obtained through the roadside survey reporting the greatest frequency, and those solicited by telephone reporting the fewest instances. It is likely, however, that the number of instances reported by DWIs is somewhat deflated by the effect of the drinking-driving arrest upon subsequent drinking-driving behavior. On that point, it is worth noting that $28 \%$ of the subjects obtained through the roadside survey had previously been arrested for DWI while $9 \%$ of those obtained through telephone solicitation reported a prior arrest. Of course, all of the subjects recruited through DWI programs had been arrested for DWI. Across the entire sample, $45 \%$ of subjects had been arrested for DWI prior to the interview. However, only $11 \%$ had been arrested for DWI more than once, that is, were "repeat offenders" under the law.

Reports obtained through the "CAGE" survey are shown in Table 5 .

Table 5. Percent of Subjects Giving Positive Responses to CAGE Survey

\begin{tabular}{||l|c|c|c|c||}
\hline CAGE Response & Phone & DWI & Roadside & Total \\
\hline $\begin{array}{l}\text { Felt they should cut } \\
\text { down on drinking }\end{array}$ & $52 \%$ & $76 \%$ & $63 \%$ & $64 \%$ \\
\hline $\begin{array}{l}\text { Been annoyed by } \\
\text { criticism of drinking }\end{array}$ & $17 \%$ & $37 \%$ & $18 \%$ & $25 \%$ \\
\hline $\begin{array}{l}\text { Felt Guilty About } \\
\text { Drinking }\end{array}$ & $40 \%$ & $62 \%$ & $36 \%$ & $48 \%$ \\
\hline $\begin{array}{l}\text { Needed an Eye Opener } \\
\text { in the Morning }\end{array}$ & $11 \%$ & $20 \%$ & $14 \%$ & $16 \%$ \\
\hline Two or more signs & $38 \%$ & $63 \%$ & $41 \%$ & $47 \%$ \\
\hline
\end{tabular}

While subjects from all three sources acknowledged signs indicative of problem drinking, those making up the DWI group were more numerous in each of the four categories than subjects from the other two groups. The likelihood that DWIs included greater numbers of problem drinkers is supported by the fact that the proportion of DWIs with BACs of .15 and higher was twice that of subjects obtained through the roadside survey during the drinking event under which they became study subjects. It is also possible that, having been publicly identified as DWIs, and having participated in some form of alcohol counseling, they may be more aware of the various CAGE signs and more willing to acknowledge them than others who have escaped public notice.

Under the CAGE procedure, two or more signs is considered to be indicative of a possible alcohol problem. Sixty three percent of the DWIs fell into this category, in comparison with $41 \%$ from the Roadside category and 38\% from the Phone category. 


\section{DEMOGRAPHIC GROUPS USED FOR ANALYSIS}

In the discussion of decisions and decision bases that follows, those demographic subgroups that were significantly overrepresented with respect to a particular basis (more people than one would expect to find) appear in the column labeled "Demographics." If a group was significantly underrepresented (fewer people than one would expect to find), it appears in the same column but is enclosed in parentheses. Statistical significance was tested in the manner described in the discussion of "Data Analysis." The .05 level of significance was employed, meaning that the likelihood is less than five chances in a hundred that a particular demographic group's apparent overrepresentation or underrepresentation was the result of chance rather than a true relationship between the decision basis and the demographic variable. The demographic variables were categorized as follows:

Gender categories are given as "Male" and "Female."

Occupation categories are given as "Blue-collar" and "White-collar."

Employment categories are "Full time", "Student" and "Underemployed" where underemployed includes the unemployed and those working part time.

Education categories are given as "High school" and "College," where High school refers to those with a high school education or less and college refers to those who have any where from some college to post graduate degrees.

Marital status is given as "Single" or "Married" where single refers to those who have never been married as well as divorced and separated subjects. Married refers to those who are married and those who are widowed.

Income categories are given as " $<\$ 25 \mathrm{~K} "$ or $" \geq \$ 25 \mathrm{~K}$ " where $" \$ 25 \mathrm{~K} "$ means $\$ 25,000$ a year.

Racial categories are given as "Caucasian," "African-American." There were too few subjects of other racial groups to show significant interactions with decision bases.

DWI History categories are given as "0 DWIs," "1 DWI," and "2+ DWIs."

BAC Levels when stopped by police are given as "BAC <.10\%," "BAC .10\%-.139\%," and "BAC .14 OR >." These BAC levels were only for subjects from the DWI and Roadside-referred groups.

Driving after Drinking categories are expressed as "Drink/drive infrequently," and "Drink/drive frequently," where "infrequently" means fewer than 25 times in a year and "frequently" means 25 or more times in a year. 
CAGE Score categories are given as "CAGE <2," and "CAGE 2+." A score of 2 or more on the CAGE is indicative of problem drinking.

Alcohol Consumption categories are given as "Light Drinker," and "Heavy drinker," where "light" refers to 6.5 or fewer drinks consumed in an average week and "Heavy drinker" refers to more than 6.5 drinks consumed in an average week.

Age categories are given as " $\leq 25$ yrs", "26 - 34 yrs," and "35+ yrs."

\section{PLANNING FOR DRINKING EVENTS}

This phase concerns decisions that were made to go out to a drinking location or event. In most cases (87\%) these were plans made in advance of drinking. The rest were plans made to go to subsequent drinking locations after having started drinking at the first.

\section{NATURE OF DECISIONS}

Before introducing the bases for decisions about planning, it is of interest to describe types of places that subjects decided to go and with whom they went. Information concerning drinking destinations and decisions related to whom to go with, along with the demographic characteristics of the people making these decisions, are summarized in the following tables:

\begin{tabular}{||l|c|l||}
\hline Drinking Destination & Frequency & \multicolumn{1}{c|}{ Demographics } \\
\hline Bar & 456 & $\begin{array}{l}\text { BAC .14 or >, Male, } \\
\leq 25 \mathrm{yrs}, \text { White-collar, Underemployed, } \\
\text { College, Single, Caucasian }\end{array}$ \\
\hline Home (own/friend's) & 203 & $\begin{array}{l}\text { Male, High school, African-American, 2+ } \\
\text { DWls, CAGE 2 + }\end{array}$ \\
\hline To another event & 137 & $\begin{array}{l}\text { Male, Blue-collar, High school, Full time, } \\
\text { Married, 2 + DWls, CAGE 2 + }\end{array}$ \\
\hline Party & 124 & $\begin{array}{l}\leq 25 \text { yrs, College, Underemployed, } \\
<25 \mathrm{~K}, \text { O DWls, CAGE < 2 }\end{array}$ \\
\hline Restaurant & 64 & $\begin{array}{l}\leq 5 \mathrm{yrs,} \mathrm{College,} \mathrm{Full} \mathrm{time,} \mathrm{Married,} \geq \\
\$ 25 \mathrm{~K}\end{array}$ \\
\hline Other Destinations & 89 & \\
\hline
\end{tabular}




\begin{tabular}{||l|c|l||}
\hline \multicolumn{1}{|c|}{ Who They Went With } & Frequency & \multicolumn{1}{|c|}{ Demographics } \\
\hline Friend & 350 & $\begin{array}{l}\text { Female, } \leq 25 \mathrm{yrs}, \text { White-collar, } \\
\text { Underemployed, }<\text { \$25K, CAGE <2 }\end{array}$ \\
\hline Alone & 229 & $35+\mathrm{yrs,} \geq \$ 25 \mathrm{~K}$, African-American \\
\hline Significant Other & 76 & Married, $\geq \$ 25 \mathrm{~K}$ \\
\hline Relative & 37 & $\begin{array}{l}\text { BAC }<.10 \%, \text { Female, Full-time, High } \\
\text { school }\end{array}$ \\
\hline Not specified & 422 & \\
\hline
\end{tabular}

\section{PLANNING FOR DRINKING EVENTS DECISION BASES}

The bases that were given by the subjects for making plans to go to drinking locations/events can be broken down into nine major classifications. Ninety eight percent of the 2,124 bases recorded fit into those major classifications. The classifications and their frequencies and percentages are presented below.

\begin{tabular}{||l|c|c||}
\hline \multicolumn{1}{|c|}{ Category } & Frequency & Percent \\
\hline Social or Environmental Influence & 678 & 31.9 \\
\hline Personal Influence & 422 & 19.9 \\
\hline Occasion & 320 & 15.1 \\
\hline Normal or Past Behavior & 191 & 9.0 \\
\hline Previous or Larger Plans & 179 & 8.4 \\
\hline Responsibility & 136 & 6.3 \\
\hline Emotional Influence & 88 & 4.1 \\
\hline Availability and Economics & 56 & 2.6 \\
\hline Miscellaneous & 54 & 2.5 \\
\hline
\end{tabular}

Most of the bases for making decisions to go to drinking locations or events involved some sort of social or environmental influence. Self-motivation was the second most common motivation and occasion-related bases was the third most common.

\section{Social or Environmental Influence}

These were cases in which subjects mentioned outside forces, such as the influence of friends, environment and situations, as being important to the decision to go out. 


\begin{tabular}{|c|c|c|}
\hline Sub-Category & Frequency & Demographics \\
\hline Overt Social Influence & 236 & Female \\
\hline $\begin{array}{l}\text { Suggested By } \\
\text { Others }\end{array}$ & 202 & $\begin{array}{l}\text { Underemployed, Drink/drive } \\
\text { infrequently }\end{array}$ \\
\hline $\begin{array}{l}\text { Miscellaneous } \\
\text { Overt Social } \\
\text { Influences }\end{array}$ & 34 & College \\
\hline Effects of Destination & 178 & $\begin{array}{l}\text { Single, Caucasian, BAC .10\%- } \\
.139 \% \text {, O DWIs }\end{array}$ \\
\hline $\begin{array}{l}\text { Destination } \\
\text { was Attractive }\end{array}$ & 116 & Caucasian \\
\hline $\begin{array}{l}\text { Other Effects } \\
\text { of Destination }\end{array}$ & 62 & Single, BAC .10\%-.139\% \\
\hline $\begin{array}{l}\text { Unstated Social } \\
\text { Influence }\end{array}$ & 166 & Female, O DWIs, Student \\
\hline $\begin{array}{l}\text { Others Were } \\
\text { There }\end{array}$ & 99 & O DWIs, Drink/drive infrequently \\
\hline $\begin{array}{l}\text { Others Were } \\
\text { Going }\end{array}$ & 51 & Student, $\leq 25$ yrs \\
\hline $\begin{array}{l}\text { Other Unstated } \\
\text { Social } \\
\text { Influences }\end{array}$ & 16 & \\
\hline $\begin{array}{l}\text { Effects of Current } \\
\text { Environment }\end{array}$ & 96 & $\begin{array}{l}\text { Underemployed, Caucasian, } \\
\text { ( } \leq 25 \text { yrs })^{*}\end{array}$ \\
\hline Miscellaneous & 4 & \\
\hline
\end{tabular}

- Note: In this and all other tables, groups listed are significantly $(p<.05)$ overrepresented relative to other demographic groups except for those in parentheses which are significantly under-represented relative to other demographic groups.

\section{Overt Social Influence}

Decision bases for the overall category "Overt Social Influence," were more likely to be associated with decisions to go to private homes. Females were overrepresented among those citing overt social influence.

Suggested By Others - The most frequently cited basis relating to overt social influence was "going suggested by others" (202). This category included invitations by others to come to an event, going along with advanced plans to go out that were made by others and going along with somewhat more spur-of-the-moment decisions to go somewhere that were made by others. Subjects citing this decision basis were more likely to go to 
restaurants and less likely to go to bars. Not surprisingly, decisions to go with friends were much more likely, and decisions to go alone far less likely, to be associated with this category. Part-time employees or the unemployed (underemployed) were slightly overrepresented for this category as were those who reported driving after drinking fewer than 24 times a year.

Miscellaneous Overt Social Influences - The rest of the decision bases within the overt social influence category fall into a "miscellaneous overt social influence" category (34). The majority of these were cases in which the decision to go was a group decision, the subject having a say in the decision. Subjects citing decision bases that fell into this category were more likely to have had at least some college education.

\section{Effects of Destination}

For the "Effects of Destination" category as a whole, subjects were more likely to be going to bars and less likely to be going to homes and parties. Single subjects, Caucasian subjects, those who had BACs of .10-.139\% and those with no DWIs were likely to cite effects of destination.

Destination Was Attractive - These were cases in which there was something about the destination that influenced the decision to go there. In most cases (116) there was something attractive about the destination. This included the availability of activities, the knowledge that familiar people would be there, and statements regarding the quality or presence of food or entertainment. Subjects citing these decision bases were more likely to be going to bars and less likely to be going to homes. These subjects were more likely to be Caucasian and less likely to have one DWI offense (as opposed to no offenses or two or more offenses.)

Other Effects of Destination - There were cases in which the effects of the destination did not involve the types of attractions described above (62). These "other effects of destination" included a sense of familiarity with the destination, e.g., "had been there before, was comfortable with going there" (27); curiosity about the destination e.g., "had never been there before, wanted to check it out" (16); statements that the destination was "the in place to be" (8) and that it was their favorite place to go (6). Single subjects were over-represented for this "other effects of destination" sub-category. Subjects with a BAC less than $0.10 \%$ were under-represented.

\section{Unstated Social Influence}

Females, subjects with no DWIs and students were likely to cite unstated social influence. This category breaks down into cases in which there were people that the subjects were going to see who were already at the destination (99), cases in which subjects believed that people would be there in the near future (51) and other unstated social influences (16). This latter group was

primarily those whose decisions were based on the belief that others were not at or would not be 
at the destination, and those who believed that going was an assumption, an unspoken rule within either the immediate social setting or society at large.

Others Were There - Subjects who went out because "others were there" were more likely to be going out alone, have no DWI offenses on record or to have reported driving after drinking fewer than 24 times a year. They were less likely to have one DWI offense on record.

Others Were Going - Subjects who went out because "others were going" were more likely to be going with friends, to be a student, or to be 25 or younger. They were less likely to be going alone or to be employed full-time. This category differs from overt social influence in that there was no apparent overt suggestion by others that the subject should go. The mere fact that other people were planning to go seemed to be enough to persuade the subject to go too.

\section{Effects of Current Environment}

These were cases in which the decision to go was based upon the environment or situation in which the subject found his or herself when making the decision. In other words, where "Effects of Destination," above, represents being pulled to the destination, "Effects of Current Environment" represents being pushed. There were a total of ninety six (96) such cases. Examples of this sub-category included situations in which the drinking location was convenient, e.g., it was close or the subject was going by there anyway (65), and arguments or other unpleasantness at home (29). Subjects who cited this decision basis were more likely to be going to bars, to be part-time employees or unemployed (underemployed) or to be Caucasian. They were less likely to be students, and 25 or younger.

\section{Personal Influence}

These were cases in which the motivation to go out came from within the subject. These included physical influences and attempts to fulfill personal goals. This category also includes cases in which the decision basis given for doing something was simply the desire to do it. 


\begin{tabular}{||l|c|l||}
\hline \multicolumn{1}{|c|}{ Sub-Category } & Frequency & \multicolumn{1}{c|}{ Demographics } \\
\hline Attempt to Achieve Personal Goals & 285 & $\begin{array}{l}\text { Female, Drink/drive frequently, } \\
\text { (O DWIs) }\end{array}$ \\
\hline Visit Friends & 125 & Student \\
\hline Enjoy Activity or Entertainment & 26 & 1 DWI \\
\hline $\begin{array}{l}\text { Get Food or Non-Alcoholic } \\
\text { Beverages }\end{array}$ & 23 & \\
\hline $\begin{array}{l}\text { See Unknown or Unspecified } \\
\text { People }\end{array}$ & 21 & \\
\hline Responsibility & 20 & \\
\hline See Something & 19 & \\
\hline Visit Family & 15 & \\
\hline Get Alcohol & 14 & \\
\hline Miscellaneous Goals & 11 & \\
\hline Stated Desires & 73 & \\
\hline Physical Influence & 27 & \\
\hline Other & 24 & \\
\hline \hline
\end{tabular}

\section{Attempt to Achieve Personal Goals}

This was, by far, the largest sub-category of the "Personal Influence" category. Females, and subjects who reported driving after drinking frequently were overrepresented. Subjects with no DWIs were underrepresented. Decisions bases within the overall category "Attempt to Achieve Personal Goal" were somewhat more likely to be associated with decisions to go to events at private homes and more likely to report sometimes feeling guilty about their drinking. The category breaks down into the following further sub-categories:

Visit Friends - There were one hundred and twenty five (125) cases in which it was the subject's goal to see or visit friends. This was the largest category within those decisions based on attempts to fulfill personal goals. This category differs subtly from the "attractiveness of destination: people were there" and "unstated social influence: others were there" categories, above, in that, in the above cases, it seemed as though the subject had first decided to go and subsequently chosen a destination based on the fact that people were there. In this category the decision to go out seemed to be based entirely upon the desire to see people. Decisions to go to homes were over-represented and decisions to go to bars under-represented for this category. Students were over-represented for this category. Full-time employees and those who use alcohol as an "eye opener" were underrepresented for this category. 
Enjoy Activity or Entertainment - These bases included going to see bands, movies, sporting events, etc. There were twenty six (26) cases of this. These subjects were more likely to have one DWI on record and less likely to have no DWIs on record.

Get Food or Non-Alcoholic Beverages - There were twenty three (23) cases of this decision basis. Predictably, subjects mentioning this decision basis were more likely to be going to restaurants.

See Unknown or Unspecified People - There were twenty one (21) cases of going out to see unknown or unspecified people. These were either decisions to "go where there were people" i.e., for general socializing or decisions to go out to meet someone as yet unknown, e.g., to meet members of the opposite sex. Some of these cases may have actually represented going out to meet a known person but, because the statement was worded vaguely it was impossible to tell, so the basis was coded as "unspecified person." Subjects who mentioned this decision basis were more likely to have stated that their plan was to go to multiple drinking locations (e.g., go bar hopping).

Responsibility - Examples within this category might include statements such as "wanted to pick up paycheck and pay bills," "was out shopping" or "stopped in to ask directions." There were 20 such bases noted. Subjects citing this basis were more likely to be going to homes and less likely to be going to bars. The heavier drinkers were overrepresented within this category.

See Something - These cases differed from going out to "enjoy activities or entertainment" in that they were not what one normally associates with activities or entertainment. Examples include, "stopped by Mother's to see new puppies," or "had just bought new boat and wanted to go see it." These were nineteen (19) cases of this. Subjects who cited this as a decision basis were more likely to be going to private homes, to have two or more DWIs and to report using alcohol as an "eye-opener."

Visit Family - There were fifteen (15) cases in which the motivating factor for going out was to see family members. Subjects who mentioned this as a decision basis were more likely to be married or to be going to homes and less likely to be going to bars.

Get Alcohol - There were fourteen (14) cases noted in which the reason for going out was to get alcohol. The reason there were not more of these cases is probably that, in most cases of going out, the decision was to go somewhere to get the alcohol and drink it there. It is not likely that subjects would state that the only reason to decide to go out, and where to out, would be "to buy alcohol." These are mostly either cases in which the subject went out to purchase alcohol, not intending to stay out and drink, or was already out drinking and left the drinking location to purchase alcohol at a store. Subjects citing this decision basis were more likely to be less educated or to have one DWI on record. 
Miscellaneous Goals - There were eleven (11) cases of going out to accomplish miscellaneous goals. There was a wide range of decision bases under this category such that it is not possible to describe any discrete sub-categories within this category.

\section{$\underline{\text { Stated Desires }}$}

Throughout the interview (i.e., in the discussion of each phase), there were cases in which the only reason given by a subject for making a decision to do something was "I wanted to." In some cases it was possible to probe more deeply. However, when there was either insufficient time for probing, or subjects had no more detailed explanations to offer, those cases were categorized as "Stated Desire" to do something (73). These included stated desires to drink (42), stated desires to go out (e.g., "I just had to get out of the house") (16), and stated desires to take part in activities (8). Subjects citing this decision basis were somewhat more likely to be going to bars, to report being annoyed by others criticism of their drinking and to have used alcohol in the morning as an eyeopener.

\section{Physical Influence}

There were twenty seven (27) cases in which some sort of physical influence played a part in the decision to go out. In seventeen (17) cases subjects went out due to hunger. Other decisions were related to the effects of alcohol (10), e.g., "alcohol caused the desire to go out," "wanted to go because I didn't realize how affected I was," "decided to go here because I was too drunk to go there." Subjects citing physical influences were more likely to be going to homes and restaurants and less likely to be going to bars and parties.

\section{Other Personal Influences}

There were twenty four (24) other cases in which decisions were motivated by personal factors. These were mostly expressions of enjoying some sort of activity and might therefore be categorized under "Enjoyment of Activity or Entertainment," above. The, admittedly subtle, distinction between the two is that, above, subjects went out because they "wanted" to do something and here they went out because they "liked" doing something. Subjects who cited this decision basis were less likely to be 25 years old or younger.

\section{Occasion}

These were cases in which the decision to go to a drinking event were based on some sort of occasion. These included holidays and other special occasions, general leisure time gettogethers, times often associated with drinking, such as weekends and happy hours, and expressions of the belief that it was "time to go drinking." 


\begin{tabular}{||c|c|l||}
\hline Sub-Category & Frequency & \multicolumn{1}{|c|}{ Demographics } \\
\hline Special Occasion & 193 & $\begin{array}{l}\text { High school, 2 + DWIs, Drink/drive } \\
\text { infrequently, (Caucasian) }\end{array}$ \\
\hline Reunion & 57 & \\
\hline Birthday Party & 40 & $1+$ DWls, Drink/drive infrequently \\
\hline Other/Misc & 27 & Underemployed \\
\hline Holiday-Related & 16 & \\
\hline Victory Party & 15 & \\
\hline Work-Sponsored & 14 & \\
\hline Farewell & 10 & \\
\hline General Party & 9 & \\
\hline Wedding & 5 & \\
\hline Leisure Time Activity & 57 & Married, BAC < .10\% \\
\hline Recognized "Going-Out Time" & 54 & White-collar, College, (2+ DWIs) \\
\hline Time To Go Out & 16 & \\
\hline
\end{tabular}

\section{Special Occasion}

There were one hundred and ninety three (193) cases of "special occasions" being a motivating factor behind decisions to go out. Special occasion tended to be cited by subjects with less education, those with 2 or more DWIs and those who reported driving after drinking infrequently. Caucasians were less likely to mention special occasion.

Reunion - This was the most frequently cited special occasion with fifty seven (57) cases in which it was mentioned. These included both the reunion of family members and friends. Very few cases were actual formal reunions such as family or class reunions. Subjects citing this decision basis were more likely to be going to parties, and less likely to be Caucasian or going to bars.

Birthday Party - There were forty (40) cases in which subjects' decisions to go out were motivated by birthday-related celebrations. Subjects who based their decision to go out on the fact that there was a birthday involved were far more likely to be going to restaurants, somewhat more likely to be going to parties and less likely to be going to bars. It is likely that decisions to go to homes were not prevalent because such decisions, when related to birthdays, were classified as parties. Subjects who cited this as a decision basis were more likely to have one or more DWIs on record and to report that they drove after drinking fewer than 24 times a year. 
Other/Misc - There were other types of special occasions (27) that did not fit into any of the above categories. They are too numerous to mention here, since they are made up of one case each of many different possible "special occasions". Subjects whose decision bases fell into this category were more likely to be going out alone, to be part-time or unemployed (underemployed) workers and to have expressed feelings of guilt over drinking. These subjects were less likely to be employed full-time.

Holiday-Related - There were sixteen (16) cases in which subjects' decisions to go out were motivated by holiday-related celebrations. These subjects were more likely to be African-American or to be going with significant others.

Victory Party - These were occasions to celebrate some sort of victory (e.g., the softball team won the league championship) or other success (e.g., celebrating a promotion). There were fifteen (15) such cases. These subjects were slightly more likely to be going out with relatives and more likely to be earning $\$ 25,000$ or more a year.

Work-Sponsored - There were fourteen (14) cases involving work-sponsored or workrelated events. These included company picnics, parties, banquets, etc. These events were more likely to be classified as parties than get-togethers at bars, restaurants or homes. Subjects who went to work-sponsored events were more likely to be earning $\$ 25,000$ or more a year.

Farewell - Overall there were ten (10) cases of "farewell" get-togethers. These were events centered mostly around the impending separation of friends (7) or co-workers (2). These get-togethers were more likely to be parties. Subjects who went to these farewell get-togethers were more likely to be students or to have one DWI on record. They were less likely to be Caucasian.

General Party - These were cases in which the reason for going out was a party that was not related to some specific occasion, i.e., it was "just a party" (9). The fact that there were so few "general parties" mentioned may indicate either that most parties given were centered around some identifiable theme, that these "theme" parties were more likely to result in drinking and driving, or that "theme" parties were more likely to be recalled by subjects who were asked to recall some drinking-driving experience in their recent past. Subjects going to general parties were more likely to be students and less likely to be full-time employees.

Wedding - There were five (5) cases involving weddings.

\section{Leisure Time Activity}

There were fifty seven (57) cases in which subjects mentioned leisure time activities during which they drank and subsequently drove. These subjects tended to be married or to have BACs below .10\%. Most of these (51) involved informal get-togethers for which there was some 
planned activity, such as dancing, playing billiards or darts, or watching sporting events on television. The other major category under "leisure time activity" involved get-togethers related to more organized activities such as participation in league sports (5).

\section{$\underline{\text { Recognized "Going-Out Time" }}$}

These were cases in which subjects stated motivation for going out was that it was "Friday Night" or "Happy Hour" or some other time widely associated with going out and, often, drinking. White-collar subjects, and subjects with some college were likely to cite this. Subjects with 2 or more DWIs were less likely to cite this. The largest sub-category within in this category was "Start of Weekend or Vacation" (43). The other major sub-category was Dinner/Eating Time (8). Subjects citing this as a reason for going out were more likely to be going alone and to report being annoyed by others' criticism of their drinking.

\section{Time To Go Out}

There were sixteen (16) cases classified under this category. Most expressed the general feeling that enough time had passed since the last time that the subject had gone out (or engaged in a certain behavior) to warrant going out (or engaging in that behavior) again. The time period passed ranged from several days to several years.

\section{Normal or Past Behavior}

These were cases in which the decision to go out was based on habitual behavior. This included habitual drinking behavior as well as habitual "going-out" behavior.

\begin{tabular}{||l|c|l||}
\hline \multicolumn{1}{|c|}{ Sub-Category } & Frequency & \multicolumn{1}{|c|}{ Demographics } \\
\hline Specific Place or Activity & 158 & $\begin{array}{l}\text { Blue-collar, 2+ DWls, Drink/drive } \\
\text { frequently }\end{array}$ \\
\hline General "Going-Out" Behavior & 31 & Student, $\leq 25$ yrs \\
\hline
\end{tabular}

Specific Place or Activity

This category breaks down into those cases in which the subject habitually went to a specific place or did some specific thing, e.g., "I always go there," or "This was a usual activity" (99); and those cases in which subjects habitually went somewhere or did something under more specific circumstances, e.g., "We always go there after practice," or "that's what I do when I'm with these friends" (57). Blue-collar workers, subjects with two or more DWIs, those that report driving after drinking more than 24 times a year and those who reported using alcohol as an eyeopener in the morning were more likely to cite the former (specific place, general circumstances) category, and subjects with no DWIs were less likely. There were no significant interactions for the latter, (specific place, specific circumstances) category. 


\section{General "Going-Out" Behavior}

There were thirty one (31) cases in which subjects said that going out, in general was a habitual behavior for them. These tended to be students and those subjects who were 25 years old or younger. Fourteen (14) cases referred to very general behavior, e.g., "I always go out." Seventeen (17) cases were more specific, e.g., "I go out every weekend."

\section{Effect of Plans}

Most of these were cases in which subjects' decisions to go out was based on some previous or larger plan. For example, a subject who planned to go out to a bar may have said that he or she planned to do so because it had been a plan that had been made sometime previously. This category also includes those cases in which subjects stated that there had been no plans made, e.g., "it was a spur-of-the-moment thing."

\begin{tabular}{||l|c|l||}
\hline \multicolumn{1}{|c|}{ Sub-Category } & Frequency & \multicolumn{1}{|c|}{ Demographics } \\
\hline Part of Larger or Previous Plans & 111 & $\begin{array}{l}\text { Underemployed, Caucasian, CAGE } \\
<2 .\end{array}$ \\
\hline No Plan Involved & 68 & Married \\
\hline
\end{tabular}

Part of Larger or Previous Plan

Some of these were cases in which plans were made by others or by a group including the subject. In other cases, plans had been made long enough before the event that subject's explanations of why they had planned to go were along the lines of "because I had already planned it earlier." While this may be circular logic, it is an example of the kind of information that is inevitable in the open-ended format in which the data was gathered. Subjects citing this as a decision basis were more likely to report feeling guilty about their drinking. They were also more likely to be underemployed and Caucasian.

\section{No Plan Involved}

These were all cases of spur-of-the-moment decisions to go out. Decisions to go to parties were slightly over-represented for this category. Surprisingly, married subjects were overrepresented for this category. While this may not mean that married people are more likely to be involved in spur-of-the-moment plans, it would certainly indicate that they are not less likely.

\section{Responsibility}

These were cases where decisions to go out were affected by either feelings of responsibility or freedom from responsibility. 


\begin{tabular}{||l|c|l||}
\hline \multicolumn{1}{|c|}{ Sub-category } & Frequency & \multicolumn{1}{c|}{ Demographics } \\
\hline Personal Relationship & 61 & $\begin{array}{l}\text { Student, Drink/drive infrequently, } \\
\text { (Underemployed) }\end{array}$ \\
\hline Time & 37 & \\
\hline Work & 21 & \\
\hline Occasion & 9 & \\
\hline Other & 8 & \\
\hline
\end{tabular}

\section{$\underline{\text { Personal Relationship }}$}

Students and subjects who drove after drinking infrequently were likely to cite personal relationships as a basis. Subjects who were underemployed were less likely. The majority (45) of bases in this category were cases in which subjects' felt that their relationship with another person created a responsibility to go out with that person or attend some event with which that person was involved, e.g.," my friend was throwing the party" or "I went there because he needed to talk to someone." In sixteen (16) cases the subject was relieved of the responsibility of being with, or caring for spouses or significant others (8) or children (8). These decisions tended to be associated more with going to parties and less with going to bars. Subjects who reported that they sometimes feel that they should cut down on their drinking were under-represented for this decision basis.

Time

Most (31) of these were cases in which subjects were relieved of any time-related responsibilities and felt that it was appropriate to spend free time by going out.

$\underline{\text { Work }}$

Freedom from work responsibilities were involved in 21 decisions to go out and Caucasians were overrepresented. Subjects expressed this through statements such as "went out because I didn't have to work the next day," or "I usually have to work on that night." In six (6) cases subjects made "going-out" decisions based on the need to work or go to school the next day.

\section{$\underline{\text { Occasion }}$}

There were nine (9) cases in which subjects were responsible for the running of an event such as a wedding, charity ball or other party. 
Other

Decisions to go were affected by other responsibilities such as the need to drive and do work around the house (8).

\section{Emotional Influence}

These are cases in which subjects were affected either by the mood that they were in or by a desire to change their mood by changing their location.

\begin{tabular}{||l|c|l||}
\hline \multicolumn{1}{|c|}{ Sub-Category } & Frequency & \multicolumn{1}{|c|}{ Demographics } \\
\hline Mood Prior To Leaving & 58 & $\begin{array}{l}\text { Females, High School, < \$25K, 35+ } \\
\text { yrs }\end{array}$ \\
\hline Presence at Drinking Location & 27 & \\
\hline
\end{tabular}

\section{Mood Prior To Leaving}

Females, subjects with only a high school education, subjects with incomes below $\$ 25 \mathrm{~K}$, and subjects 35 and older often cited their mood prior to leaving. The fifty eight (58) cases of decisions to go out based on mood before leaving break down into those who felt good (11), those who felt bored (13), those who felt bad, e.g., depressed (12), angry (7) or other (6), and those who were in a "drinking or partying mood" (8).

\section{Presence at Drinking Location}

Of the twenty seven (27) cases in which subjects were attempting to affect their mood by going out, 17 made statements to the effect that they wanted to feel good. Six (6) were motivated by the desire to relieve stress.

\section{Availability and Economics}

These were cases in which the decision to go out was based upon the cost or availability of alcohol, alternatives to alcohol and other expenses related to going out. Not surprisingly, bases under this broad category were over-represented in decisions related to going to bars and underrepresented for decisions related to going to houses and parties. 


\begin{tabular}{||l|r|r||}
\hline \multicolumn{1}{|c|}{ Sub-Category } & Frequency & Demographics \\
\hline Costs & 24 & \\
\hline Availability of Drinks & 17 & \\
\hline Other Availability Considerations & 8 & \\
\hline Availability of Money & 7 & \\
\hline
\end{tabular}

$\underline{\text { Costs }}$

Of decisions made governing going out that were made based upon the cost of going out, seven (7) were affected by the fact that drinks were free, six (6) were affected by the fact that drinks were cheap, and five (5) were affected by the fact that there was no cover charge.

\section{Availability of Drinks}

Of decisions made governing going out that were made based upon the availability of drinks, 7 were made because drinks were not available somewhere, 6 were made because drinks were available somewhere, and the rest (4) were made because drinks would be more available elsewhere.

\section{Other Availability Considerations}

These were mostly concerned with the availability of places to go, e.g., "went there because it was open."

\section{Availability of Money}

These were cases in which the decision to go out was driven by the availability of money, e.g., " I decided to go out because I had just gotten paid."

\section{ALTERNATIVE OPTIONS}

Some of the subjects offered alternative plans that they could have pursued, alternatives which, if followed through, could have prevented the subject from ultimately being in the position of driving while intoxicated. In some cases the discussions also included explanation of what they saw as the benefits of the alternative and/or the reasons why they failed to take advantage of them. In fifty three (53) cases subjects mentioned that a possible alternative to drinkingdriving would have been to make plans that did not include attending the event where the alcohol was present. The most common benefit mentioned in connection with this alternative was the positive effect of reducing the chance of unpleasant consequences (12). The desire to drink was stated most frequently as reason not to pursue the alternative (9). 


\section{TRANSPORTATION DECISIONS}

This section deals with decisions on how get to where one has decided to go. Decisions to go included decisions regarding who would be the driver, who would be the passenger and whose car would be driven. These decisions also included plans regarding designated drivers and other plans to avoid impaired driving. It is important to note when reading this that plans made to avoid impaired driving were not always kept.

\section{NATURE OF DECISIONS}

Many subjects described their decisions regarding who would drive and in whose vehicle. These decisions, along with interactions with demographic characteristics, are shown below:

\begin{tabular}{||l|c|l||}
\hline \multicolumn{1}{|c|}{ Transportation } & Frequency & \multicolumn{1}{|c|}{ Demographics } \\
\hline $\begin{array}{l}\text { Drive Alone In Own } \\
\text { Vehicle }\end{array}$ & 152 & $\begin{array}{l}\text { Full-time, Married, } \\
\geq \$ 25 \mathrm{~K}, 35+\text { yrs }\end{array}$ \\
\hline $\begin{array}{l}\text { Drive Self and Others } \\
\text { In Own Vehicle }\end{array}$ & 123 & O DWls \\
\hline $\begin{array}{l}\text { Ride With Another } \\
\text { Driver In Driver's } \\
\text { Vehicle }\end{array}$ & 46 & $\begin{array}{l}\text { Female, Underemployed, 0 } \\
\text { DWls }\end{array}$ \\
\hline Not Driving & 28 & $\begin{array}{l}\leq 25 \text { yrs, Underemployed, }< \\
\$ 25 K\end{array}$ \\
\hline Other Plans & 113 & \\
\hline
\end{tabular}

\section{TRANSPORTATION DECISION BASES}

Bases for making transportation plans were classified into seven major categories. 721 bases were recorded and ninety five percent of these were classifiable. The univariate distributions of frequencies and percentages for these categories are found in the following table: 


\begin{tabular}{||l|c|c||}
\hline \multicolumn{1}{|c|}{ Category } & Frequency & Percent \\
\hline Social/Environmental Influence & 192 & 26.6 \\
\hline Availability of Transportation & 175 & 24.3 \\
\hline Response to Personal Influence & 86 & 11.9 \\
\hline Responsibility & 79 & 11.0 \\
\hline Vehicle-Related Factors & 59 & 8.2 \\
\hline Previous Plans & 48 & 6.7 \\
\hline Normal/Past Behavior & 46 & 6.4 \\
\hline Miscellaneous & 36 & 5 \\
\hline
\end{tabular}

The most commonly cited bases for making transportation plans were categorized as social/environmental influence. Almost as common, was availability of transportation. Response to personal influence and responsibility were mentioned less frequently. Subjects were least likely to mention vehicle-related factors, previous plans and normal/past behavior.

\section{Social/Environmental Influence}

Social/environmental influence was cited most frequently as a basis for making transportation plans. These bases were further classified into environmental effects on driving, overt social influence and unstated social influence. The frequencies for these categories are presented below:

\begin{tabular}{||l|c|l||}
\hline \multicolumn{1}{|c|}{ Sub-Category } & Frequency & \multicolumn{1}{|c|}{ Demographics } \\
\hline Environmental Effects on Driving & 90 & (Caucasian) \\
\hline Overt Social Influence & 66 & Married, O DWls \\
\hline Unstated Social Influence & 36 & \\
\hline
\end{tabular}

Environmental effects were more likely to be cited as influencing transportation plans than were either overt or unstated social influences.

\section{Environmental Effects on Driving}

Environmental-effects bases most often related to whether the situation was conducive to driving (77). These bases included wanting to drive because the subject had a new car, driving because there was no room to ride in another vehicle, driving because the subject was already on the road or driving others because the subject was passing their homes on the way to the destination. Environmental effects also included the situation not being conducive to driving (8) and the situation being conducive to driving more than necessary (3). Environmental effects were 
commonly cited as bases for making transportation plans to drive oneself, while there were no instances where environmental effects were cited as bases for making a decision regarding a designated driver. Of those citing environmental effects on driving plans, Caucasians were underrepresented. Subjects getting a ride with another driver in that driver's vehicle were overrepresented.

\section{Overt Social Influence}

Overt social influence was often mentioned as a basis for making transportation plans. Overt social influence most often meant that driving was suggested by others (58). This may have meant that others did not want to drive, others could not drive or the group's plans involved more than one person driving. There were only a few cases in which subjects mentioned that driving was discouraged by others (3) or that no one suggested that they avoid driving (2). Subjects driving themselves often cited overt social influence as a basis for making transportation plans, while those who made plans not to drive never mentioned it. Among the group citing overt social influence, married subjects were over-represented. Subjects with one DWI were under-represented. Subjects with no DWI were over-represented.

\section{Unstated Social Influence}

Bases relating to unstated social influence included others having no transportation (18) or others having a reason (such as an expired license) not to drive their transportation (17). Unstated social influence was a commonly reported basis for subjects making the decision to drive themselves and others, and was not likely to be a factor for those deciding to drive alone. Unstated social influence was not cited as a factor for subjects riding with another driver in that driver's vehicle.

\section{Availability of Transportation}

Availability of transportation was the second most frequently cited basis. This category was further broken down into the following sub-categories: 


\begin{tabular}{|c|c|c|}
\hline Sub-Category & Frequency & Demographics \\
\hline Availability of Alternatives to Driving & 145 & \\
\hline $\begin{array}{l}\text { Alternative Transportation Not } \\
\text { Available }\end{array}$ & 68 & $\begin{array}{l}\text { High school, } 35+\text { yrs, CAGE } 2+\text {, } \\
\text { BAC . } 10 \%-.139 \%\end{array}$ \\
\hline $\begin{array}{l}\text { Alternative Transportation Was } \\
\text { Available }\end{array}$ & 44 & $\begin{array}{l}\text { Single, } \leq 25 \mathrm{yrs},<\$ 25 \mathrm{~K} \\
\text { Student, } 0 \mathrm{DWl}\end{array}$ \\
\hline $\begin{array}{l}\text { Did Not Consider Alternative } \\
\text { Transportation }\end{array}$ & 10 & \\
\hline Availability of Alternate Driver & 10 & \\
\hline Availability of Vehicle & 28 & \\
\hline
\end{tabular}

Availability of Alternatives to Driving

Bases given by subjects regarding availability of transportation most often involved availability of alternatives to driving.

Alternative Transportation Not Available - Subjects often based their driving plans on alternative transportation not being available (68). Subjects may have mentioned that they could not find anyone to ride with or that there was no public transportation or taxi service in the area. This basis was especially common among subjects driving alone and subjects driving themselves and others. More specifically, subjects who drove alone, in their own car, were also likely to mention a lack of alternative transportation. Subjects riding with another driver and subjects making plans to avoid drinking and driving were under-represented, with respect to subjects making other plans. Subjects with a high school education or less cited this more frequently than those with more education. Subjects 25 or under were under-represented and subjects 35 and over were overrepresented. Those with BACs between $.10 \%$ and $.139 \%$ were also over-represented. Subjects with a CAGE score of 2 or more were over-represented.

Alternative Transportation Was Available - Subjects sometimes said that an alternative to driving was available and was a factor when making transportation plans (44). Examples of this were that the destination was close enough to walk, a friend agreed to drive or there was a designated driver. Subjects mentioning that alternative transportation was available were likely to make plans which did not include driving, while subjects driving themselves and others were not likely to base their decision on this. Single subjects were over-represented in this group. Subjects age 25 and under, students and subjects with incomes under $\$ 25,000$ a year were over-represented in this group. Subjects with no DWIs were also over-represented. 
Did Not Consider Alternative Transportation - A few subjects reported not considering alternative transportation (10). Subjects with incomes above $\$ 25,000$ a year were likely to say this.

Availability of Alternate Driver - Availability of an alternate driver for the subject's car was mentioned by a few subjects (10).

Miscellaneous - Bases cited less frequently were that alternative transportation was available but not desirable (6), alternative transportation was preferable (3) and availability/cost of a place to stay (3).

\section{Availability of Vehicle}

Vehicle availability was sometimes cited by subjects as a basis for making transportation plans. Examples of vehicle-availability bases included the vehicle being available or convenient (14) and the vehicle being unavailable or inconvenient (13). Subjects choosing to drive alone, and those driving alone in a vehicle they did not own, frequently cited this basis. Subjects who decided to ride with another driver or, more specifically, ride in another driver's vehicle, were also likely to base the decision on the availability of the vehicle.

\section{Response to Personal Influence}

Response to personal influence was sometimes cited as a factor in making transportation plans. Personal influence was further divided into five sub-categories. These categories and their frequencies are shown in the following table:

\begin{tabular}{||l|c|l||}
\hline \multicolumn{1}{|c|}{ Sub-Category } & Frequency & \multicolumn{1}{c|}{ Demographics } \\
\hline Physical Influence & 36 & Single, $<\$ 25 \mathrm{~K}$ \\
\hline Stated Desire & 16 & \\
\hline Goals & 14 & \\
\hline Feelings About Relying on Others & 12 & \\
\hline Spur-of-the-Moment Decision & 7 & \\
\hline
\end{tabular}

Response to personal influence most frequently involved physical influence. Stated desire, goals, and feelings about relying on others were cited less frequently. Spur-of-the-moment decisions were mentioned infrequently. 


\section{Physical Influence}

Physical influence most often included plans to be, or not be, physically affected, and consequently was often cited by subjects who made plans to avoid driving while feeling physically affected by alcohol. Single subjects were over-represented among those citing physical influence, as were subjects with incomes under $\$ 25,000$ a year.

\section{$\underline{\text { Stated Desire }}$}

Stated desires included whether the subject had a desire to drive, to be at a certain location or to take advantage of alternatives. Stated desire was commonly cited as a basis by subjects who made plans that did not involve driving and by subjects who made plans to avoid drinking and driving. Subjects who decided to drive themselves and others did not mention stated desires as a basis for their decisions.

\section{$\underline{\text { Goals }}$}

Goals were sometimes cited by subjects as bases for making specific transportation plans. Driving was either conducive (8) or not conducive (6) to achieving those goals. An example of driving that was conducive to goals is driving to relax or blow off steam. Examples of driving not being conducive to goals includes wanting to ride with someone else or wanting to drink. Decisions regarding designated drivers were over-represented for this basis.

\section{Feelings About Relying on Others}

Feelings about relying on others were occasionally cited as bases for making transportation plans. Subjects sometimes reported that they did not want to rely on others (8), or less frequently, that they did not trust others driving (3). Subjects driving only themselves were likely to base their decision on these feelings. Subjects with CAGE scores of 0 or 1 were overrepresented for this decision basis.

\section{Spur-of-the-Moment Decision}

Spur-of-the-moment decisions were mentioned as a basis only a few times.

\section{Responsibility}

Subjects sometimes mentioned presence of, or freedom from, responsibility as a basis for decisions. Ninety one percent of these bases were further classified into driving responsibility and feelings about consequences, as shown in the following table: 


\begin{tabular}{||l|c|c|}
\hline \multicolumn{1}{|c|}{ Sub-Category } & Frequency & Demographics \\
\hline Driving Responsibility & 43 & \\
\hline Consequences & 29 & \\
\hline Miscellaneous & 7 & \\
\hline
\end{tabular}

More than half of the bases dealing with responsibility related to driving responsibility, while almost thirty seven percent of the bases related to feelings about consequences.

\section{Driving Responsibility}

Driving responsibility included whether the subject felt his or her driving was preferable to other drivers (eg., was a better driver or more sober than others) (21), or less desirable than other drivers (eg., was a worse driver or less sober than others) (11). Subjects making the decision to ride with another driver or making decisions regarding a designated driver more frequently cited driving responsibility.

\section{Consequences}

Subjects sometimes mentioned feelings about potential consequences of drinking-driving as a factor in making transportation decisions. These consequences were usually nonspecific (e.g., driving would be a "bad idea") (23), but occasionally subjects specified that they were worried about safety (3) or legal (2) consequences.

\section{Vehicle-Related Factors}

Vehicle-related factors were divided into vehicle ownership and vehicle characteristics. The frequencies of these categories is shown in the following table:

\begin{tabular}{||l|c|c||}
\hline \multicolumn{1}{|c|}{ Sub-Category } & Frequency & Demographics \\
\hline Vehicle Ownership & 33 & \\
\hline Vehicle Characteristics & 26 & \\
\hline
\end{tabular}

\section{Vehicle Ownership}

When subjects mentioned vehicle ownership, it was more often someone else's vehicle (24), than their own (9). Subjects riding with another driver often cited vehicle ownership as a factor in their decision. Those subjects who chose to drive alone were not likely to cite vehicle ownership as a factor in the decision. 


\section{Vehicle Characteristics}

Subjects often based their decision to have a particular person drive on vehicle characteristics, such as whose vehicle was most attractive, or bigger (21). Less frequently, a decision was based on not wanting to take a particular car (5). Vehicle characteristics were frequently mentioned as a basis for the decision to drive oneself and others. Subjects who made the decision to drive alone never cited vehicle characteristics. This is most likely due to the fact that subjects driving alone tended to drive their own vehicle.

\section{Previous Plans}

Subjects sometimes cited stated plans as a basis for making transportation decisions. These plans included plans concerning drinking, and driving after drinking. Subjects who made no transportation plans were over-represented and subjects who made plans to avoid drinking and driving were over-represented. Subjects who rode with another driver were under-represented. Subjects who were employed full-time were under-represented. Married subjects, subjects with BACs equal to or greater than .14 were over-represented.

\section{Normal/Past Behavior}

Subjects cited normal/past behavior less often than any other basis when making transportation plans. Most normal/past behavior bases included behavior concerning driving, or drinking and driving under general circumstances (37), or these specific circumstances (8). Among the group who did cite normal/past behavior, subjects with BACs between $.10 \%$ and $.139 \%$ were under-represented. Subjects who made no plans regarding transportation were overrepresented.

\section{ALTERNATIVE OPTIONS}

Fifty subjects mentioned that they could have assigned one of the people in their group to be the designated driver. The reduction of negative consequences was given as a good reason for pursuing this alternative (18). Some subjects went on to elaborate that reduced possibility of negative consequences would have made them more likely to enjoy the event. The most common reason for not using this alternative, was that they were following their normal behavior (6), the implication being that their normal behavior precludes using a designated driver.

\section{PLANNING FOR DRINKING}

This section of the report will deal with the decisions involving plans to drink at the place and time that drinking occurs. 


\section{NATURE OF DECISIONS}

Subjects frequently described the specific decisions they made relative to plans for drinking. These decisions will be briefly reviewed before embarking upon discussion of the decision bases.

\begin{tabular}{||l|c|l||}
\hline \multicolumn{1}{|c|}{ Drinking Plan } & Frequency & \multicolumn{1}{|c|}{ Demographics } \\
\hline Purchase Alcohol & 122 & $\begin{array}{l}\text { Male, Blue-collar, High school, } \\
\text { African-American, CAGE 2 +, } \\
\text { Heavy drinker }\end{array}$ \\
\hline $\begin{array}{l}\text { Bring Specific Amount } \\
\text { of Money }\end{array}$ & 48 & $\begin{array}{l}\text { Female, } \leq 25 \text { yrs, White- } \\
\text { collar, College, } \\
\text { Underemployed, Single, } \\
<\$ 25 K, 0 \text { DWls, CAGE <2 }\end{array}$ \\
\hline Bring Alcohol & 47 & BAC .14 or >, Heavy drinker \\
\hline Other Plans & 34 & \\
\hline
\end{tabular}

In addition to the above plans, subjects occasionally described how much they intended to drink. Most often, these plans were either to drink lightly or to get drunk. Demographics of those subjects mentioning drinking lightly and getting drunk are shown below:

\begin{tabular}{||l|c|l|}
\hline \multicolumn{1}{|c|}{ Drinking Plan } & Frequency & \multicolumn{1}{c|}{ Demographics } \\
\hline Drink Lightly & 65 & $\begin{array}{l}\text { Female, White-collar, College, } \\
\text { CAGE <2, Light drinker }\end{array}$ \\
\hline Get Drunk & 35 & Underemployed \\
\hline Other Plans & 39 & \\
\hline
\end{tabular}




\section{PLANNING FOR DRINKING DECISION BASES}

The following table analyzes the subdivision of drinking plans by major category.

\begin{tabular}{||l|c|c||}
\hline \multicolumn{1}{|c|}{ Category } & Frequency & Percent \\
\hline Previous Plans & 188 & $19.1 \%$ \\
\hline Availability and Economics & 161 & $16.4 \%$ \\
\hline Normal Drinking Pattern & 145 & $14.8 \%$ \\
\hline Desire to Drink & 128 & $13.0 \%$ \\
\hline Social/Environmental & 116 & $11.8 \%$ \\
\hline Personal Influences & 101 & $10.3 \%$ \\
\hline Feelings of Responsibility & 72 & $7.3 \%$ \\
\hline Occasions to Drink & 50 & $5.1 \%$ \\
\hline Preparation for Later Drinking & 12 & $1.2 \%$ \\
\hline
\end{tabular}

\section{Previous Plans}

Previous plans were the most frequently mentioned of the considerations with which subjects approached drinking. This decision category accounted for $18.8 \%$ of all of the decision bases. The relationship of prior planning to demographics of subjects was determined by the subcategory involving the largest numbers - those planning to consume relatively small amounts of alcohol. The following table analyzes the nature of the planning that influenced the decisions.

\begin{tabular}{||l|c|l||}
\hline \multicolumn{1}{|c|}{ Nature of Plan } & Frequency & \multicolumn{1}{c|}{ Demographics } \\
\hline Drink Some & 110 & $\begin{array}{l}\text { 35+ yrs, Drink/drive } \\
\text { infrequently, Light drinker, } \\
\text { CAGE < 2. }\end{array}$ \\
\hline Drink A Lot & 11 & \\
\hline Not Drink & 6 & \\
\hline No Plans & 43 & \\
\hline Miscellaneous & 18 & \\
\hline
\end{tabular}

Those planning to drink modest amounts made up 107 of the 188 subjects who mentioned planning at all. As might be expected, subjects in this sub-category came from the more responsible segment of the impaired driving population, reporting the fewest instances of drinking as well as drinking and driving, and reporting fewer than two signs on the CAGE. 


\section{Availability and Economics}

Considerations of cost and availability were among the leading considerations in subjects with respect to drinking. It accounted for $16.4 \%$ of all decision bases. Economic considerations were noted most often by those under age 25 and least often those over age 35, most often by those in school and least often by those employed full-time, more often by those with a college education than by those with only a high school education, more often by those reporting less than two CAGE signs than those reporting two or more signs, and more often by those without a previous DWI than those with one or more. Economic considerations are analyzed in the following table.

\begin{tabular}{||l|c|l||}
\hline \multicolumn{1}{|c|}{ Sub-Category } & Frequency & \multicolumn{1}{|c|}{ Demographics } \\
\hline Availability & 68 & \\
\hline Expense & 58 & $\begin{array}{l}\text { Female, White-collar, Student, College, } \\
\text { Single, < \$25K, 0 DWls, CAGE < 2 }\end{array}$ \\
\hline Price & 31 & Student \\
\hline
\end{tabular}

$\underline{\text { Availability }}$

The term "availability" referred to alcohol being provided by hosts, brought by the drinker, or otherwise available essentially without cost to the drinker at the time drinking was initiated. It applied generally across all subsamples.

\section{Expense}

Expense had to do with cost in relation to how much alcohol was received, how much money the drinker had available, either total or after other anticipated expenses, or simply how much money the drinker had available. Expense was a more significant influence upon women than men, upon those involved in white-collar than those involved in blue-collar jobs, for those in school rather than those employed full-time, among the college-educated vs those with only a high school education, among the single vs the married, among those in the low- rather than high-income bracket, among those with no prior DWI record vs those with a previous conviction, and among those with less than two signs on the CAGE.

\section{$\underline{\text { Price }}$}

Finally, "price" had to do with the absolute cost of alcohol, particularly whether there was any charge at all (e.g., "free beer"). Not surprisingly, those still in school were over-represented in this category. 


\section{Normal Drinking Pattern}

Usual, or habitual patterns of drinking were significant in subjects' approaches to drinking situations, accounting for $14.8 \%$ of the decision bases mentioned. As a decision basis, normal patterns tended to rank highest among the full-time employed and lowest among students, higher among the married than the single, among the higher versus lower income brackets, and among the heavy rather than light drinkers. Normal drinking patterns tended to assume particular importance for those who were employed full-time, as opposed to part-timers and those in school, those for who were married as opposed to those who were single, those in the higher income brackets, and those who most often reported driving after drinking.

The following table presents the frequency with which various normal drinking patterns were reported as decision bases.

\begin{tabular}{||l|c|l||}
\hline \multicolumn{1}{|c|}{ Sub-Category } & Frequency & \multicolumn{1}{c|}{ Demographics } \\
\hline Drink Normal Amount & 57 & Female, Light drinker \\
\hline Normal Type of Beverage & 18 & Heavy drinker \\
\hline Normal Place to Drink & 19 & Married \\
\hline Normal Time to Drink & 14 & \\
\hline $\begin{array}{l}\text { Normal Drinking } \\
\text { Companions }\end{array}$ & 9 & \\
\hline Miscellaneous & 28 & \\
\hline
\end{tabular}

\section{Drink Normal Amount}

As far as habitual behavior is concerned, the amount that subjects usually drank was the primary determiner, being reported by 57 people or roughly a tenth of the total sample. Sometimes the normal amount was a lot, sometimes, it was relatively little. In a few cases, what was normal took the form of a self-imposed limit. Planning to gear one's drinking to normal consumption was more characteristic of women than men and people whose weekly alcohol consumption was on the low side.

\section{Normal Type of Beverage}

Of the 18 people who reported that their choice of beverage was a function of their normal behavior, 14 indicated that the choice was beer. With the small numbers involved, one would not expect to find significant differences among subsamples. Only one such inference appeared; those who reported normally drinking a particular beverage tended to be among the more frequent drinkers. 


\section{Normal Place to Drink}

This decision basis involved the influence of drinking location upon normal alcohol consumption, not simply the type of place where people normally drank. Those subjects who reported that their drinking was influenced greatly by the type of place in which they normally drank revealed a great variety of places, including bars, restaurants, parties, private clubs, and sporting events. Married subjects were somewhat over-represented in this category.

\section{Normal Time to Drink}

Of the 14 people who attributed their drinking to a regular time period, five routinely drank everyday, five on weekends, and three during the evening. The remaining case involved a New Year's Eve. All 14 subjects in this category were male and younger age groups were significantly over-represented.

\section{Normal Drinking Companions}

The nine individuals falling in this category reported that their alcohol consumption was influenced by friends with whom they normally drank. The frequency ranged from "usually" to "always." Eight of the nine people in this category scored two points or more on the CAGE measure, indicating a potential alcohol problem. While social drinking is generally considered less serious than solitary drinking, ritual drinking with the same group appears to be somewhat problematic.

\section{$\underline{\text { Miscellaneous }}$}

Of the 28 bases that do not fall neatly into any of the categories listed above, half (14) were combinations of bases listed above, e.g., "always drink there with those people. The remaining 14 bases were mostly individual miscellaneous bases too numerous to list here.

\section{Desire to Drink}

The simple desire to drink represented $13.0 \%$ of the decisions bases. As a decision basis it ranked higher among the older age groups, higher among African-Americans than among others, highest among multiple-DWIs, higher among those with two or more CAGE signs, particularly those acknowledging a need to cut down on their drinking, and higher among those employed part-time than among students.

The table that follows divides frequencies in this decision category by the three major subcategories. 


\begin{tabular}{||l|c|l||}
\hline \multicolumn{1}{|c|}{ Sub-Category } & Frequency & \multicolumn{1}{c|}{ Demographics } \\
\hline General Desire to Drink & 66 & Underemployed, CAGE 2+ (O DWIs) \\
\hline Desire to Feel the Effects & 35 & $35+$ yrs \\
\hline $\begin{array}{l}\text { Desire for Specific } \\
\text { Beverage }\end{array}$ & 27 & African-American \\
\hline
\end{tabular}

\section{General Desire to Drink}

The majority of subjects whose drinking was based, at least in part, on a simple desire to drink did not specify any specific beverage. Most said no more than that they wanted to drink. Seven of them identified the beverage to be consumed as beer, but it was just mentioned in passing. A few indicated the intent to drink very little and a few quite a lot. The demographic characteristics of subjects in this sub-category are essentially those of the category at large, which is not surprising since it is by far the largest sub-category. The desire to drink, without qualification, was most often mentioned by those who were employed full- or part-time rather than being in school; those who had prior DWI convictions, including those whose participation was solicited as DWIs, those reporting two or more signs in the CAGE, specifically those who reported feeling a need to cut down and those who reported needing a drink as an eye-opener.

\section{Desire to Feel the Effects}

Approximately two-thirds of the subjects in this category wanted to feel no more than a mildly euphoric effect ("get buzzed"). The remainder were drinking with a specific intent to get drunk. Other than over-representation by those over 35, this group was drawn from across the range of demographics and drink history.

\section{Desire for Specific Beverage}

Most of the subjects who were specific with respect to the beverage sought specified beer, primarily because they thought it to be less intoxicating, because it was most likely to be readily available, or because it went with what they were eating. African-Americans and those seeking to cut down on their drinking were over-represented in this group.

\section{Social/Environmental}

Social influence, or the effects of the immediate drinking environment (e.g., ambience) accounted for $15.5 \%$ of the bases for this phase. It was cited most often as a basis by those with prior DWIs and those who felt they should cut down on their drinking. Groups in this category were divided as shown in the table. 


\begin{tabular}{||l|c|l||}
\hline \multicolumn{1}{|c|}{ Sub-category } & Frequency & \multicolumn{1}{|c|}{ Demographics } \\
\hline Unstated Social Influences & 52 & $1+$ DWls \\
\hline Overt Social Influences & 34 & $\begin{array}{l}\leq 25 \text { yrs, Full-time, High } \\
\text { school, CAGE 2+, 1+ DWls }\end{array}$ \\
\hline Environmental Influences & 24 & Female \\
\hline Miscellaneous & 6 & \\
\hline
\end{tabular}

\section{Unstated Social Influences}

Passive influences upon drinking were primarily the drinking of others, including the larger group present, friends, or dates. Another significant influence was sharing alcohol brought or purchased by the group or other individuals. This particular decision basis was identified with only one other variable, the over-involvement of individuals convicted of drinking and driving.

\section{Overt Social Influences}

Overt social influences on drinking included simply offering alcohol or suggesting its consumption. Only in a few cases did it involve more persuasive influences (e.g., nagging). Drinkers who reported having been objects of the more persuasive influences formed a distinctive subgroup in that the demographic characteristics described in the table above for the socially influenced category as a whole were primarily those of this sub-category. Those susceptible to overt social influence tended to be under age 25 , to be employed full-time, not to have gone beyond high school, had previous DWI convictions, and to have reported more than two CAGE signs, namely feeling the need to cut down and feeling guilty about their drinking.

\section{Environmental Influences}

The primary environmental influence was simply being where alcohol was served, mostly a bar. In a few cases, it involved a party or sporting event. While females tended to be somewhat over-represented among those influenced by surroundings, the group was not distinguishable on any other basis.

\section{Personal Influences}

Personal influences, those of a physical, medical, or emotional nature, accounted for $10.3 \%$ of decisions. The DWIs were over-represented in this group. Decision bases in this category break down as follows: 


\begin{tabular}{||l|c|l||}
\hline \multicolumn{1}{|c|}{ Sub-Category } & Frequency & \multicolumn{1}{c|}{ Demographics } \\
\hline Relaxation & 43 & CAGE $<2,1+$ DWIs \\
\hline Mood & 30 & CAGE 2 +, Underemployed, 1 + DWIs \\
\hline Physical Influences & 16 & \\
\hline Mood Change & 11 & \\
\hline
\end{tabular}

\section{$\underline{\text { Relaxation }}$}

The largest number of drinkers responding to internal or personal influences consumed alcohol largely as a "downer," to relax, to feel confident, to be able to meet people more readily. Over-represented in this sub-category were subjects with prior DWIs, and subjects who did not feel the need to cut down on alcohol and did not report annoyance at having people criticize their drinking. Among drinking drivers, this group in its decision making, might appropriately be labeled, "laid back."

\section{$\underline{\text { Mood }}$}

A rather different group appears to be constituted of those who drink in order to alter a mood, which was primarily depression, anger, or being upset over some event. In all but one case, the mood was one that is conducive to drinking; in only one case was mood given as a reason for not drinking. Like the previous group, this group was over-represented by subjects having DWI experience. In contrast, however, subjects in this category were among those reporting two or more CAGE signs and reported feeling guilt over their drinking. They tended to come from the ranks of part-timers and those in school rather than the full-time employed.

\section{Physical Influences}

Many subjects reported not feeling well at the time of the drinking event, a condition that generally suppressed their drinking, even though they had acknowledged having driven while alcohol impaired. One individual reported drinking primarily because of thirst. Because of its size, this group did not evidence significant relationships with demographic or other characteristics.

\section{Mood Change}

The mood change sought by alcohol was universally to have a good time. Here, alcohol was to serve primarily as a "upper." This group evidenced no significant relationship to other variables. 


\section{Feelings of Responsibility}

Feelings of responsibility accounted for $7.3 \%$ of decision bases. The following table summarizes the manner in which responsibility influenced drinking-driving decisions.

\begin{tabular}{||c|c|l||}
\hline Sub-Category & Frequency & Demographics \\
\hline Driving Responsibilities & 59 & \\
\hline $\begin{array}{l}\text { Responsibility to Drive } \\
\text { (limit drinking) }\end{array}$ & 25 & \\
\hline $\begin{array}{l}\text { No Responsibility to Drive } \\
\text { (no limit) }\end{array}$ & 15 & \\
\hline Fear of Consequences & 7 & \\
\hline Miscellaneous & 14 & \\
\hline Responsibility or Work & 11 & \\
\hline
\end{tabular}

As might be expected, those for whom responsibility was a consideration tended to be women, white-collar, without previous DWIs, not among those feeling the need to cut down on their drinking or annoyed by criticism of their drinking, and showing no CAGE signs.

\section{Driving Responsibility}

The decision bases in this sub-category had the same demographic make up as the "responsibility" category as a whole, meaning that it was this sub-category that was responsible for the demographic relationships that have been described. The sample sizes of groups within sub-categories are too small to permit further analysis of demographics.

Those subjects who had to drive (25) entered the drinking situation with the intent to drink lightly to moderately. The fact that they acknowledged driving while impaired indicates that they failed to follow through on their intentions. Those who intended not to drive, usually because they did not have to, gave that as a basis for a decision to drink heavily. What changed in their planning was the decision not to drive. Of those considering the consequences of drinking - primarily the prospects of a chance of an accident - all but one felt that the amount they intended to drink would not raise concern.

Of the subjects relating their drinking to work responsibilities, eight limited their drinking because of the need to work, while three gave not having to work as the basis for the level of intended drinking. 


\section{Occasions to Drink}

The nature of the occasion leading to the drinking accounted for $5.1 \%$ of decision bases. Mention of this decision basis was unrelated to any demographics, although the low frequency would have made it difficult for significant relationships to emerge. The following table identifies the types of occasions that lead to drinking.

\begin{tabular}{||l|c|l||}
\hline \multicolumn{1}{|c|}{ Sub-Category } & Frequency & Demographics \\
\hline Special Occasion & 26 & \\
\hline Recognized Drinking Time & 10 & \\
\hline Other Occasions & 13 & \\
\hline
\end{tabular}

\section{Special Occasion}

Decisions to drink rose from a variety of occasions, including celebration of birthdays (one's own or a friend's), graduation, holidays, or a purely local event. This decision basis was unrelated to any demographic characteristics.

\section{$\underline{\text { Recognized Drinking Time }}$}

This category included occasions that are traditionally associated with drinking, including happy hour, the start of a weekend, or drinking with dinner. This specific decision basis was most common among those in the 26 - 34 year age group, those with no prior DWIs, and those with less than two CAGE signs.

\section{Other Occasions}

Other occasions included the first drink after a long period of abstinence (5) and leisure time activities such as watching television or fishing.

\section{Preparation for Later Drinking}

The remaining decision bases involved considerations that did not fall into any of the above categories and could not be grouped into additional categories, at least not into categories having a sufficient number of cases to permit analysis into sub-categories. The largest of the miscellaneous categories involved "warming up" in preparation for later drinking, a decision basis mentioned by only 12 subjects.

\section{ALTERNATIVE OPTIONS}

The most frequently mentioned alternative was to drink less or not at all, cited by 148 subjects. Eighteen (18) subjects stated that this would have been a good alternative because it 
would have reduced the possible negative consequences associated with not pursuing the alternative. Thirteen (13) subjects specifically said that this would have been a good alternative because it would have prevented them from getting drunk. The most commonly cited reason for not accepting this alternative was a basic desire to consume alcohol (27). Blue-collar workers were more likely than others to mention this basis.

Another alternative that was mentioned by five subjects was to have brought less alcohol. There were too few cases of the mention of this alternative to identify common reasons for doing it or not. There were no significant interactions between demographics and the mention of this alternative.

\section{DECISION TO DRINK ALCOHOL}

Once the subjects had arrived at the drinking site, another decision is presented to them. That decision is whether or not they should actually drink. If they do choose to drink, they must decide what to drink, and how much to drink. Subjects were generally prolific in relating bases for making such decisions.

\section{NATURE OF DECISIONS}

Various alcoholic beverages, along with demographic characteristics of subjects selecting them, are shown below:

\begin{tabular}{||l|c|l||}
\hline \multicolumn{1}{|c|}{ What to Drink } & Frequency & \multicolumn{1}{|c|}{ Demographics } \\
\hline Beer & 848 & $\begin{array}{l}\text { Male, } \leq 25 \text { yrs, } \\
\text { Underemployed, Caucasian, } \\
\text { O DWls, Heavy drinker }\end{array}$ \\
\hline Mixed Drinks & 170 & $\begin{array}{l}\text { BAC .14 or >, 35 + yrs, } \\
\text { College, Student, } \geq \$ 25 \mathrm{~K}, 2+ \\
\text { DWls, Light drinker }\end{array}$ \\
\hline Shots & 144 & $\begin{array}{l}\text { Male, Blue-collar, High school, } \\
\text { Student, African-American, } \\
2+\text { DWls }\end{array}$ \\
\hline $\begin{array}{l}\text { Wine, Champagne or } \\
\text { Brandy }\end{array}$ & 97 & $\begin{array}{l}\text { Female, 35 + yrs, College, } \geq \\
\$ 25 \mathrm{~K}, \text { Light drinker }\end{array}$ \\
\hline Other Drinks & 28 & \\
\hline
\end{tabular}

While less than twenty five percent of the subjects reported the pace at which they drank at, decisions regarding drinking pace are still important. Demographic characteristics of subjects reporting quitting drinking, drinking slowly or slower, and drinking quickly or quicker, are found in the following table: 


\begin{tabular}{||l|c|l|}
\hline \multicolumn{1}{|c|}{ At What Pace to Drink } & Frequency & \multicolumn{1}{|c|}{ Demographics } \\
\hline Quit Drinking & 149 & Underemployed \\
\hline Quicker/Quickly & 142 & O DWIs \\
\hline Slower/Slowly & 104 & $\begin{array}{l}\text { BAC }<.10 \%, \text { O DWIs, CAGE } \\
<2\end{array}$ \\
\hline Other & 15 & \\
\hline
\end{tabular}

\section{DRINKING DECISION BASES}

The bases given by the subjects for actually drinking once at the event could be broken down into eight major classifications. Ninety five percent of the 3,399 bases recorded could be fit into one of those major classifications. The classifications and their frequencies are presented below:

\begin{tabular}{||l|c|c||}
\hline \multicolumn{1}{|c|}{ Category } & Frequency & Percent \\
\hline Social Influence & 1,008 & 29.7 \\
\hline Personal Influence & 688 & 20.2 \\
\hline Specific Motivation to Drink & 430 & 12.7 \\
\hline Availability and Economics & 371 & 10.9 \\
\hline Drinking Occasions & 227 & 6.7 \\
\hline Feelings of Responsibility & 190 & 5.6 \\
\hline Typical Drinking Routine & 168 & 4.9 \\
\hline Effect of Previous Plans & 137 & 4.0 \\
\hline Miscellaneous & 180 & 5.3 \\
\hline
\end{tabular}

The presence of social influence was the most common factor in the decision to drink. Less common, but still frequent were internal influences such as the physical drive to be intoxicated, and a specific motivation to drink. The availability of the alcohol was also often cited as a general class of bases for the decision to drink, as was the nature of the occasion itself. It was relatively uncommon for the participant to mention the presence of a typical routine, the consideration of their responsibilities, or the effect of having made previous plans.

\section{Social Influence}

The most frequently cited category of bases for deciding to drink involved some sort of social influence. Specific aspects about the social environment could be further categorized into four sub-categories that are presented, with their frequencies, in the following table. 
Alcohol Induced Drinking - There were some subjects who stated that the effect of intoxication was a reason for drinking more (52). It was often cited when explaining why the subject had consumed more than expected and for drinking quickly. It was less commonly cited for those drinking beer, but more often cited for blue-collar workers. Subjects under 25 years old were more likely to state this, as were the those subjects that typically drank more per week (greater than 8 drinks per week).

Desired State Achieved - The intoxicating effects of alcohol did not make all of the subjects drink more, in fact some subjects specifically mentioned that they used the fact that they were at their desired state as a basis for deciding whether or not to continue drinking (45). This was most often cited as reason for discontinuing drinking, and was more likely for those switching to an alternative beverage. It was more common for those who had no DWI arrests, and those scoring less than 2 on the CAGE questions.

Effect Unawareness - Some subjects specifically stated that they were unaware of their level of intoxication at the time that they were deciding whether to drink (30). This was more likely to be mentioned for those drinking more than expected, and by those who had one DWI arrest.

Relieve Thirst - Obviously one may drink a beverage (either alcoholic or not) merely to relieve thirst, and that was a basis mentioned by many subjects (50). This was an especially common basis for those choosing to have their first drink, for those drinking quickly, and for those drinking beer. Full-time employed subjects, and those making more than $25 \mathrm{~K}$ a year were more likely to cite this, as were married subjects and those ages 26-34 years. Those with no DWI arrests were also more likely to mention this. Subjects who were under 25 years old were under-represented, as were those who were typically heavy drinkers.

Other physical states that were mentioned rather infrequently were the following:

To Relieve Pain (10)

Too Full to Drink (12)

Fatigue (12)

\section{Emotional State}

Just being in a particular emotional state was a basis some people used for the decision whether or not to drink.

Feeling Bad - Being in a bad mood (feeling depressed, lonely, or angry) was the most frequent emotional basis for drinking (95). It was over-represented as a reason for people who drank at home. It was cited as a reason for drinking quickly, and never cited as a reason for drinking more slowly. Those choosing to drink mixed drinks were more likely to mention this basis, as were those drinking malt liquor. Beer drinkers were less likely 
to report considering this. Blue-collar workers were also over-represented in stating this, as were those who were unemployed or part-time (underemployed). those making less than $\$ 25,000$ a year, and those over 35 . Students, those under 25 , and those with some college were less likely to cite this. It is probable that the necessary correlations between these demographic variables represent some underlying construct that accounts for all of these significant relationships. Specifically, drinking because one feels bad may be related to a state of under-employment, or poor economic prospects.

Those with one DWI arrest were much more likely to cite this as a reason for drinking than those with no arrests. It seems likely that the most important relationship among these highly inter-related demographic variables is that of the DWI measure. This seems especially relevant given that those scoring above 2 on the CAGE questions were greatly over-represented in citing this reason. Apparently, drinking because one feels bad is strongly related to employment or economic prospects, and potentially having a drinking problem. It is worth reiterating that those in this sample were people who drank enough to get intoxicated. So it may not be true that people who have a drink because they are in a bad mood are more likely to have a drinking problem. But those who drink heavily because they are in a bad mood (as opposed to other reasons for drinking heavily) may be more likely to have a drinking problem.

Feeling Good - Being in a good mood was the next most frequent emotional basis for drinking (89). Those drinking more than expected were over-represented for this basis. It was rare that anyone mentioned this as a basis for deciding to stop drinking. When BACs was reported, subjects below .10\% BAC were less likely, and subjects between $.10 \%-.139 \%$ more likely to state this reason.

Nine subjects mentioned feeling bored as a basis for drinking, while five described a specific mood to drink as a reason for drinking.

\section{$\underline{\text { Affective Goal }}$}

Many subjects mentioned that a particular affective state was desired. This desired state was considered when deciding whether or not to drink. These desired states were not ones of intoxication (which are discussed elsewhere) but instead other states that may be facilitated or inhibited by alcohol.

Increased Sociability - Most often, subjects sought a heightened state of sociability through alcohol (126). This was never considered as part of a decision to slow down or quit drinking. Those who had some college education were less likely to consider this. Subjects who scored at least two on the CAGE questions, heavy drinkers and those over 35 year old were more likely to consider this. Those under 25 were under-represented in reporting this basis. 


\section{Specific Motivation to Drink}

Possibly the most obvious reason for someone deciding to drink is because they desired to drink. It may be surprising then that this was not the most frequently cited category of bases. That said, there were still 430 instances of this category being mentioned. It was most often cited in the consideration to change drinks, and was rarely cited as an explanation for drinking more than expected. Full-time workers were over-represented, as were married subjects.

This motivation could be further categorized into three sub-categories. Those categories and their frequencies are listed in the table below.

\begin{tabular}{||c|c|l||}
\hline Sub-Category & Frequency & Demographics \\
\hline Desire For a Particular Beverage & 241 & \\
\hline Non-Specific Reason & 127 & $\begin{array}{l}\text { Male, Full-time, High school, } \\
\text { Heavy drinker }\end{array}$ \\
\hline Taste & 42 & Married \\
\hline Alcohol Content & 24 & \\
\hline Novelty & 22 & \\
\hline Change & 19 & \\
\hline Tradition & 6 & \\
\hline Sophistication & 1 & \\
\hline General Desire to Drink Alcohol & 130 & \\
\hline $\begin{array}{l}\text { Desire With Unspecified } \\
\text { Amount }\end{array}$ & 80 & 2 DWIs, (O DWI), BAC .10\%- \\
\hline Desire to Drink Less/None & 23 & \\
\hline Desire to Drink More & 20 & \\
\hline Desire to Drink a Little & 4 & \\
\hline Desire to Drink a Lot & 2 & \\
\hline Desire for the Effects of Alcohol & 59 & \\
\hline \hline
\end{tabular}

\section{Desire for a Particular Beverage}

If a subject mentioned a preference for or against a specific type of beverage, that desire was coded in this category. There were 127 instances in which a subject mentioned this as a basis for making the decision about drinking, without elaborating more specifically about the reasons for the desire. This explanation was most common for those drinking with a meal. This was rarely given as an explanation for drinking quickly or quitting consumption. Those drinking 
shots, wine and malt liquor were over-represented in stating this motivation. Men were more likely than women to give this as a reason. Full-time employed, those having only high-school educations, and heavy drinkers were also among the most likely to mention it.

Subjects were sometimes fairly specific as to what it was about the drink that made them either want or not want it. Taste was the most common reason stated (42). This was particularly common for those drinking with a meal, beer drinkers, and married subjects. Other specific drink qualities mentioned were: alcohol content (24), novelty (22), change (19), tradition (6), and "sophistication" (1).

\section{General Desire to Drink Alcohol}

At times the subjects did not mention a desire for a specific drink, only a general desire to either drink or not drink an alcoholic beverage.

Desire With Unspecified Amount - Generally, the desire to drink was not accompanied by a specific quantity (80). Only the desire to drink was considered. This was more common for those choosing to change drinks, and for those drinking mixed drinks. Those with more than two DWIs were more likely to mention this, while those without arrests were not. Those reporting BACs between $.10 \%$ and $.139 \%$ were more likely to report this, while those below $.10 \%$ were under-represented.

Desire With Relative Amount - Some subjects reported a desire to drink a relative amount of alcoholic beverage as a basis for deciding whether or not to drink. Those specified amounts were classified as the following:

Drink Less/None - (23)

Drink More - (20)

Drink a Little - (4)

Drink a Lot - (2)

Interestingly, although all of the subjects eventually went on to drink a significant quantity of alcohol, very few stated the desire to drink a lot as a basis for the decision to actually drink.

\section{Desire for the Effects of Alcohol}

One might expect that the desire to feel the effects of alcohol would be an important basis for the decision to drink. However, surprisingly few subjects (59) mentioned this as a factor in their decision to actually consume alcohol. Those drinking at home were over-represented in stating this basis, as were those drinking malt liquor. 


\section{Availability and Economics}

Subjects sometimes mentioned that the availability of alcoholic beverages was a consideration. Availability could involve the quantity of drinks present and also the cost and ability of the subject to pay for the drink. This category could be further divided into the subcategories listed below with their frequencies. Men were more likely to give this as a basis, as were those in school and those under 25. Full-time workers, those with one DWI arrest, and those over 35 years old were less likely to report considering this.

\begin{tabular}{||l|c|l||}
\hline \multicolumn{1}{|c|}{ Sub-Category } & Frequency & Demographics \\
\hline Drinks Were Plentiful & 113 & White-collar, CAGE < 2, (35+ yrs) \\
\hline Cost of Drinks & 101 & $\begin{array}{l}\text { O DWI, (BAC .10\%-.139\%), 35+ yrs, } \\
(\leq 25 \mathrm{yrs})\end{array}$ \\
\hline Drinks Were Available & 81 & $(35+\mathrm{yrs})$ \\
\hline Unavailability of Drinks & 20 & \\
\hline Availability of Money for Drinks & 19 & \\
\hline $\begin{array}{l}\text { Desire to Finish Drinks That Were } \\
\text { Present }\end{array}$ & 13 & \\
\hline Pending Unavailability of Drinks & 12 & \\
\hline
\end{tabular}

\section{Drinks Were Plentiful}

The mere plentitude of the drinks was a basis for many in deciding whether or not to drink. This was especially true for those drinking beer, and also more likely for those having more than expected. White-collar workers were more likely to cite this as a basis for decisions. Those scoring less than 2 on the CAGE questions were also more likely to mention this. Subjects who were over 35 years old were under-represented for this basis.

\section{Cost of Drinks}

The next most common aspect of the availability of the drinks that was considered for this decision was the cost of the drinks. Those subjects drinking free drinks were the most likely to cite this aspect. Those drinking rounds of drinks, and pitchers of beer, and malt liquor also were more likely to mention this. Subjects who had never been arrested for a DWI were more likely to mention this than those who had one DWI arrest. Subjects with measured BACs of .10\%$.139 \%$ were under-represented. Those subjects over 35 were over-represented, while those under 25 were under-represented. 


\section{Drinks Were Available}

Almost as though some subjects were saying "because it was there," the mere availability of the drinks was a basis for some to drink. This was most common among those drinking at home, and malt liquor drinkers. Those subjects over 35 years old were less likely to say this.

\section{Other Issues of Availability}

Other, less frequent bases were mentioned as well. The unavailability of alcohol was mentioned 20 times, almost exclusively as a basis for deciding to quit drinking. The amount of money available to the subject was mentioned 19 times and was usually used in the decision to either drink pitchers of beer, or accept a drink bought by another person. Having an unfinished drink present was part of the decision process 13 times. Finally, knowing that drinks would become unavailable (i.e., "last call") was considered 12 times.

\section{Drinking Occasions}

Some aspect of the type of occasion or event was often mentioned. This could have been a reference to the fact that the subject was at a special event (like a birthday celebration), or a non-special occasion (like a happy-hour). Men, and those with some college were more likely than women to mention some aspect of the event as a basis for deciding whether or not to drink. Caucasians, and those under 25 years old were less likely to mention this basis. Those over 35 , however, were over-represented.

Many of the bases in this coding category could be further divided into sub-categories of events. Those sub-categories are considered in the table below.

\begin{tabular}{||l|c|l||}
\hline \multicolumn{1}{|c|}{ Sub-Category } & Frequency & Demographics \\
\hline Special Occasion & 79 & \\
\hline Drinking Time & 58 & $35+$ yrs \\
\hline Other Leisure Activity & 45 & $\begin{array}{l}\text { Male, Blue-collar, 26-34 yrs, } \\
\text { African-American, 1 DWI }\end{array}$ \\
\hline End of Drinking Time & 39 & $\begin{array}{l}\text { Full-time, Caucasian, College, 0 } \\
\text { DWls }\end{array}$ \\
\hline
\end{tabular}

\section{Special Occasion}

Subjects often said they drank because they were at a celebration for a special occasion (79). Many types of occasions were mentioned, including birthday parties, victory parties, and reunions. Subjects who drank more than expected were more likely to cite this as a reason, while those who decided to drink quickly or to stop drinking never cited this as a reason. 


\section{Drinking Time}

Without the need for a special occasion, some of the subjects reported drinking because it was, for them, a normal time to drink, for instance, if it was cocktail or happy-hour, or during a meal. For some subjects (58) this was a basis to drink. This was especially true for those subjects who chose to drink while eating a meal, or chose to drink at home. Those subjects over 35 were more likely to state this basis, possibly accounting for their over-representation in the general category of "The Occasion."

\section{Other Leisure Activity}

Some subjects mentioned that they were participating in some sort of leisure activity that for them is associated with drinking alcohol. For example, for some subjects, the reason for drinking was the fact that they were watching sports on television. This was a common basis for those drinking at home, and for those drinking beer or malt liquor. Men were much more likely to cite this as a basis than women. Blue-collar workers, subjects aged 26-34, and AfricanAmericans were also over-represented. Those who had one DWI arrest were also overrepresented.

\section{End of Drinking Time}

Just as the presence of a recognized drinking period (like a meal or special occasion) was cited as a reason for drinking, the end (or the approaching end) of such a period affected some of the subjects' decisions regarding drinking. Subjects were likely to cite this as a reason for slowing or quitting consumption. Full-time employed subjects, Caucasians, those with some college, and those with no DWI arrests were more likely to give this basis.

\section{Feelings of Responsibility}

At times, subjects reported considering their responsibilities when deciding whether or not to drink. They may have cited a responsibility to drive, work, or to use the time more efficiently. Of course, at times the consideration of these was only a factor because the subject felt at the time free from the responsibilities. Consideration of responsibilities was more likely for those who chose to drink a non-alcoholic beverage. African-Americans, and those over 35 were less likely to mention responsibilities as a basis, while those under 25 were over-represented. It is worth remembering that although some groups may have been more likely to consider their responsibilities, all of these subjects ended up drinking and driving, therefore, it cannot be concluded that any group acted more responsibly. It is also important to note that subjects who made "responsible" decisions may have avoided less responsible behavior (e.g., getting more intoxicated or driving more while intoxicated).

Many of the types of responsibilities considered could be sub-categorized further. These sub-categories are presented in the following table. 


\begin{tabular}{||c|c|l||}
\hline \multicolumn{1}{|c|}{ Sub-Category } & Frequency & \multicolumn{1}{|c|}{ Demographics } \\
\hline Driving & 132 & \\
\hline Needed to Drive & 93 & $\begin{array}{l}\text { (Underemployed), (African-American), } \leq \\
25 \text { yrs, (26-34 yrs) }\end{array}$ \\
\hline Did Not Need to Drive & 24 & Single \\
\hline Good Use of Time & 26 & \\
\hline Work Related & 17 & \\
\hline
\end{tabular}

\section{Driving}

Many of the subjects reported considering the fact that they either had to drive, or did not have to drive when deciding whether or not to drink.

Needed to Drive - Some 93 subjects reported considering the fact that they had to drive when deciding not to drink further. Most of them reported switching to an alternative beverage. The fact that they all acknowledged ultimately drinking impaired means that the decision came too late. However, it is instructive that no one reported even considering their need to drive when deciding to have their first drink, or after drinking commenced. Part-time and unemployed (underemployed) subjects were under-represented, as were African-Americans. Those under 25 years old were over-represented, while those between 26-34 were under-represented. Of those who mentioned that concern about driving, only a small number alluded to the consequences of driving drunk (12) or the length of the drive (2).

Did Not Need to Drive - Some subjects reported that they thought that they would not need to drive. This was sometimes factored into their decision about drinking (24). This was most common for those drinking beer. Single subjects were also more likely to state this.

\section{Good Use of Time}

At times, people chose to drink (or not to drink) after considering how good a use of time drinking would be (26). It was most likely to be considered by those choosing to stop drinking.

\section{Work Related}

Some subjects (17) reported that feelings of responsibilities about work played a part in their decision. This concern was usually expressed by those choosing to stop drinking. 


\section{Typical Drinking Routine}

Having a set pattern of drinking behavior was a basis for choosing whether or not to drink a beverage for some of the subjects. They may have mentioned that they had a usual drink, amount, time or place that they were pursuing. Not surprisingly, this was rarely a reason for drinking more than expected, but was commonly cited as a reason for drinking while eating. Men were more likely than women to mention this. Blue-collar workers, and those over 35 years old were also over-represented.

The particular routines regarding drinking will be discussed below. The table below presents the different routines mentioned by the subjects.

\begin{tabular}{||l|c|l||}
\hline \multicolumn{1}{|c|}{ Sub-Category } & Frequency & \multicolumn{1}{|c|}{ Demographics } \\
\hline Type of Drink & 42 & Blue-collar, 1 DWI \\
\hline Amount of Drink & 35 & Heavy drinker \\
\hline Rate of Drinking & 30 & \\
\hline Time to Drink & 25 & Male, High school, Married \\
\hline Place to Drink & 10 & \\
\hline
\end{tabular}

\section{Type of Drink}

Having a typical drink was the most common aspect of a normal routine considered when deciding whether or not to consume a particular beverage. It was most likely to be mentioned by those choosing to drink beer. Blue-collar workers, and those with one DWI arrest were slightly more likely to consider this.

\section{Amount to Drink}

Some subjects (35) reported considering the fact that they had an amount of alcoholic beverage which they typically consumed. Heavy drinkers (more than eight per week) were also more likely to consider this.

\section{$\underline{\text { Rate of Drinking }}$}

Subjects occasionally reported that they had a regular rate in which they consumed alcohol (30). This rate was considered when the subject was making a decision concerning actually drinking. 


\section{$\underline{\text { Time to Drink }}$}

Some subjects stated that they had a regular time to drink, and that this influenced their decision concerning drinking (25). Men were more likely to mention this, as were those who had only finished high school. Married subjects were also over-represented in reporting this.

\section{Place to Drink}

Only 10 subjects mentioned the typicality of the drinking site when discussing the reasons that they chose to drink or not to drink.

\section{Effect of Previous Plans}

Previously made plans were cited frequently as a basis for the drinking decision. Those with one DWI were the most likely to consider previous plans during this phase.

The specific types of plans that were considered formed the sub-categories for this group of bases. They are discussed below.

\begin{tabular}{||l|c|l||}
\hline \multicolumn{1}{|c|}{ Sub-Category } & Frequency & Demographics \\
\hline Plans to Drink & 67 & \\
\hline Change in Event Plans & 26 & \\
\hline Driving Plans & 20 & \\
\hline Lack of Plans & 15 & \\
\hline Plans to Abstain & 7 & \\
\hline
\end{tabular}

\section{Plans to Drink}

An obvious answer to why someone drank was that they planned to drink all along. Basically, many of the subjects responded as such (67). This was infrequently cited as a reason for drinking more than expected.

\section{Change in Event Plans}

Some subjects reported that the fact that plans had changed affected their decision concerning drinking. For instance, one subject reported that a party had lasted longer than expected. Since he was staying at the party he decided to drink more alcohol. Those drinking more than expected and pitcher-of-beer drinkers were the most likely to cite this basis. 


\section{Driving Plans}

Driving plans were surprisingly infrequent as a basis for the decision whether or not to drink. Only 20 instances of subjects mentioning that they considered the driving plans they had made were recorded.

\section{Other Plans}

Fifteen instances in which subjects mentioned the fact that they had no plans were recorded. Only seven subjects considered the fact that they had planned to abstain while making a decision regarding drinking.

\section{ALTERNATIVE OPTIONS}

Alternatives that might have been taken when making decisions concerning drinking while at the drinking event are listed, along with their frequencies, in the table below. Following the table is a discussion of the most frequently mentioned benefits and reasons for not pursuing the alternatives.

\begin{tabular}{||l|c||}
\hline \multicolumn{1}{|c|}{ Alternative } & Frequency \\
\hline Pace Drinking & 26 \\
\hline Stop Drinking Earlier & 15 \\
\hline Eat & 9 \\
\hline
\end{tabular}

\section{Pace Drinking}

Many subjects expressed the belief that if they had slowed down their drinking they could have avoided driving drunk. Only two bases were considered by more than two subjects. Some subjects considered the advantage that they would not feel the negative effects of becoming overly intoxicated (5). However, four subjects reported that their intoxication precluded the proper consideration of this alternative.

\section{$\underline{\text { Stop Drinking Earlier }}$}

Another strategy for avoiding becoming overly intoxicated would be to stop drinking earlier. Fifteen subjects considered this alternative. Six subjects reported that this would have helped them avoid the unpleasant effects of becoming overly intoxicated. But four subjects reported that the effects of the already consumed alcohol made them less likely to stop drinking. 
Eating as a strategy to avoid intoxication was considered an alternative to the chosen behavior by nine subjects.

\section{ACTIVITIES DURING EVENT}

Decisions regarding activities during the event included decisions to eat, dance, play cards, play or watch sports, listen to music or bands, play drinking games, watch TV or videos, and watch or participate in karaoke. These decisions also included playing pool, pinball, darts and other games.

\section{NATURE OF DECISIONS}

The demographics for various decisions are found below:

\begin{tabular}{||l|c|l||}
\hline \multicolumn{1}{|c|}{ Activity } & Frequency & \multicolumn{1}{c|}{ Demographics } \\
\hline Eating & 266 & High school, Full-time \\
\hline Dancing & 45 & $\begin{array}{l}\text { Female, College, } \\
\text { Underemployed, CAGE < 2, } \\
\text { Light drinker }\end{array}$ \\
\hline $\begin{array}{l}\text { Pool, Pinball, Darts, or } \\
\text { Other Games }\end{array}$ & 33 & Male, Blue-collar \\
\hline Other Activities & 80 & \\
\hline
\end{tabular}

\section{ACTIVITIES DURING EVENT DECISION BASES}

The bases for these decisions were classified into two major categories depending on whether they were eating or entertainment-related. Ninety nine percent of the 467 bases recorded were classifiable. The univariate distributions of frequencies and percentages for these categories are shown in the following table:

\begin{tabular}{||l|c|c||}
\hline \multicolumn{1}{|c|}{ Category } & Frequency & Percent \\
\hline Eating-Related & 274 & 58.7 \\
\hline Entertainment-Related & 189 & 40.5 \\
\hline Miscellaneous & 4 & .9 \\
\hline
\end{tabular}


Subjects were more likely to cite eating-related bases than they were to cite entertainmentrelated bases.

\section{Eating-Related}

Eating-related bases were further classified into two sub-categories. The frequencies for these categories are found in the following table:

\begin{tabular}{|c|c|c|}
\hline Sub-Category & Frequency & Demographics \\
\hline Did Eat & 224 & \\
\hline Availability of Food & 50 & ( $\leq 25$ yrs $)$ \\
\hline Hunger & 41 & \\
\hline $\begin{array}{l}\text { Eating Driven by } \\
\text { Drinking }\end{array}$ & 39 & Single, BAC $<.10 \%$, O DWls \\
\hline $\begin{array}{l}\text { Recognized Eating } \\
\text { Time }\end{array}$ & 29 & Full-time, High school \\
\hline $\begin{array}{l}\text { Food/Eating was } \\
\text { Attractive }\end{array}$ & 20 & $\geq \$ 25 \mathrm{~K}, 0 \mathrm{DWls}$ \\
\hline Social Influence & 11 & Female, College \\
\hline Did Not Eat & 43 & \\
\hline Miscellaneous & 7 & \\
\hline
\end{tabular}

\section{Did Eat}

Eating-related bases most often involved bases for eating (rather than not eating).

Availability of Food - Subjects often based their decision to eat on food being available (50). Subjects who chose to eat during the event, as opposed to before or after, were likely to cite that they ate because food was available. Subjects 25 and under were less likely to cite food availability than older subjects.

Hunger - Hunger was sometimes cited as a basis for eating (41). Subjects who made the decision to eat after the event were over-represented in this group, while subjects who chose to eat beforehand were under-represented.

Eating Driven by Drinking - Subjects sometimes reported that their eating was driven by drinking (39). Some examples of this include subjects eating to prevent feeling ill or to prevent becoming drunk. Subjects who made the decision to eat before the event were especially likely to say that their eating was driven by drinking. Single subjects were 
over-represented, as were subjects with BACs less than .10\%. Subjects with no DWIs were over-represented. Subjects with $1 \mathrm{DWI}$ were under-represented.

Recognized Eating Time - Subjects sometimes reported eating because it was a recognized time to eat (29), such as dinner time. Subjects may have reported eating before, after or during an event. Subjects eating during the event were under-represented among those citing that it was a recognized eating time. Subjects employed full-time were over-represented. Subjects with only a high school education were more likely to cite this as a basis than subjects with more education.

Food/Eating was Attractive - Subjects occasionally stated that food or eating was attractive (20). Examples of this were that food was cheap, free or special in some way. Subjects who ate during the event often cited this as a basis for their decision. Subjects with incomes of $\$ 25,000$ a year or higher were more likely than those with lower incomes to mention this. Subjects with no DWIs were over-represented and subjects with 1 DWI were under-represented.

Social Influence - Social influence was infrequently cited as a basis for the decision to eat (11). Social influence may have meant that food was suggested or provided by someone else. Among those citing social influence, females were over-represented. Subjects with at least some college education often cited social influence as a basis, while those subjects with a high school education never mentioned social influence.

\section{Did Not Eat}

Subjects who decided not to eat sometimes cited bases for that decision. These bases included food not being available (5), available food not being appetizing (2), or eating not being conducive to plans (10) or drinking (6).

\section{Entertainment-Related}

Entertainment-related bases were further divided into two sub-categories. These subcategories were bases for joining, or continuing in an entertainment-related activity, and bases for not joining, or stopping participation in such an activity. The frequencies for these sub-categories are found in the table below: 


\begin{tabular}{|c|c|l||}
\hline Sub-Category & Frequency & \multicolumn{1}{|c|}{ Demographics } \\
\hline To Join or Continue & 175 & \\
\hline Desire to Participate & 54 & 1 DWI \\
\hline Social Influence & 43 & Student, $\leq 25$ yrs \\
\hline Something to Do & 38 & \\
\hline Conducive to Goals & 17 & African-American, 35 + yrs \\
\hline To Not Join or Stop & 14 & \\
\hline
\end{tabular}

Subjects were much more likely to cite bases for joining in, or continuing in, an activity, than to cite bases for not joining or stopping participation in an activity.

\section{To Join or Continue}

More than $92 \%$ of entertainment-related bases involved the decision to join or continue participation in an activity.

Desire to Participate - A desire to participate was frequently cited by subjects who made the decision to participate or continue in an activity (54). This was often cited as a basis for watching sports, dancing, and playing games such as pool, pinball and darts. Caucasians were under-represented in this group. Subjects with one DWI were overrepresented.

Social Influence - Subjects often cited social influence as a basis for participating in an activity (43). Social influence may have been overt, as in being asked to join, or unstated. This was a common basis for subjects who made the decision to dance, play drinking games or play games such as pool, pinball and darts. Students and subjects 25 and under were also over-represented. Subjects 35 and over were under-represented.

Something to Do - Subjects often stated that they participated in an activity because it was something to do or because it was there (38). This was especially true of subjects who made the decision to listen to music or who made the decision to dance.

Conducive to Goals - Subjects sometimes stated that participating in an activity was conducive to fulfillment of other goals (17), such as meeting people. Subjects who made the decision to dance were likely to cite this as a basis. In the group citing that participation in an activity was conducive to fulfillment of goals, Caucasians were underrepresented and African-Americans over-represented. Of those subjects citing that participation was conducive to goals, subjects with no DWIs and subjects 25 and under were under-represented. Subjects 35 and over were over-represented. 
Miscellaneous - Other bases that were mentioned infrequently were that these activities were normal behavior (9), that alcohol caused a desire to participate (5), and that participation in activities was conducive to drinking (2).

\section{To Not Join or Stop}

Less than eight percent of entertainment-related bases involved the decision to not join in an activity or stop participation. Bases which were mentioned include the fact that it was normal behavior to not participate (3) and that there was a desire to not participate (1). Other bases for not participating were that the subject was feeling the effects of alcohol (3) or that participation was not conducive to drinking (1) or other goals (2).

\section{ALTERNATIVE OPTIONS}

There were no cases of subjects who mentioned decisions regarding alternatives that might have been made at the point of making decisions regarding activities. Therefore there will be no discussion of alternative options here.

\section{DECISION TO LEAVE}

The next decision presented to the subject was that concerning whether or not they should leave. Necessarily, all of the subjects eventually considered this decision. Some subjects faced this decision multiple times since they had either traveled to multiple drinking sites or because the initial outcome of this decision was the conclusion that they should stay at the drinking site. Those who initially decided to stay, eventually decided to go home, although not necessarily directly from the first or second drinking site. Those that decided to go to a different drinking site, often mentioned three possible alternative destinations: a bar, a party, and a restaurant.

\section{NATURE OF DECISIONS} below:

Destinations at the time of leaving, along with demographic characteristics, are found

\begin{tabular}{||l|c|l||}
\hline \multicolumn{1}{|c|}{ Destination } & Frequency & \multicolumn{1}{|c||}{ Demographics } \\
\hline $\begin{array}{l}\text { Go Home } \\
\text { (Own/Friend's) }\end{array}$ & 445 & $(\leq 25 \mathrm{yrs})$ \\
\hline $\begin{array}{l}\text { New Socializing } \\
\text { Destination }\end{array}$ & 280 & BAC .10\% $-.139 \%, \leq 25 \mathrm{yrs}$ \\
\hline Stay & 61 & Female \\
\hline
\end{tabular}




\section{LEAVING DECISION BASES}

The bases for making the decisions varied widely, but could be reduced into five broad categories. Ninety seven percent of the 1,436 bases recorded could be classified into one of the five general categories. The categories and their frequencies are presented in the table below.

\begin{tabular}{||l|c|c|}
\hline \multicolumn{1}{|c|}{ Category } & Frequency & Percent \\
\hline Personal Influence & 576 & 40.1 \\
\hline Social Influence & 528 & 36.8 \\
\hline Feelings of Responsibility & 214 & 14.9 \\
\hline Availability of Alcohol & 59 & 4.1 \\
\hline Effect of Previous Plans & 15 & 1.0 \\
\hline
\end{tabular}

Those subjects who decided to stay where they were usually stated social influences as the bases for that choice. Subjects who decided to go home most often cited consideration of responsibilities in their reasoning. Consideration of responsibilities were unlikely bases, however, for those deciding to go to a new drinking site. Those subjects who did change drinking locations were most likely to give some sort of internal state as a justification. For instance, they might say that they were "feeling good", so they wanted the evening to continue.

\section{Personal Influence}

The most common category of basis for making a decision regarding leaving the drinking site was that of personal influence. An internal-state basis was any justification that involved a reference to the subjects' feelings. The feelings could have been physical comfort, or emotional affect. This type of basis was mentioned most frequently by those deciding to go to another drinking site. It was less common for anyone to mention internal states as a justification for going home or for staying at their current place. Those subjects with some college education were less likely to mention this.

Within the general class of internal states, more specific sub-categories could be formed. The specific sub-categories and their frequencies are presented in the following table: 


\begin{tabular}{||c|c|l||}
\hline Sub-Category & requency & Demographics \\
\hline Motivational State & 347 & \\
\hline $\begin{array}{c}\text { Desire to be Somewhere } \\
\text { Else }\end{array}$ & 224 & $\begin{array}{l}\text { Blue-collar, High school, Full- } \\
\text { time, 1 DWI, (BAC <.10\%) }\end{array}$ \\
\hline Desire to Go Home & 46 & \\
\hline Physical State & 140 & \\
\hline Effect of Alcohol & 61 & Female \\
\hline Fatigue & 61 & \\
\hline Hunger & 14 & \\
\hline Emotional State & 87 & \\
\hline Boredom & 58 & $<\$ 25 \mathrm{~K}$ \\
\hline Other Negative Emotions & 20 & \\
\hline Positive Emotions & 5 & \\
\hline
\end{tabular}

\section{Motivational State}

An internal motivational state was the most common justification for a decision to either stay or leave a particular drinking site.

Desire to be Somewhere Else - The most common basis given for any decision regarding leaving was that the subjects wanted to do something somewhere else that they could not do at their current location (224). For instance, a subject may have wanted to meet a friend at another location, thus requiring them to leave. The implication here is that many of the decisions to leave were efforts to continue the evening's, or outing's, activities.

Not surprisingly this was most often cited as a reason for going to another drinking site. Blue-collar workers, and those with only high school educations were more likely to offer this as a basis, as were full-time employed subjects. Those with one DWI arrest were over-represented in reporting this, while those without any DWI arrests were underrepresented. For subjects with tested BAC levels, those with under .10\% BAC were less likely to mention this.

Desire to Go Home - There were 46 instances of subjects reporting that they were motivated specifically to go home. This was almost exclusively considered by those who decided to go home. 


\section{Physical State}

The subject's physical state was the next most common type of internal state that was mentioned. The effects of alcohol, fatigue and hunger accounted for most of those physical states.

Effects of Alcohol - The fact that the subject was feeling a certain way due to the consumption of alcohol was cited a number of times as a basis for this decision (61). It was less common that this would be mentioned in conjunction with a decision to go to another drinking site. Instead, it was more common that the subject decided either to stay where they were, or go home. Women were more likely to mention this than men.

Fatigue - Equally likely, subjects cited that being tired played a part in their decision (61). Not surprisingly, this was almost exclusively cited as a reason for going home.

Hunger - A much less frequently cited basis was hunger (14). The infrequency of its occurrence precludes any further analysis.

\section{Emotional State}

Emotional or mood states were the next most frequently cited basis for making a particular decision concerning leaving.

Boredom - Most often, when a subject considered their mood as a basis for the decision, they reported that boredom was their mood state at the time (58). This basis was most likely to be mentioned in conjunction with a decision to go to another drinking site. Those making less than $\$ 25,000$ a year were more likely to report this.

Other emotions - Other than boredom, feeling bad played a role in 20 decisions to leave. Good feelings were reported to be considered five times in conjunction with a decision regarding leaving.

\section{Social Influence}

The next most frequently cited class of bases was that of social influence. Again this category contained those bases that dealt with specific aspects of the social environment. The social environment could include overt social influences, unstated social influences, or other aspects of the social situation.

In general, social influences were most likely to be considered in decisions that ended in the subject leaving for home. Subjects with some college education were more likely to mention this, as were those with no DWI arrests. 
The types of social influence could be further delineated into sub-categories. The subcategories will be addressed below.

\begin{tabular}{|c|c|l||}
\hline Sub-Category & Frequency & Demographics \\
\hline Overt Social Influence & 252 & \\
\hline Host's Suggestion & 118 & Student, (Full-time), O DWls \\
\hline Other Person's Suggestion & 105 & O DWIs, $\leq 25$ yrs, (1 DWIs) \\
\hline Unstated Social Influence & 71 & \\
\hline Social Environment & 204 & \\
\hline Environment Unpleasant & 80 & \\
\hline Environment Pleasant & 49 & $<\$ 25 \mathrm{~K}$, Caucasian \\
\hline Time Period Ended & 71 & $\begin{array}{l}\text { Male, White-collar, Full-time, } \\
\text { College, Married, } \geq \$ 25 K, \\
\text { CAGE }<2, ~(\leq 25 \text { yrs) }\end{array}$ \\
\hline
\end{tabular}

\section{Overt Social Influence}

The most common form of social influence mentioned as a basis for making the decision whether or not to leave involved some sort of overt influence.

Host's Suggestion - The most common of the overt social influences to leave was that of the host suggesting that the subject leave (118). This could have been done by indicating that the party was over, or if the host was a bartender at a bar, that it was closing time. This basis was most commonly mentioned by those who had decided to go home. Those subjects in school were more likely to report this, while full-time employed subjects were under-represented. Subjects with no DWI arrests were over-represented.

Other Person's Suggestion - The next most frequently reported basis was that of a suggestion from some other person, usually a friend (105). This was never offered as a basis for staying at the event. Subjects with no DWI, and those who were under 25 years old were over-represented in stating this, while subjects with one DWI were underrepresented.

\section{Unstated Social Influence}

While less commonly recorded than overt social influence, subjects identified a variety of unstated social influences that influenced their decision regarding leaving (71). The fact that others were leaving, or getting ready to leave was a common example of such non-verbal, possibly non-intentional influence. 


\section{$\underline{\text { Social Environment }}$}

Aspects of the social environment sometimes cued the subject to either stay or leave. Sometimes it was a qualitative evaluation of the social situation, for instance, thinking that a party was not very good. Other observations suggested the passing of a given time period, which cued the subject that it was "time to leave."

Environment Unpleasant - Being in an unpleasant environment was the most common of these bases (80). This was a common basis for those deciding to go to another drinking location. It was less common for those deciding to go home. This of course implies that those subjects considering the unpleasantness of the environment were still motivated to continue the episode, but merely needed to find a new location. Those subjects who decided to go to a bar upon leaving were the most likely to mention this basis.

Environment Pleasant - Not everyone was in an unpleasant environment. Some of the subjects reported that the fact that they were in a pleasant environment was considered as a basis to leave (4). While they may have considered the pleasant quality of their environment, they still decided to leave. So the quality of the environment must have been discounted by some other factor making them want to leave. Those subjects earning less than $\$ 25,000$ a year were more likely to state this, as were Caucasians.

Time Period Ended - Other than the quality of the time being spent, the quantity of that time was also a factor. Specifically, when its time to go, people leave. Subjects reported that one of the bases that they used in the decision to leave was that it was time to go (71). Often they felt it was time to leave because the dinner or party was over. Not surprisingly, this was not a basis that was considered by those who chose to stay at their current location. Men were more likely to consider this than women. White-collar, fulltime workers, and those with some college education were also more likely to mention it. Married subjects were more likely to mention this, as were those who made more than $\$ 25,000$ a year. Also, those that scored less than two on the CAGE questions were overrepresented, while those under 25 years old were under-represented.

\section{Feelings of Responsibility}

At times, subjects reported considering their responsibilities when deciding whether or not to leave. They may have cited a responsibility to drive, work, or to use the time more efficiently. Of course, at times the consideration of responsibility was only a factor because the subject felt free from responsibilities. Responsibilities in general were more likely to be considered by those who chose to go home. Those in school at the time of the study were less likely to mention responsibilities, as were single people, and those who make less than $\$ 25,000$ a year. Subjects who scored less than two on the CAGE questions were more likely to consider them however. 
The specific responsibilities that were considered are addressed below.

\begin{tabular}{||l|c|l||}
\hline \multicolumn{1}{|c|}{ Sub-Category } & Frequency & \multicolumn{1}{|c||}{ Demographics } \\
\hline Good Use of Time & 95 & \\
\hline Work Related & 48 & \\
\hline Responsibilities at Home & 26 & Female \\
\hline Other & 25 & \\
\hline
\end{tabular}

\section{Good Use of Time}

Many of the subjects felt that spending their time appropriately was an important factor in their decision regarding whether or not to leave. Some thought that staying would be a poor use of their time. Those deciding to go home were the most likely to mention this, while this was rarely mentioned as a reason to stay, or move to another drinking site. None of the demographic variables demonstrated a significant relationship with the consideration of this basis.

\section{Work Related}

The next most frequent type of responsibilities mentioned were those concerning work (48). Again it was most frequently considered by those choosing to go home.

\section{Responsibilities at Home}

A less common basis that was considered were responsibilities at home. When they were mentioned the issue was usually related to child care. Some subjects mentioned that they needed to relieve a baby-sitter, others were less specific, only saying that they needed to get back to their children. Just as with the consideration of responsibilities in general, this specific responsibility was considered most frequently by those choosing to go home. Women were more likely to report considering this than men.

\section{$\underline{\text { Other }}$}

Other responsibilities were also mentioned, particularly having some other commitment (25), and needing to drive (11).

\section{Availability of Alcohol}

For some subjects, the availability of alcohol influenced their decision regarding leaving (59). Particularly, when the alcohol ran out, the subject decided to leave. This was more common for those subjects deciding to go to a different drinking location. Blue-collar workers were more likely to consider this than white-collar workers. And those subjects that scored two 
or greater on the CAGE questions were more likely to report considering this, as were those subjects under the age of 25 . Subjects over 35 were less likely to report this basis.

\section{Effect of Previous Plans}

The least frequently cited category of basis was that of previous plans. Only fifteen instances of subjects considering their previously made plans when deciding whether or not to leave were recorded. For most of those instances in which it was considered (10), the subjects decided to go to another drinking location. This basis was not considered frequently enough to warrant further analysis with the demographic variables.

\section{ALTERNATIVE OPTIONS}

Alternatives that might have been taken at the point of deciding whether to leave, along with their frequencies, are listed in the table below. Following the table is a discussion of benefits of, and reasons for not pursuing, the most frequently mentioned alternatives.

\begin{tabular}{||l|c||}
\hline \multicolumn{1}{|c|}{ Alternative } & Frequency \\
\hline Stay Over Night & 124 \\
\hline Stay at Event Longer & 53 \\
\hline Stay to Eat & 5 \\
\hline Stay to Drink Coffee & 4 \\
\hline Plan to Stay Overnight & 3 \\
\hline
\end{tabular}

\section{Stay Over Night}

The most frequently cited alternative to leaving was to stay over night. Most subjects mentioning this meant staying at the location where they were drinking, however 32 subjects suggested different locations. Twenty eight thought going home with a friend was an alternative, while four others thought going to a friend's house that was near the location was possible. Those that considered this alternative offered a variety of factors that affected the outcome of their decision. Cost was an attractive element to this alternative for twenty eight subjects. Ten subjects mentioned that this would have helped them reduce the possibility of the negative consequences of drunk driving. But thirteen subjects thought that this was an unattractive alternative because staying over would not have been fun. Eleven thought that it would have been too inconvenient to be practical. And some subjects (10) thought it was unnecessary.

\section{$\underline{\text { Stay at Event Longer }}$}

Another alternative mentioned by many of the subjects was to delay leaving to allow themselves time to sober up. The reasons for or against this alternative varied from subject to 
subject. No clear advantage or disadvantage predominated the thinking of those who offered this alternative.

\section{DECISION TO DRIVE}

This section deals with the decision to drive after drinking. Of the 2,039 bases recorded, more than $97 \%$ were classifiable into one of seven major categories. The frequencies and percentages for these categories are shown in the table below:

\begin{tabular}{||l|c|c|}
\hline \multicolumn{1}{|c|}{ Category } & Frequency & Percent \\
\hline Personal Influence & 821 & 40.3 \\
\hline Responsibility & 593 & 29.1 \\
\hline Social/Environmental Influence & 213 & 10.4 \\
\hline Availability of Transportation & 207 & 10.2 \\
\hline Vehicle-Related Factors & 61 & 3.0 \\
\hline Effect of Plans & 48 & 2.4 \\
\hline Normal/Past Behavior & 43 & 2.1 \\
\hline Miscellaneous & 53 & 2.6 \\
\hline
\end{tabular}

Decisions to drive were most often based on a response to personal influence. Responsibility was also frequently cited as a basis for the decision to drive after drinking. Social/environmental influence and economic considerations were cited less often. Vehiclerelated factors, plans, and normal/past behavior were less likely to be mentioned.

\section{Personal Influence}

Ninety nine percent of bases relating to personal influence were further classified into four sub-categories. The frequencies of these categories are shown, with demographic information, in the following table: 


\begin{tabular}{|c|c|c|}
\hline Sub-Category & Frequency & Demographics \\
\hline Physical Influence & 701 & \\
\hline Did Not Feel Effects of Alcohol & 456 & $\begin{array}{l}\text { Blue-collar, Full-time, High school, } \\
\text { Married, African-American, BAC } \\
<.10 \%, 35+\text { yrs }\end{array}$ \\
\hline $\begin{array}{l}\text { Did Not Think Effects of Alcohol } \\
\text { Would Affect Driving }\end{array}$ & 60 & \\
\hline $\begin{array}{l}\text { Felt Effects and Thought Driving } \\
\text { Would Be Somewhat Unsafe }\end{array}$ & 38 & $\begin{array}{l}\text { Student, College, } \geq \$ 25 K, 0 \\
\text { DWIs, BAC }<.10 \%, \text { CAGE }<2\end{array}$ \\
\hline $\begin{array}{l}\text { Felt Effects and Thought Driving } \\
\text { Would Be Very Unsafe }\end{array}$ & 17 & College, $\geq \$ 25 \mathrm{~K}$ \\
\hline Amount of Alcohol Consumed & 51 & $\mathrm{BAC}<.10 \%$ \\
\hline Perceived BAC & 15 & Full-time \\
\hline $\begin{array}{l}\text { Taken Steps to Counteract } \\
\text { Drinking }\end{array}$ & 12 & \\
\hline Goals & 60 & \\
\hline Presence Not Conducive to Goals & 38 & Blue-collar, High school, 1 DWI \\
\hline Presence Conducive to Goals & 11 & $1 \mathrm{DWI}$ \\
\hline Stated Desire & 38 & \\
\hline Desire to Be Somewhere Else & 23 & Underemployed \\
\hline Desire to Drive & 9 & \\
\hline Wanted to Go to More Comfortable Place & 17 & Female \\
\hline Miscellaneous & 5 & \\
\hline
\end{tabular}

Most personal influence bases involved physical influence. Less than $8 \%$ involved goals. The desire to go to a more comfortable place and other stated desires were rarely mentioned.

\section{Physical Influence}

Eighty five percent of personal influence bases related to some type of physical influence.

Did Not Feel Effects of Alcohol - Subjects often stated that they made a decision to drive based on not feeling the effects of alcohol (456). Subjects who decided to drive home alone or to drive to someone else's home alone, often cited this as a reason. Subjects who drove home with someone else in the car were not as likely to cite this. Subjects with only a high school education were more likely to mention this than those 
with more education. Blue collar subjects and married subjects were over-represented. Subjects employed full-time were over-represented and students were under-represented. Caucasians were less likely than African-Americans and other races to mention this. Subjects age 25 and under were under-represented, while subjects age 35 and over were over-represented. Subjects with no DWIs were under-represented and subjects with at least one DWI were over-represented. Subjects with BACs under $.10 \%$ were overrepresented and subjects with BACs of $.14 \%$ or greater were under-represented.

Did Not Think Effects of Alcohol Would Affect Driving - Some subjects reported that while they felt effects of alcohol, they did not feel that their driving would be negatively affected (60).

Felt Effects and Thought Driving Would Be Somewhat Unsafe - Subjects occasionally stated that they felt the effects of alcohol and thought driving would be somewhat unsafe. Subjects who reported that they drove carefully to avoid negative consequences were over-represented among this group. Subjects who reported poor driving behaviors were under-represented. Students were over-represented. Subjects with some college were more likely than those with only a high school education to mention this basis. Subjects with incomes of $\$ 25,000$ a year or above were more likely than those with lower incomes to mention this basis. Subjects with BACs less than $.10 \%$ were over-represented. Subjects with one DWI were under-represented. Subjects with no prior DWIs were overrepresented. Subjects with CAGE scores of 0 or 1 were over-represented and subjects with CAGE scores of 2 or more were under-represented.

Felt Effects and Thought Driving Would Be Very Unsafe - Some subjects felt the effects of alcohol and thought driving would be very unsafe (17). Subjects with some college often mentioned this basis. Those subjects with only a high school education never mentioned that they felt driving would be very unsafe. Subjects with incomes under $\$ 25,000$ a year were less likely than subjects with incomes of $\$ 25,000$ a year or more to mention this basis.

Amount of Alcohol Consumed - Sometimes subjects based their decision to drive on the amount of alcohol consumed (51). Subjects with BACs under .10\% were over-represented in this group.

Perceived $B A C$ - Subjects infrequently mentioned that their decision to drive was based on their perceived BAC (15). Subjects employed full-time were over-represented among this group.

Taken Steps to Counteract Drinking - It was uncommon for subjects to base their decision to drive on their having taken steps to counteract the effects of drinking (12). No significant relationships were found between having had taken steps to counteract drinking and any demographics or specific decisions. 
Miscellaneous - Other bases mentioned were being hungry (6), tired (8), and sick (2).

$\underline{\text { Goals }}$

Occasionally, personal influence related to goals.

Presence Not Conducive to Goals - Subjects sometimes mentioned driving because their presence at their current destination was not conducive to their goals (38). These subjects may have wanted to be somewhere else to see someone or do something. Among this group, subjects driving home were under-represented. Subjects driving to other nonsocializing destinations were over-represented. Subjects driving to these other destinations alone were also over-represented. Blue-collar subjects were more than twice as likely to cite that their presence was not conducive to their goals as white-collar subjects. Subjects with a high school education were more likely than those with more education to cite this. Subjects with no DWIs were under-represented. Subjects with one DWI were overrepresented.

Presence Conducive to Goals - Subjects rarely reported that they made a decision to drive based on their presence at a location being conducive to their goals (11). Of those who mentioned this basis, subjects driving home were under-represented, while subjects driving to other non-socializing destinations were over-represented. Caucasian subjects were under-represented. Subjects with one DWI were over-represented.

Miscellaneous - The other bases for driving that were mentioned were that presence at the location was not furthering goals as expected (5) and driving was conducive to goals (6).

\section{$\underline{\text { Stated Desire }}$}

Personal-pressure bases sometimes included stated desires.

Desire to Be Somewhere Else - Desire to be somewhere else was occasionally a basis for driving after drinking (23). Subjects driving to a new socializing destination often cited a desire to be somewhere else. Subjects part-time or unemployed (underemployed) were over-represented.

Desire to Drive - 9 subjects mentioned a desire to drive as a basis for their decision to drive after drinking.

Miscellaneous - Other bases cited were: desire not to be somewhere else (1), desire not to take advantage of an alternative to driving (2), and avoid an accident (2). 


\section{Wanted to Go to More Comfortable Place}

Subjects sometimes mentioned that they wanted to go to a more comfortable place. A more comfortable place may have meant a friend's home. It is not surprising therefore, that subjects driving home were over-represented. Females were also over-represented.

\section{Responsibility}

Responsibility-related bases were further classified into three sub-categories. The frequencies and demographic information for these categories are found in the following table:

\begin{tabular}{|c|c|c|}
\hline Sub-Category & Frequency & Demographics \\
\hline Consequences & 414 & \\
\hline Considerable Chance of Being Caught & 108 & $\begin{array}{l}\text { Female, Student, } \leq 25 \\
\text { yrs, College, Caucasian }\end{array}$ \\
\hline Situation Reduced Chance of Being Caught & 86 & $\begin{array}{l}\text { Caucasian, O DWls, } \leq 25 \\
\text { yrs }\end{array}$ \\
\hline Safety & 40 & $\begin{array}{l}\text { White-collar, College, } \\
\text { Caucasian, O DWls }\end{array}$ \\
\hline Did not Consider Negative Consequences & 39 & $\begin{array}{l}\text { Blue-collar, High school, } 1 \\
\text { or more DWls }\end{array}$ \\
\hline Small Chance of Negative Consequences & 31 & \\
\hline Possible to Avoid Negative Consequences & 26 & $\begin{array}{l}\text { O DWIs, College, White- } \\
\text { collar }\end{array}$ \\
\hline Considered Negative Consequences & 22 & $26-34$ yrs \\
\hline No Negative Consequences & 21 & \\
\hline Driving & 152 & \\
\hline Driving Was Preferable to Other Solutions & 121 & $\begin{array}{l}\text { Female, } \leq 25 \text { yrs, White- } \\
\text { collar, Student, College }\end{array}$ \\
\hline Effect of Who Drove To Drinking Location & 18 & \\
\hline Responsibility to Be Elsewhere & 27 & $\begin{array}{l}\text { Female, Blue-collar, < } \\
\$ 25 \mathrm{~K}, 1 \mathrm{DWI}\end{array}$ \\
\hline
\end{tabular}

Consequences were a factor in almost seventy percent of responsibility bases. Driving was mentioned less frequently. Responsibility to be elsewhere was considerably less likely to be cited. 


\section{Consequences}

Responsibility bases often related to consequences.

Considerable Chance of Being Caught - Many subjects mentioned that there was a considerable chance of being caught driving after drinking (108). Subjects who reported that they were motivated to drive carefully often stated this. Subjects who engaged in behaviors to cope with being drunk and subjects who mentioned specific careful driving behaviors, however, were under-represented. Females and students were over-represented. Subjects age 25 and under were over-represented and subjects age 35 and over were under-represented. Subjects with some college were five times more likely than subjects with only a high school education to mention a considerable chance of being caught. Caucasian subjects were over-represented and African-Americans under-represented.

Situation Reduced Chance of Being Caught - Some subjects believed that the situation (e.g., short distance, back roads) reduced the chance of being caught (86). Subjects who made the decision to drive home based on this belief were over-represented, while subjects who drove to other non-socializing destinations were under-represented. Caucasian subjects were over-represented and African-Americans under-represented. Subjects with no DWIs were over-represented and subjects with one DWI were underrepresented. Subjects age 25 and under were over-represented. Subjects age 35 and over were under-represented.

Safety - While subjects were more likely to be concerned with legal consequences than safety, some subjects did cite safety concerns as a basis for driving carefully (40). Subjects citing that they were motivated to drive carefully by fear of police or an accident were over-represented among this group. White-collar subjects were over-represented. Subjects with a college education were six times more likely to cite safety than subjects with only a high school education. Caucasian subjects were over-represented. Subjects with no DWIs were over-represented, while subjects with one DWI were underrepresented.

Did Not Consider Negative Consequences - Some subjects (39) did not consider that driving would be unsafe or likely to result in being caught. Those driving to nonsocializing destinations other than home were likely to state that they did not consider the consequences. Blue-collar subjects were over-represented, as were subjects with only a high school education. Subjects with no DWIs were under-represented. Subjects with 1 or more DWI were over-represented.

Small Chance of Negative Consequences - Occasionally, subjects mentioned that they felt there was only a small chance of negative consequence (31). Subjects who decided to drive home often stated that their decision was based on this. Subjects who drove to other non-socializing destinations were under-represented in this group. Subjects driving 
to new socializing destinations never mentioned that they felt there was only a small chance of negative consequences.

Possible to Avoid Negative Consequences - Some subjects drove because they felt that it was possible to avoid negative consequence (26), by driving slowly or more carefully. White-collar subjects were over three times more likely to state this than blue collar subjects. Subjects with some college education were over ten times more likely than subjects with only a high school education to mention this. Subjects with no DWIs were over-represented.

Considered Negative Consequences - Some subjects mentioned that they did consider negative consequences at the time of leaving their current location (22), whether or not they eventually drove. Subjects age 26 to 34 years-old were more likely than subjects 25 and under to mention this concern.

No Negative Consequences - The belief that there were no potentially negative consequences influenced subjects' decisions to drive (21). Subjects who decided to drive home were most likely to base their decision on this belief.

\section{Driving}

Driving responsibility was sometimes mentioned by subjects.

Driving Was Preferable to Other Solutions - Subjects often mentioned that their driving was preferable to other solutions, including having someone else drive (121). Subjects who drove home with someone else in the car often cited that their driving was preferable to other solutions. Subjects who drove home alone were under-represented. Subjects who drove someone else's car home (who they came with) were over-represented. Females were over-represented. White-collar subjects were twice as likely as blue-collar subjects to cite this. Students were over-represented and subjects employed full-time underrepresented. Subjects with some college were over five times as likely as subjects with a high school education to believe that their driving was preferable to other solutions. Subjects age 25 and under were over-represented.

Effect of Who Drove To Drinking Location - Occasionally, subjects based their decision to drive on who drove to the drinking location (18).

\section{Responsibility to Be Elsewhere}

Responsibility to be elsewhere was mentioned infrequently. Subjects who drove to someone else's home were likely to cite responsibility to be elsewhere as a basis for that decision. Females were over-represented. Blue-collar subjects were over four times more likely than whitecollar subjects to mention this basis. Subjects with incomes under $\$ 25,000$ a year were more than 
three times as likely as subjects with higher incomes to report a responsibility to be elsewhere. Subjects with one DWI were over-represented. Subjects with no DWIs were under-represented.

\section{Social/Environmental Influence}

Bases relating to social/environmental influence were classified into three sub-categories. All but $2 \%$ were classifiable. The frequencies and demographics for these categories are shown in the following table:

\begin{tabular}{||l|c|l||}
\hline \multicolumn{1}{|c|}{ Sub-Category } & Frequency & \multicolumn{1}{c|}{ Demographics } \\
\hline Overt Social Influence & 84 & BAC .10\% $-.139 \%$ \\
\hline Environmental Effects & 70 & Blue-collar, Single, <\$25K \\
\hline Unstated Social Influence & 55 & $\begin{array}{l}\text { High school, } \leq 25 \text { yrs, Caucasian, 1 } \\
\text { DWl, BAC .10\% - .139\% }\end{array}$ \\
\hline Miscellaneous & 4 & \\
\hline
\end{tabular}

Almost $40 \%$ of social/environmental bases dealt with overt social influence. Environmental effects were mentioned almost as frequently. Unstated social influence was mentioned less often, but still frequently.

\section{Overt Social Influence}

Subjects often cited overt social influence as a basis. Overt social influence may have meant that driving was suggested by others (60), driving was discouraged by others (3), or there was no influence not to drive (18). Subjects driving home with someone else, and subjects driving to someone else's home with someone else, were especially likely to cite overt social influence. Subjects with BACs of .10\% to $.139 \%$ were more likely than those with higher BACs to base their decision on this basis.

\section{Environmental Effects}

Environmental effects were often cited by subjects as a basis for driving after drinking. Environmental effects included the situation being conducive to driving (39), the situation being conducive to driving more than necessary (17) and the situation not being conducive to driving (2). Subjects who drove home with someone else often cited environmental effects as a factor in their decision. Blue collar subjects were over-represented. Single subjects were over nine times as likely as married subjects to mention environmental factors. Subjects with incomes under $\$ 25,000$ a year were more likely than subjects with higher incomes to cite this. 


\section{Unstated Social Influence}

Subjects sometimes mentioned unstated social influence. Examples of unstated social influence were others had no transportation (20), others had a reason not to drive, such as an expired license (16), there was an unstated understanding (7) and others were discussing the likelihood of drivers being pulled over (1). Subjects who made the decision to drive to someone else's home were likely to cite unstated social influence but subjects driving to their own home were not. Subjects driving to non-socializing destinations other than home were underrepresented. Subjects driving to someone else's home with someone else in the vehicle were over-represented. Subjects with a high school education were more likely than subjects with more education to mention unstated social influence as a basis. Subjects age 25 and under were over-represented and subjects over age 35 were under-represented. Caucasian subjects and subjects with one DWI were over-represented. Subjects with BACs under $.10 \%$ were underrepresented and subjects with BACs of $.10 \%$ to $.139 \%$ were over-represented.

\section{Availability of Transportation}

The availability of transportation was classified into alternatives to driving and vehicle availability. The frequencies and demographics for these sub-categories are shown in the table below:

\begin{tabular}{||c|c|l||}
\hline Sub-Category & Frequency & Demographics \\
\hline Alternatives to Driving & 127 & \\
\hline Ride Was Not Available & 69 & $26-34$ yrs \\
\hline $\begin{array}{c}\text { Did Not Consider } \\
\text { Alternatives }\end{array}$ & 29 & CAGE < 2 \\
\hline Availability of Place to Stay & 11 & \\
\hline Ride Was Not Feasible & 5 & \\
\hline Availability of Vehicle & 80 & Full-time, Caucasian \\
\hline
\end{tabular}

Over $60 \%$ of economic consideration bases related to alternatives to driving. Availability of vehicle was cited less frequently.

\section{Alternatives to Driving}

Availability of alternatives to driving was often a factor in making the decision to drive.

Ride Was Not Available - Subjects mentioned that their decision to drive was based on there being no ride available (69). Subjects who decided to drive to a new socializing destination or home alone often cited this as a basis for that decision. Subjects age 26-34 were over-represented and those age 35 and over were under-represented. 
Did Not Consider Alternatives - Some subjects drove because they did not consider alternatives (29). Subjects who decided to drive home alone were over-represented. Subjects with a CAGE score of 0 or 1 were over-represented and subjects with CAGE scores of 2 or more were under-represented.

Availability of Place to Stay - Subjects rarely mentioned that the availability of a place to stay played a role in their decision to drive (11).

Ride Was Not Feasible - It was uncommon for a subject to mention that a ride was available but not feasible (5).

\section{$\underline{\text { Availability of Vehicle }}$}

Subjects sometimes cited availability of a vehicle as a basis for driving. Availability of a vehicle may have meant that the vehicle was available or convenient (73), the vehicle was unavailable or inconvenient (6), or one vehicle was more convenient than another (1). Subjects who were employed full-time and subjects who were Caucasian were over-represented. It was unusual for subjects who drove home with someone else in the car to cite vehicle availability as a reason for the decision they made.

\section{Vehicle-Related Factors}

Vehicle-related factors were further categorized into two categories. The frequencies and demographics for these sub-categories are shown in the following table:

\begin{tabular}{||l|c|c||}
\hline \multicolumn{1}{|c|}{ Sub-Category } & Frequency & Demographics \\
\hline Vehicle Ownership & 49 & Single, 1 DWI \\
\hline Vehicle Characteristics & 12 & \\
\hline
\end{tabular}

Most vehicle-related factors dealt with vehicle ownership, as opposed to vehicle characteristics.

\section{Vehicle Ownership}

The decision to drive was often based on vehicle ownership. Vehicle ownership usually related to the subject owning the vehicle (46). Subjects only mentioned that someone else owned the vehicle a few times (3). Subjects driving home with someone else in the car often cited vehicle ownership as a basis for their decision. Single subjects were more than ten times as likely to cite vehicle ownership as a factor in the decision to drive than were married subjects. Subjects with one DWI were over-represented and subjects with no DWIs were under-represented. 


\section{Vehicle Characteristics}

It was uncommon for subjects to mention vehicle characteristics as a factor in their decision to drive. When vehicle characteristics played a part in the decision it was because the vehicle had a manual transmission or the decision was based on the vehicle's attractiveness.

\section{Effect of Plans}

Some decisions were affected by some previous plan that had been made. Bases for these decisions were classified into four categories. The frequencies of these categories and demographic information can be found in the following table:

\begin{tabular}{||l|c|l||}
\hline \multicolumn{1}{|c|}{ Sub-Category } & Frequency & \multicolumn{1}{c||}{ Demographics } \\
\hline Plans Made and Kept & 18 & O DWIs, CAGE < 2 \\
\hline No Plans & 14 & \\
\hline Had Plans But Deviated & 11 & \\
\hline $\begin{array}{l}\text { Had Plans But Situation } \\
\text { Changed }\end{array}$ & 5 & \\
\hline
\end{tabular}

\section{Plans Made and Kept}

Subjects occasionally mentioned that they made plans and kept them. These plans included drinking and driving (8), plans to have the party member who was least affected drive (1) or to drive a short distance to find a place to stay, rather than driving all the way home (2). Subjects making a decision to drive to someone else's home often mentioned keeping to a plan as a basis. Subjects with no DWIs were over-represented and subjects with one DWI were underrepresented. Subjects with a CAGE score of 0 or 1 were over-represented, while subjects with a CAGE score of 2 or more were under-represented.

\section{No Plans}

Few subjects mentioned that their decision to drive was based on having no plans concerning driving after drinking.

\section{$\underline{\text { Had Plans But Deviated }}$}

Subjects rarely mentioned that they had plans, which they deviated from, that resulted in their decision to drive. 


\section{Had Plans But Situation Changed}

It was uncommon for subjects to base their decision to drive on having the situation change around plans that were made previously. For example, a friend may have wanted to leave earlier than planned or a party may have lasted longer than expected.

\section{Normal/Past Behavior}

Normal/past behavior bases were further classified into four sub-categories. The frequencies for these tables are found below:

\begin{tabular}{||l|c|l||}
\hline \multicolumn{1}{|c|}{ Sub-Category } & Frequency & Demographics \\
\hline $\begin{array}{l}\text { Had Driven in That Condition } \\
\text { Before }\end{array}$ & 17 & \\
\hline Always Drive & 11 & \\
\hline Always Drink and Drive & 9 & \\
\hline $\begin{array}{l}\text { Always Drive in Certain } \\
\text { Manner }\end{array}$ & 6 & \\
\hline
\end{tabular}

\section{$\underline{\text { Had Driven in That Condition Before }}$} before.

A number of subjects (17) based their decision to drive on having driven in that condition

\section{Always Drive}

Many subjects (11) stated that they made the decision to drive because they always drive.

\section{Always Drink and Drive}

Some subjects (9) mentioned that they based their decision to drive on the fact that they always drink and drive.

\section{$\underline{\text { Always Drive in Certain Manner }}$}

A few subjects (6) attributed their decision to dive after drinking to a characteristic way of behaving.

\section{ALTERNATIVE OPTIONS}

Many of the subjects offered alternatives to their decision to drive after drinking. These alternatives are listed along with their frequencies in the table below. Following the table is a 
discussion of the most frequently mentioned benefits of, and reasons for not pursuing, the alternatives.

\begin{tabular}{||l|c||}
\hline \multicolumn{1}{|c|}{ Alternative } & Frequency \\
\hline Get a Ride & 256 \\
\hline Take a Taxi & 183 \\
\hline Have Someone Else Drive & 143 \\
\hline Walk & 59 \\
\hline Take Bus & 26 \\
\hline Sleep in Vehicle & 19 \\
\hline Stay in Hotel & 15 \\
\hline Give the Keys to Someone & 6 \\
\hline
\end{tabular}

\section{$\underline{\text { Get a Ride }}$}

The most common alternative discussed was getting a ride from someone else. This could have meant someone who was at the event already (124), or calling and getting a ride from someone who was not at the event (131). These two alternative ride options will be discussed separately.

Call For a Non-Participant - Aside from asking those already at the event for a ride, some of the subjects mentioned that they could have called someone else to come and pick them up. The most frequently mentioned advantage to such a decision is that it would be cheap (38), while the most frequent disadvantage cited was that it would be too much bother for the other person (24). Twelve subjects also mentioned that doing this would cause inconvenience. For instance, the subject would have to leave a car somewhere.

Another Guest - Accepting a ride from another participant in the event was an option commonly discussed. The most often cited benefit of this alternative was that it was cheap (35). However, many subjects also mentioned some negative aspects of such a decision, particularly, the other person that they would get a ride from was also drunk (28) and leaving their car at the event would be inconvenient (27). Fifteen subjects thought that they would be inconveniencing another person if they asked that person for a ride.

\section{Take a Taxi}

The next most frequently mentioned alternative was to take a taxi. Cost was the most commonly cited problem with this alternative (63). Forty three subjects stated that taking a taxi 
would cause them some sort of inconvenience. Usually this was that they would have to leave their car. Married subjects were more likely to state this concern.

\section{Have someone else drive}

Another alternative frequently cited was to have someone else drive the subject's car. Such an option would eliminate the problems of leaving a car at the site, and the expense of a taxi. Of those who considered this a plausible alternative, 34 thought that there was no one in a better condition to drive their car, and 13 thought that it would be too much of an imposition to have another person drive their car.

$\underline{\text { Walk }}$

Of those who thought that walking was an alternative, seventeen thought that they were too far from their homes. Thirteen thought that the inexpensive nature of the alternative was positive, however.

\section{$\underline{\text { Take Bus }}$}

Twenty six subjects mentioned taking a bus as an alternative. However, eleven of those subjects thought that doing so would be too inconvenient.

\section{Sleep in Vehicle}

Nineteen subjects suggested that sleeping in their vehicle would have been an alternative that could have prevented them from leaving and driving after drinking. This alternative was exclusively mentioned by men. Blue-collar workers were also more likely to mention this alternative. However, five of these subjects reported feeling that it was not absolutely necessary that they sleep in their cars.

\section{$\underline{\text { Stay in Hotel }}$}

Fifteen subjects thought staying at a hotel could have been a viable alternative to driving home after drinking. There were too few instances of this alternative for further analysis of the basis for rejecting it.

\section{Give The Keys to Someone}

Six subjects suggested that giving their keys to someone else was the best way of avoiding drinking and driving at this point. 


\section{DEMOGRAPHICS AND DECISION BASES}

From the results presented thus far, it as apparent that a number of demographic variables were related to decision bases. Some demographic variables were found to relate to more bases than others. This section summarizes the demographic variables appearing in the previous tables, in decreasing order of frequency. It is important to recognize that the number of relationships examined assures the appearance of some apparently significant relationships by chance alone. Consequently, any conclusions drawn from the patterns and frequency of their significant relationships are offered tentatively.

This analysis of decision bases in terms of demographics will not identify all the specific decision bases relating to each demographic variable. To do so would be to restructure the entire presentation of results in terms of demographics rather than decision bases. Reference will be made to the decision categories related to many of the demographic variables. For more detailed information, the reader may consult the tables associated with those categories.

\section{Previous DWIs}

Interestingly, the most frequently significant variable was previous DWI experience. Subjects were divided into three groups, those with no DWIs, those with one DWI, and those with two or more DWIs. In keeping with the axiom that the best predictor of future behavior is past behavior, the subjects' past behavior seemed most likely to influence their decision bases. There were 52 instances of this variable demonstrating a significant relationship with a decision basis. Over half of these relationships were found to be in the decisions regarding planning to drink, and decisions concerning actual drinking. In general, those who had some sort of DWI record were more likely to mention personal influences throughout their interview, e.g. influences upon the choice of transportation and choices made just prior to or during drinking. There is also a slight tendency for those with DWIs to cite social and environmental influences. It is possible that this reflects a real difference in their susceptibility to such influence agents. Alternatively, those with DWI records may be more likely to offer such external attributions for their behavior as part of a strategy for preserving a positive self-evaluation. It may be less threatening to blame being arrested for a DWI on the influence of others than on internal states and motivations.

Subjects with no DWI arrests were more likely to mention considering the consequences of impaired driving in their plans than those with prior DWIs. Again, it is worth remembering that although they may have considered the consequences, all of these subjects ultimately drove while impaired. They were also less likely to indicate that their decisions were based on a routine, or typical pattern of behavior. This may reflect the fact that multiple DWI arrests is an indication of alcohol problems. Therefore, one would expect those with DWI arrests to be more likely to have a routine drinking pattern. 


\section{Employment Status}

Employment status was the next most frequently significant demographic variable. There were 39 instances of a significant relationship between levels of this variable and the mentioning of a specific basis. The most useful distinction seemed to be that of student vs subjects employed full-time. Students were more likely to go out because of a party, and were more concerned with the cost of their drinks. This, of course, likely reflects the general lifestyle of students. Full-time workers were more likely to mention patterns of drinking-related activity, possibly reflecting the fact that they were older and therefore had the time to develop patterns of behavior. It may also be that those who are old enough to have full-time employment and yet still drink to the point of considering themselves intoxicated could be more likely to have a problem with alcohol. Parttime or unemployed (underemployed) status was infrequently over- or under-represented in mentioning a specific basis.

Age

Another frequently significant demographic variable was age (41). This may not be surprising given that employment status was such an important variable. Being a student was strongly associated with being under 25 years of age. So it was not surprising that frequently when students were over- or under-represented, those under 25 years of age were also over- or under-represented. Both variables (age and employment) are probably measures of the social environment of the subjects. The earlier analysis of decision bases showed students, and younger people, are more likely to find themselves going to where drinking is a central activity, and to go out drinking in larger groups. The differences in environments necessarily makes certain decision bases relevant. For instance, one must be at a party in order for the fact that the party is going well to influence one's decisions.

\section{Education}

Another demographic variable that was found to be commonly significant was education. Just as with age, education was necessarily related to the employment variable. Those who were classified as students were almost always college students. Therefore, students were almost always classified as having at least some college. There were 28 significant relationships found. However, no consistent patterns within these relationships were observed.

\section{Gender}

Although gender is one of the most salient distinctions that one can use to classify subjects, it was not the most likely to produce significant relationships. There were 24 instances of such significant relationships. Women were more likely to report being affected by social influences and to consider their responsibilities. For instance, they were over-represented in reporting pressure from other people when deciding whether or not to drink. Men were more likely to be influenced by the occasion itself. For instance, they were more likely to cite the fact that they were participating in a leisure activity when deciding whether or not to drink. There 
are a number of explanations for this difference. The first is straight forward, women are more affected by social influences. A second possible explanation is that men and women vary in their reporting of social influences. Reporting differences could occur because women may be more capable of consciously detecting the presence of social pressure, thus making them more able to report it, or they may relate their bases in such a way that they appear to be more social. There is another plausible explanation that stems from data generated in this study. It seems likely that women participating in this study were more likely than men to mention social forces upon their decisions because they were more likely to be going out with friends. None of these explanations are mutually exclusive, however, making the possibility of a combination of explanations seem likely.

\section{$\underline{\text { Marital Status }}$}

Marital status was the next most frequently significant variable. There were 23 instances of significant relationships between marital status and the frequency of a decision basis. There were no discernable patterns to these relationships however.

\section{Occupation}

There were also 23 significant relationships found between occupational classifications and decision bases. This variable was a measure of occupation type. People were classified as either being "blue-collar" meaning technical, service, and other of the more physical occupations, or "white-collar" in reference to professional, managerial, sales, and other occupations that are primarily mental. The significant relationships were found in spite of the crudeness inherent in a dichotomous split of this type. Generally speaking, white-collar workers were more affected by social and environmental variables, while blue-collar workers were more affected by internal states and motivations. For example, the earlier analysis of bases for decisions to drink showed that white-collar workers were more likely to state that they drank because others around them were drinking, while blue collar workers were more likely to state that they drank because they were feeling bad. Again, this difference may reflect a difference in drinking patterns, with whitecollar subjects more likely to drink socially, or it may reflect a difference in communicating reasons for their drinking behaviors.

$\underline{\text { Race }}$

Just as with gender, race is another highly salient demographic variable, and just as with gender, there were relatively few instances of significant relationships between race and decision bases. There were 21 instances of such relationships. There were no discernable patterns to these relationships however.

\section{Income}

A dichotomous variable (above or below $\$ 25,000$ a year) was constructed to indicate income levels. There were 19 significant relationships between levels of this variable and 
decision bases. Those making less money were more likely to mention bases that involved negative feelings. For instance, they were more likely to drink because they were feeling bad. And not surprisingly, they were also more likely to consider the cost of the activity that they were engaged in.

\section{CAGE Score}

Whether or not the subject answered "yes" to two or more of the CAGE questions related to the likelihood of mentioning a specific bases 17 times. The CAGE questions are frequently used as an indication of a drinking problem. There were no discernable patterns to these relationships however.

\section{Weekly Consumption}

Another indication of the subjects' drinking behavior is their weekly consumption. A median split was performed on the reported weekly consumption so that two groups were made, light (less than 8.23 drinks per week) and heavy drinkers (more than 8.23 drinks per week). There were 10 significant relationships found between the levels of this variable and the reporting of specific bases. Not surprisingly, heavy drinkers were more likely to report typical patterns of behavior as bases, while light drinkers were more likely to mention external reasons for their behaviors.

\section{RESULTS OF DEBRIEFINGS}

When all interviews had been finished, interviewers from each site were debriefed for there impressions of:

- Common Behavioral Patterns and Circumstances Leading to Drinking and Driving - trends that they might have noticed that may not have been evident from looking at the body of data collected.

- $\quad$ Suggested Countermeasures - drinking and driving countermeasures that seem to be potentially effective, based on impressions made during the interview process.

The major impressions of interviewers with regards to these issues are summarized below

\section{Common Behavioral Patterns and Circumstances}

What follows is a summary of opinions expressed by interviewers concerning common behavioral patterns and circumstances that they found during their interviews. It is important to note that these statements are based on opinions of individual interviewers with exposure to relatively small samples of subjects. It is not intended that they be given the same weight as the results of the analysis of the data. In many cases interviewers came to similar conclusions and often their opinions agreed with findings of the analysis of data. However, in some cases 
interviewers expressed opposing opinions. These opinions are not presented as objective scientific findings but as expressions of opinion that raise issues not specifically addressed by other analyses.

\section{Ineffectual Planning}

- Some people plan to drink and drive from the outset. Some of the episodes were habitual plans - people do the same thing every weekend. This came up more in the over-thirty crowd.

- Many people give little thought to the possibility that their behavior will lead to drinking and driving. "I just didn't think about driving home while I was drinking." It's almost as though there was no way to foresee that the drinking part of the situation would be linked to the driving part. "When it was time to drive home I suddenly realized that I was too drunk to drive home, but at that point there was nothing I could do about it." This is linked to the idea some subjects expressed that they never really realized how impaired they were until they were out of the drinking situation and walking to the car or driving.

- Some people plan to stop drinking early and stay for an hour after, but do not realize how long it takes to sober up.

\section{Unforeseen Changes in Circumstances}

- A few people had gotten drunk and then encountered a misfortune which required that they drive somewhere. (e.g., one man's mother died, one woman's cousin got shot, a couple of people's cars or friend's cars broke down and they needed rides).

- Some people make plans that would avoid drinking and driving then circumstances change; the designated driver leaves or gets drunk, the subject plans to spend the night but then everybody (including the host) leaves for a bar.

\section{$\underline{\text { Reasons for Drinking }}$}

\section{Emotions}

- Celebrating was a frequent reason given for drinking. The word "reunion" came up a lot, e.g., celebrations involving seeing old friends kept popping up. Many people mentioned being motivated to drink due to having a really good time. This may be due to the fact that most of these people were driving after drinking at social events. 
- Many people mentioned drinking due to stress. This included immediate stress, e.g., fights with significant others and work problems and longer term stress, e.g., working hard, money problems, separation or divorce.

- Some interviewers felt that working-class people were inclined to say that they drink out of stress, whereas college students and younger people were likely to associate drinking with good times. This matches findings of interactions between decision bases and demographics. Some interviewers felt that people drink because they feel good while others felt the opposite, i.e., that people mostly drink because they feel bad. Differences between these impressions are understandable when one considers with whom the interviews took place. Interviewers of DWIs and blue collar subjects heard primarily stories of stress-related drinking. Those that heard primarily stories of feeling good as a reason for drinking tended to be interviewing subjects who were younger and/or more likely to drink due to social influences.

- Some people seemed to drink due to loneliness or boredom.

\section{Cost and Quantity}

- Cheap drinks or unexpected free drinks were often listed as a reason for people to drink more than they planned. These happened when someone knew the bartender, someone bought them drinks, at weddings, etc. Some bars also charge a set fee where people can drink as much as they want for a flat price.

- Many people "warm up" by drinking before they leave home. For people over college age, this seems to be a social lubricant. Younger people most often say that they do this because drinks are cheaper at home than in a club so they are saving money by getting a start on drinking.

- $\quad$ Some young women mention going out with very little money or even none at all. Some say this is to keep from drinking too much, others say they know the guys will pick up the tab. This, however, makes taking a cab impossible, and means that they cannot eat when they're hungry.

- Buying pitchers seemed to encourage people to drink more. It is cheaper, it is easier, it makes others encourage them to keep their glasses full.

- It was suggested that it was difficult to control drinking by limiting the amount of money or alcohol that one brings because one never knows how much alcohol may be provided by others (e.g., people buying drinks for others). There seems to be a feeling that it's better to bring more alcohol than you need so that you can share. 


\section{$\underline{\text { Social Influences }}$}

- $\quad$ Buying "rounds" seems to assure that everyone is drinking. There tends to be some pressure to drink associated with this. Obviously if there are 8 people in a group that starts buying rounds, and everyone feels compelled to buy one round, each member would then have to drink 8 drinks.

- $\quad$ Drinking games contributed to heavy drinking.

- Attempts at intervention by others were extremely rare. When they were mentioned it was often successful in preventing some degree of drunk driving, but not successful enough to prevent it entirely. Subjects seemed far more likely to be encouraged by others to drive after drinking than to be encouraged not to drive.

\section{Common Perceptions Regarding Impairment}

- By and large the biggest reason people cite for not having someone else drive is that "everyone else was as drunk or drunker than I was." It seems to the subject that everyone was drinking as much as they were. Studies have found that college students who drink together do tend to drink at about the same pace. However, one man was at a family reunion, he drank a case of beer, and expressed the opinion that everyone else had as much as he did.

- $\quad$ Subjects often said "I thought I was o.k. to drive." Subjects felt this way while acknowledging signs of impairment that ranged from feeling tired after having one beer to still being able to stumble to the car. Many people feel o.k. to drive even with signs such as slurring words. Many of the drivers said that they were o.k. to drive but that they would have gotten a DWI if they had been pulled over.

- Many people claim to have internal alarms or "signals" which tell them whether they are drunk or buzzed.

- People mention that they did not know how much they had drunk when they were drinking from pitchers because people would fill up their glass before they had finished the last one. The same was true about drinking kegs.

\section{Common Perceptions about Alcohol}

- Some subjects believed that shots were more intoxicating than beer. After 6 beers, they felt nothing - it was the shot of Jagermeister that did it.

- Tequila is seen as having specially intoxicating qualities. 
- Beer is often the main drink, and they seem to think it is a less harmful drink than hard liquor.

\section{Driving}

- $\quad$ People are more afraid of being caught by the police than being in an accident. Plans are often based not around avoiding drinking and driving but around not getting caught. Most of the people drove more cautiously to avoid attention by the police. People had different strategies - go slower, take the backroads, etc. A smaller number mentioned driving more recklessly.

- $\quad$ Although people are motivated more by fear of apprehension by the police than of accidents, most people did not seem to believe that anything bad was likely to happen.

- Many people got on the road and realized they should not be driving. They would run off the road, hit the median, lose hubcaps, get lost. Many considered pulling over but decided not to because they were afraid of being caught by the police.

- Many of the people had driven while under the influence so many times they did not think anything could happen to them. Others were apprehensive but took the risk.

- Many people had known someone who was involved in a drunk driving accident. They mentioned it on their own, and some said that it had changed their own behavior, the way their group of friends made plans, or that it had changed their behavior for a while.

- Some interviewers expressed the belief that women, more often than men, seemed to mention the fear of being in an accident or hurting someone else. Other interviewers claim to have found the opposite.

- There were a lot of cases where even if a man drank more than the woman he was with, he still drove home.

- In cases where unexpected misfortunes lead to driving, people said that they were overcome by emotions and not thinking about drinking and driving.

- Whether the drinking location is far from home or close to home, there were excuses for driving after drinking associated with the distance. Often people were not worried about drinking and driving because of the short distance. If it was a long distance, it was considered too far to take a cab and too inconvenient to return for the car that was left behind. 


\section{Common Perceptions Regarding Alternatives}

\section{Designated Driver}

- The most commonly mentioned alternative was probably a designated driver. Many people mentioned having used this before, and people though of it without any prompting. (Many of the subjects were the designated driver.)

- Reluctant designated drivers are inclined to get drunk anyway. Subjects often said that their friend was supposed to be the designated driver but they did not and therefore the subject had to drive. Some designated drivers mentioned feeling pressured into drinking despite the fact that they were the designated driver. The designated driver ends up drinking so often that the phrase "designated drunk driver" seemed to be a common joke.

- When people think they have a designated driver, they give no consideration to slowing down, stopping, changing drinks, etc.

- As with many other highly-publicized anti-drunk driving slogans, "designate a driver" is well known and well accepted but not actually carried out properly, if at all.

\section{Eating}

- Many people said they do not like to drink on an empty stomach. It makes them feel sick. Many people said that they did not have time to eat and were very hungry.

\section{Getting a Ride}

- It is often possible to call friends or family for rides but subjects do not want to call them at early hours of the morning, or they do not want to be an imposition. Even when alternative drivers or rides are available at the subject's location, the subjects do not always feel comfortable asking for a ride.

- People do not want to leave their vehicle. They are worried about the safety of vehicles, and the inconvenience of having to come back and get them. Many people did not want to let other people drive their car. "If anyone is going to wreck my car, it should be me." People also expressed hesitancy towards driving other people's cars. 


\section{$\underline{\text { Public Transportation }}$}

- Often there is no public transportation available. Other times subjects were discouraged by the fact that they were unfamiliar with using public transportation to get home.

\section{$\underline{\text { Staying Over }}$}

- This was frequently mentioned by younger people. Many people knew from the outset that they could stay at a friend's house if they wanted to. Young people who were drinking at bars mentioned as an alternative, staying at a friend's house who lives closer to the bar. Some people said they wanted to stay over but were not invited. Even when subjects had a tacit understanding that event attendees could stay over there was no way of knowing how many others might be staying and whether there would facilities for all of them.

\section{$\underline{\text { Cabs }}$}

- Many subjects mentioned taxicabs as a potential alternative but went on to say that taking a cab was not practical because it was too expensive or because they had run out of money at the end of the evening. Taking cabs was also seen as inconvenient because it necessitated leaving the car. As is mentioned above under "Driving," people feel that cabs are unnecessary for short trips and unfeasible for long trips.

\section{$\underline{\text { Activities }}$}

- There are differing opinions as to the effects of activities, e.g., "Dancing makes you drink more - you're thirsty," "Dancing makes you drink less - you're busy," "Dancing makes you less drunk - you sweat out the alcohol."

\section{General Observations Regarding Alternatives}

- Many people were very intoxicated and knew that it would be a struggle to get home safely. At the same time, they could think of no alternatives. For example, one man was drinking with his boss. He could not admit that he had too much, so he drove the company van home and passed out in the van once he reached his house. Another young woman thought of many alternatives to get home from a bar, stayed an extra 30 minutes to sober up after her friends left, and then drove.

- There is big difference between the kinds of alternatives that are available in bigger cities and those that are available in smaller cities and rural areas. Specific alternatives not available in rural areas and not already mentioned above include 
staying in hotels and going to restaurants which are open late and located near the drinking location.

\section{$\underline{\text { Miscellaneous }}$}

- Some interviewers expressed the belief that older people appear to feel more remorse. They worry about what their church or families will think about them.

- There is not a lot of recognition that this sort of behavior is irresponsible. People seem to much more aware of drinking-driving issues than they were ten years ago but this does not seem to have resulted in any real change in practices. When people express responsible opinions about the importance of avoiding drinking and driving, they often seem able to do so without recognizing the contradiction between those opinions and their own behavior.

- In some rural areas where bars are scarce, cars serve as traveling bars. People drive to various meeting spots, either homes or outdoor locations, to meet and drink. In these situations alcohol consumption is a focus of activities.

- $\quad$ Many people mention that fatigue plays a part in their ability to drive safely. It also affects their desire to get home right way. Much of the impaired driving discussed in this study was done in the early hours of the morning.

\section{Suggested Countermeasures}

Interviewers were asked to suggest drinking-driving countermeasures that they believed might be effective based on the information they heard during the interviews. It should be noted that the interviewers were not experts in the field of drinking-driving countermeasures, nor were they expected to be. Some of the countermeasures suggested have been tried previously with little success. The comments below may be more notable for the countermeasures that were omitted, due to the belief that they would be ineffective, than for those that were included.

Publicize DWI Problems - The problems associated with getting a DWI should be more widely publicized.

- A video could be used to describe the problems associated with having your driver's license revoked. This includes problems far beyond not being allowed to drive. It makes it difficult to cash checks, get into nightclubs, etc.

- $\quad$ Publicize the costs. After drinking, a person may not think of the danger to others, but they may think about the personal cost. Financial consequences e.g., increased insurance, might motivate some people.

- $\quad$ Publicize the career problems caused by DWI. 
- Use a one-on-one session where the offender tells their story, and then with a counselor, comes up with a written plan to avoid drinking and driving in a similar situation.

Impairment Education - Countermeasures involving the modification of the public's perception of what impaired people look or act like:

- Illustrate true signs of early impairment. DUI offenders did not seem to be able to recognize when they were impaired and their friends also could not recognize when they were impaired. Messages need to show people with moderate impairment instead of only showing people who are severely impaired.

- $\quad$ Help people to understand tolerance. They need to know that someone who drinks a lot will not necessarily show it. They need to know that this, in itself, is a problem. They also need to know that high-tolerance drinkers are still dangerous when driving while intoxicated.

- Change perceptions of what heavy or moderate drinking is. Show people what percent of people who drink, drink as much as they do. As a means of helping people understand the concept of moderate and heavy drinking, substitute a nonalcoholic drink for alcohol and ask how many glasses they'd drink and how much would be a lot?

- Accurate information about the amount of alcohol required to reach legal limits should be more widely publicized.

\section{$\underline{\text { Responsible Alcohol Service }}$}

- $\quad$ Make it illegal for bars to charge a set fee (i.e. \$5.00) for unlimited drinks, or to serve free drinks to women.

- A successful way to discourage over-drinking might be to eliminate the economic incentive to drink more, for example, keep the price per amount that is charged for 12 packs, pitchers, full carafes on a par with that charged for individual drinks.

\section{Public Information Approaches}

- Have commercials where people show how they avoid drinking and driving. Use social modeling. For example, show someone at a party, who has had too much to drink, finding an alternate way home.

- Have commercials that show people in situations where they do not plan to drink and drive, but end up doing it, for example, a case in which someone has been drinking at home when a friend calls and asks for help with fixing a flat tire. 
- Target messages toward specific groups. For example, some rural groups cannot relate to taxis, motel rooms, or staying at someone's home. There is often no place for them to stay because they are drinking in the woods or around a pick up truck. Need to pay attention to socio-economic indicators. TV messages need to be shown on appropriate programs. Messages need to appeal to the target audience.

\section{Effective Strategies to be Used by Drinkers}

- Have the drinkers pay the designated driver to make it worth the designated driver's while. Do not give the designated driver the money until they have safely dropped off the last person.

- Use contracts like those used by SADD. The emphasis is not to not drink, but if you are going to drink, then do not drive.

- $\quad$ Getting people to stop drinking earlier may be successful because there are many people who are doing this already.

- Use shuttle buses for events like weddings, where it is known that a lot of people will be going from one place to another, drinking, and returning.

\section{Increased Penalties}

Some interviewers seemed to feel that the only countermeasure that will ever work is raising the severity of penalties to the point that drinking drivers are forced to consider alternative transportation arrangements.

\section{SUMMARY}

This final section of the report will attempt to summarize the bases for drinking driving decisions and the implications for action.

\section{Decision Bases}

Attempting to summarize the bases for drinking-driving decisions is a bit like attempting to summarize the telephone directory; the essence is in the detail. The sources of drinkingdriving decisions tend to involve very specific reasons for doing particular things. However, results expressed in broad categories of decision bases can help provide an understanding of why people drink and drive that cannot be perceived in the minutia of individual decision bases. The following section will review and summarize decision bases in broad categories, cutting across the various phases of the decision-making process (e.g., planning, transportation, etc.). Priority will be given to those bases that underlie the largest share of decisions, which tend to be those that figure prominently in more than one phase of decision making. The discussion will also 
describe interactions between decision basis categories and individual demographic characteristics. For each decision basis category there is also discussion of the implications of findings to countermeasures.

Not all of the decisions made in route to alcohol impaired driving contributed directly to it. Often, quite responsible decisions were reached too late to prevent impaired driving or were later negated by irresponsible decisions. In some cases relatively responsible decisions were made that did not prevent impaired driving but lessened the severity of the situation. Irresponsible and responsible decision influences involve the same categories.

\section{Predisposing Decisions}

Probably the most important discovery in the analysis of decision bases is the extent to which decisions quite removed in space and time from the act of alcohol impaired driving predispose an individual to its occurrence. Early decisions as to what kind of events to attend, where they are held, who will do the driving, whom to go with, how to get there, and what to do once there frequently create a situation in which over-consumption of alcohol and subsequent driving are almost certain to occur. For example a decision to attend a going-away party at a friends house may require driving a car to an event at which drinking to intoxication is very likely, with little chance of avoiding the drive home. Often the drinking event was such that merely deciding to take part meant drinking to the point of impairment. Typically, when the time came for the impaired person to leave, the opportunity of riding with someone else, getting someone else to drive or spending the night where the drinking occurred was not available.

\section{Social-Environmental Influences}

By far the single biggest influence on drinking and driving decisions comes from environmental influences, primarily those of a social nature. People who made decisions based on social influences tended to be younger people, including college students, and to be females. They also tended to be relatively high on the socioeconomic ladder, for example, with larger incomes, more education and white collar jobs.

In deciding whether or not to attend an event at which drinking would occur, overt encouragement by friends played the biggest role, with the prospect of meeting friends and acquaintances also being a strong influence. Influences of a more general environmental nature, "ambience," were of somewhat lesser importance. Social influences also played a significant role in transportation, drinkers riding with others because there was room in the car, because the driver wanted company, or because people were traveling as a group. In the plans that immediately preceded drinking, the primary social influences were passive, that is, being influenced simply by the drinking behavior of others. However, once drinking commenced, its extent was strongly influenced by social factors, which were divided almost equally among overt social influences, including having drinks offered or directly provided by others, and passive 
social influences, which included being where others were drinking or having others buying rounds, and the general atmosphere of a large party where people were having a good time.

In deciding to leave, social influences in order, were hosts' suggestions that they leave, the suggestion of someone else that they depart, and a generally unpleasant social environment. Finally, social influence played a significant, though lesser role, in driving after drinking, including direct suggestions or requests that the drinker do the driving, being in a social situation in which driving home was more or less expected, and in a few cases, the mere absence of any suggestion that the individual not drive.

Social Intervention - Of the drinking-driving appeals aimed at using social influence to intervene in drinking behavior, the best known is probably "friends don't let friends drive drunk." While this appeal certainly has merit, subjects frequently mentioned that they drove while impaired because friends asked them to. These influences were not so much a deliberate attempt to encourage impaired driving as much as a need for transportation that could be fulfilled by the impaired driver.

Designated Drivers - Another social influence, designating someone to serve as a driver was frequently mentioned. However, designated drivers were generally thought of, not as people who do not drink, but as people who (1) were expected to drink little or nothing, but may or may not actually limit their drinking, (2) are the best at driving after drinking, or (3) are referred to as the designated driver simply because they are the driver.

Staying Over - Where the social environment had been a private residence, both drivers and hosts seem to be aware of the possibility of "staying over" and there was frequently an understanding that guests could do so. However there were rarely any advanced preparations to provide a comfortable place to sleep or to make guests aware of it, and there was frequently no way of knowing how many people might be expecting to use it. In addition, lack of planning on the part of the drinkers frequently resulted in obligations that necessitated driving, such as passengers who had to be driven home, next-day commitments, or others (e.g, parents, spouses) awaiting their return.

\section{$\underline{\text { Personal Influences }}$}

Influences of a personal nature were second in importance to social influences. People making decisions based on internal motivations tended to be the opposite of those influenced by social factors in that they were generally older, in blue collar jobs, with lower incomes and less education. The exceptions were decisions in which there was a social element to the personal influence, such as a strong personal need to see other people.

Among the personal reasons for attending an event were a desire to be with people, find entertainment or food, visit family members, consume alcohol, and a variety of other objectives. When it came to transportation, the amount one wanted to drink influenced the choice of transportation mode to some extent, although it was not a major consideration. However, it was 
in making plans to drink, and the actual drinking activity that personal influences played a major role. Decision bases in this category include the simple desire to drink, to achieve relaxation, to feel the effects of alcohol, to achieve a particular mood or mood change, to satisfy the taste for a particular beverage, or overcome the effects of stress or depression.

Personal influences also came to the fore in the decision to leave a place where one had already been drinking. Specific bases included (in descending order) the simple desire to be somewhere else, feeling the effects of alcohol, fatigue, boredom, and the desire to go home. Finally, personal influences were also paramount in decisions regarding driving after drinking, the single greatest influence being the failure to feel the effects of alcohol, followed by the belief that impairment would not affect driving, the belief that not enough alcohol had been consumed to worry about, or the simple need to get somewhere else. In very few instances were decisions influenced by the belief that it would be unsafe to drive.

To alter internal, personal influences would require changing the views and perceived needs of drinking drivers themselves, a task that seems particularly daunting when one considers that people most responsive to personal influences tend to be older, less educated and with drinking and driving histories that seem to indicate more deeply ingrained drinking and driving behavior. Yet many in this category accepted the need to make basic changes in their use of alcohol, frequently saying that they had effectively used this alternative in the past and just did not happen to do so in this case. Others found it more realistic to alter their driving by riding with others, walking to drinking locations or by doing their drinking at home. Drivers with prior DWIs were more positive about such possibilities than they were about altering their drinking behavior.

Using transportation for hire as an alternative to driving had little appeal for the study sample as a whole. Reasons cited for this included inconvenience (e.g., having to return for the vehicle), cost (e.g., taxi fare), worry (e.g., that the car would be stolen, vandalized, ticketed or towed), unfamiliarity (e.g., do not know bus schedules) and unavailability (e.g., no taxis, subway stops running at midnight).

\section{$\underline{\text { Responsibility }}$}

The third most commonly cited category of decision basis involved feeling greater or lesser degrees of responsibility. These bases were expressed by people who made decisions which reduced the seriousness of the drinking-driving situation, people who felt relieved of some responsibility and, hence, free to get into a drinking-driving situation, and people who found themselves in a drinking-driving situation due to feelings of responsibility to others. As might be expected, subjects who made decisions based on feelings of responsibility tended to be in the more responsible demographic groups (e.g., female, no prior DWIs, employed full-time, drive after drinking infrequently). In cases where feelings of responsibility contributed to drinking and driving (e.g., "I went because my friend was having the party," or "I drove because my friend needed a ride") it was generally born of a social situation, and subjects expressing such decision bases tended to match the profile of the socially-influenced drinker. 
The fact that these drivers seem to be motivated by a sense of responsibility gives some hope that appeals to this sense may be successful in getting them to recognize the need to reexamine priorities, and to understand that involvement in a drinking and driving situation due to some responsibility is an abdication of larger responsibilities.

\section{$\underline{\text { Occasion }}$}

Next in importance as a decision basis was the nature of the occasion that prompted the drinking. The influence of occasions was greatest in initial decisions to attend a drinking event, where participation in the event was determined by specific occasions recognized as "special" events, such as family reunions, birthdays, holidays, work-related parties, farewell parties, and others. Making up a small minority of occasions were leisure time activities such as playing games or watching sports on television, and regularly scheduled events such as happy hours and Friday night parties. The nature of an occasion was seldom cited as an influence upon plans for drinking and actual drinking. However, this may be largely a reflection of the degree to which the nature of the occasion predetermined the amount and type of drinking that would take place. So, while subjects may have mentioned other bases for drinking, part of the decision to drink was made by simply deciding to attend an event where the nature of drinking was known in advance. Therefore the occasion may have actually had more influence on drinking than is apparent from the bases mentioned.

It is difficult to characterize subjects who made decisions based upon the nature of the occasion, as those characteristics are different from one type of occasion to another and for the same types of occasions from decision to decision (i.e., decisions to go versus decision to drink). The only demographic trends that seem to remain fairly constant were the tendencies for these subjects to be male and older. It appears that, if alcohol consumption associated with specific occasions is to controlled, the burden will fall upon those hosting the events---the way in which they present it and the way alcohol is dispensed.

Both drinkers and hosts of parties need to avoid the creation of, or involvement in, situations in which celebration of an occasion is considered an excuse for over-consumption of alcohol.

\section{$\underline{\text { Availability and Economics }}$}

Availability of alcohol and economic considerations were interrelated in that decisions tended to be based upon availability in relation to cost to the drinker. Whether one elected to attend an event and how much one intended to drink was influenced greatly by whether it was provided by someone else, price in relation to quality and quantity received, and absolute price - in that order. In actual drinking, sheer availability or plentitude was the major consideration, followed by availability in relation to cost and, lastly, mere availability. Lack of availability by itself was an occasional consideration in the cessation of drinking. The influence of cost itself was largely confined to transportation, where the cost of alternative transportation ranked second to social influences in deciding how to get to and from a drinking event. Merely having a 
vehicle available to drive, without cost, was the chief consideration in this regard, followed by the possibility of a ride from someone else.

There were no clear-cut tendencies for certain demographic groups to be associated with availability-driven decisions across all decisions. Such is somewhat surprising since one might expect subjects with low incomes to be particularly likely to make decisions based upon economic considerations.

The absolute cost of alcohol appears to have played a relatively small part in the decisions leading to alcohol impaired driving, at least over the price range at which alcohol was available. A greater influence was the amount in which it was available in relation to is cost. As with drinking occasions, the prospects of altering decision bases seem to depend upon providers rather than consumers. Decisions leading to impairment could be discouraged by (1) not providing drinks that have not been requested, (2) not displaying large quantities of alcohol, or (3) not offering volume discounts.

\section{Prior Plans}

In decisions about participating in an event, about a fifth of the subjects reported that their decision to attend a drinking event was part of a larger plan, while about a tenth indicated that the decision was of the "spur-of-the-moment" type. While previous plans were the single most frequently mentioned influence upon the intent to drink, the majority of drinkers intended to consume modest amounts of alcohol. The actual influence of this intent upon the actual consumption of alcohol was obviously minimal. In short, among alcohol impaired drivers, attending drinking events often occurs in keeping with plans, while heavy drinking more often occurs in spite of them.

A phenomenon that was noted by many interviewers that would not have appeared in the data due to the way it was collected and analyzed is that people are continuing to drive to places at which they drink without recognizing that they are putting themselves in a situation where they face driving while impaired. These people often seem surprised to find themselves in this situation, even though it should have been obvious from their plans.

\section{Usual Behavior}

The last decision basis reported often enough to warrant mention involves extension of one's customary behavior patterns. In decisions to participate in events, determining when and where to drink often involved doing what the individual usually did under the circumstances that prevailed. Extension of usual, typical behavior patterns also applied to the choice of transportation, the decision of how much and what to drink, and the manner in which one actually drank, although in these decisions it played a relatively minor role. Subjects who made decisions to drink heavily based on normal or past behavior were likely to be similar to those whose decisions were governed by personal influences, in that they customarily drank heavily, drove after drinking, had prior DWIs, and tended to come from the ranks of blue collar workers. 
College students and females were over-represented among those whose usual behavior would be considered "responsible" behavior. For example, females were likely to make decisions to drink very little because that is how much they "normally" drink (even though they eventually actually drank to impairment).

Perhaps the most noteworthy aspect of prior planning and usual behavior is the extent to which they did not influence decisions, that is, the extent to which (1) they were superseded by more transitory influences, and (2) influences of a responsible nature were negated by less responsible influences. The fact that so few subjects mentioned normal behavior as a motivating factor in decisions is not necessarily indicative of the role that normal behavior plays in drinking and driving. Many of the interviewers were left with the impression that many or most of the people to whom they spoke were drinking and driving on a regular basis. It seems likely that, while people may be engaging in behavior on a regular or habitual basis that continues to put them in drinking-driving situations, they are not going to say that the reason they do so is that that's what they always do.

\section{Implications for Action}

What actions might be taken to alter the influences leading to alcohol-impaired driving? While the data collected in this study are insufficient to support the formulation of specific countermeasures, they do carry implications for types of changes that will help reduce the likelihood of alcohol-impaired driving among the population of drivers for whom this is a common activity. Action implications arising out of this study can be grouped into three categories: advanced planning, social intervention, planning alternatives, and redefining responsibilities.

\section{$\underline{\text { Early Decisions }}$}

One of most salient findings of the analyses that have been described involves the extent to which decisions early in the chain of events leading up to alcohol impaired driving make it almost inevitable. Efforts to intervene in drinking before driving, or driving after drinking, are often defeated by the circumstances surrounding the acts themselves. More attention needs to be directed toward early decisions.

Events characterized by heavy drinking are generally recognizable as such at the outset. By the nature of the event itself (e.g. celebration) or the people involved in the drinking, the prospect of drinking to impairment is often evident at the time the decision is made to participate. That is the point at which decisions that will avoid impaired driving need to be made. It is when alternative transportation needs to be arranged; a car not driven to an event cannot be driven home. It is the point at which arrangements to spend the night rather than come home at all need to be made; the interviews showed that this solution to impaired driving is not amenable to last minute arrangements. Informational and educational programs to combat drunken driving could be profitably oriented toward these early decisions. Such an orientation might be particularly beneficial to those previously convicted of alcohol impaired driving offenses, who are often 
highly motivated to stay clear of situations likely to lead to recidivism but who focus their attempts on decisions arising too late in the process.

\section{$\underline{\text { Social Intervention }}$}

The past decade has witnessed an effective broadening of efforts to combat drinking and driving to address not only those who do the drinking and driving, but those who are in a position to intervene. They include friends, social hosts, and those who sell alcohol. While the information gathered through interviews with alcohol-impaired drivers certainly support interventions intended to prevent drinking and driving, they also evidence a need to go further to combat what are widespread practices that actually encourage alcohol-impaired driving. Agents of such encouragement include friends, hosts, and sellers of alcohol.

Friends. Two ways in which friends frequently encourage consumption of alcohol to the point of impairment is by buying drinks for friends when they are not requested and by the practice of buying drinks in "rounds." The person for whom the drink is bought, who may have had enough already, will often accept the drink to avoid the embarrassment of declining it. Or, if the friend is not within earshot, the drink may arrive before it is too late to decline it. The friend now feels obliged to return the favor, ordering another pair of drinks as a neighborly gesture. The result may be at least two drinks beyond the friend's personal limit, and even worse if the series of purchases continues. More dangerous is the group form of the same arrangement, whereby someone pays for a "round" of drinks, thereby obligating everyone else at the table to follow suit and assuring that everyone receives as many drinks as there are people present at the table. The arrival of newcomers adds to the number of drinks that are offered, and usually consumed.

Efforts to promote social intervention with the notion that "Friends don't let friends drive drunk" need to be expanded to include the idea that "Friends don't encourage friends to drive drunk." The target of social intervention must be expanded to include discouraging the purchase of drinks without knowing whether people want them, acceptance of drinks that are not wanted and initiating or participating in what is destined to be a series of drink purchases. It will thus be necessary to overcome both the belief that buying drinks is socially desirable or that declining them is socially unacceptable.

Subjects in this study frequently mentioned that they drove because friends asked them to. Drinkers need to know not to encourage others, or be encouraged by others, to get on the road when, by staying (and ceasing drinking), they will at least be reducing their level of impairment while driving. While such a step may not eliminate impaired driving it would at least lessen its severity.

Hosts. Those who are supposed to keep "friends" from driving drunk include hosts as well as drinking companions. Again, the concept needs to be broadened to prevent inadvertently encouraging excessive drinking by displaying large quantities of alcohol or by actively "pushing" 
drinks as a form of "hospitality." Hosts must beware of creating situations in which special occasions become an excuse for the over-consumption of alcohol.

What we know of host intervention establishes that efforts to prevent impairment are more likely to meet with success than efforts to deal with it after it occurs. Unfortunately, even when signs of impairment become evident, the response of many hosts and "friends" is usually to ignore, rather than call attention to them. This may be due to a lack of interest in the condition of guests or a lack of understanding of what an impaired person looks like. Efforts to encourage responsible service of alcohol by social hosts need to help them recognize the sometimes subtle, and sometimes overt ways in which they may be encouraging over-consumption of alcohol by their guests. Hosts, friends and drinkers alike need to be able to recognize signs of alcohol impairment that appear before slurring and staggering.

Sellers. In recent years, a great deal of effort has been devoted to altering practices involving the sale of alcohol in bars and restaurants. From the interviews, it is apparent that one of the biggest contributors to alcohol impairment is the encouragement given to over-consumption by quantity discounts ("Two-for's"), volume service (e.g., pitchers of beer or margaritas), or unlimited quantities (e.g., "All you can drink for ..."). While these are seldom practices of responsible establishments, they were frequent features of the establishments where those interviewed became impaired. Evidence from this study supports educational and regulatory measures to reduce these promotions, revealing the extent to which they contribute to alcohol impaired driving.

The influence of economic issues is not limited to special promotions in bars and restaurants. Many drinkers take advantage of volume discounts by purchasing larger amounts of alcohol (e.g., twelve-packs and large pitchers of beer or full carafes of wine rather than six-packs, small pitchers or half carafes) simply because the price per drink is reduced by a few cents. Drinkers need to recognize the potential for problems due to this type of economic influence.

\section{$\underline{\text { Planning Alternatives }}$}

Most of the subjects who acknowledged driving while impaired noted the availability of alternatives of which they did not avail themselves, primarily due to lack of adequate planning. They include alternatives to alcohol, to driving and alternatives to going home. It is apparent from the study that the perceived availability of alcohol and transportation plays a role in decisions leading to drinking and driving. It may be that a solution to the drinking-driving problem is not only to decrease the perceived availability of drinks and vehicles, but to increase the perceived availability of alternatives.

Alternatives to Alcohol. Many alcohol-impaired drivers may have switched to nonalcoholic beverages had they been available or had their availability been more apparent. However non-alcoholic beverages, such as non-alcoholic beers, were rarely mentioned as being available, and when they were, were rarely displayed prominently. It is interesting to note that subjects who chose to eat at an event did so most often because the food was perceived as being 
available. Alternatives to drinking will not lessen the likelihood of alcohol-impaired driving unless the need for alternatives is recognized in advance and provision of them is made an object of planning.

Alternatives to Driving. The extent to which alcohol-impaired subjects served as "designated drivers" evidences the need for clarification and for better planning for this alternative to driving. First, those that provide transportation to and from a drinking event need to recognize they are de facto designated drivers, that their obligation is not simply to provide transportation, but to assure an acceptable degree of safety. If they are unprepared to fulfill their responsibilities, they should not be accepting passengers (or driving themselves, for that matter).

Responsibility is also shared by passengers. It is evident that many of them accepted transportation without making any inquiry as to the driver's plans with regard to drinking. Once drivers and their passengers had been drinking it was often passengers who suggested leaving. In some cases passengers may have been ignorant as to the driver's impairment. In other cases they may have known and not cared. If a driver was only going to drink more and become more impaired by staying, the pressure to leave may have improved the situation. However, some subjects stated that they generally stop or slow their drinking toward the end of the evening. If these drinkers are pushed out the door and into their cars earlier than they might have otherwise, the passenger doing the pushing is likely making matters worse. It must be noted that many subjects seemed unaware of the length of time necessary for BACs to come down after the cessation of drinking, so there may be minimal benefits to be obtained by allowing them to stay long enough that they feel they've "sobered up." In any case, efforts to convince people of the benefits of alternatives to driving would do well to target potential passengers as well as drivers.

The negative attitudes shown toward the use of public transportation in general, and taxi cabs in particular, indicates that efforts to encourage drinkers to use such systems, without making any changes to those systems, may be a wasted effort.

Alternatives to Going Home. The lack of planning was perhaps most evident in the failure of efforts to avoid alcohol-impaired driving by allowing drivers to spend the night at the drinking site rather than attempting to drive home. Offers to "stay over," whether made when the drinker arrived, or was about to leave, were generally too late to be taken seriously. Belated attempts to encourage staying over were too often thwarted by obligations that the driver had already incurred. Commitments on the part of both the host and the guest are needed; informal arrangements too often resulted in confusion. Commitment on the part of the host would be to provide a specific place to stay. Commitment on the part of the guest is to notify others not to expect them home (which avoids the implication that they were too drunk to get there) and bringing with them necessary clothing, shaving/cosmetic gear and so on.

Redefining Expectation Some instances of alcohol-impaired driving can be traced to what drivers see as expectation. Drivers who recognize that they are too impaired to drive may decline to stay the night or to accept a ride home because they believe they are expected to provide 
transportation to others. Similarly, passengers of an impaired driver may decline alternative transportation because they think they are expected to leave with the person who brought them. Drinkers who might otherwise be encouraged to stay longer to sober up often leave due to perceived expectation to be elsewhere. At least within certain segments of society, an effort to redefine what constitutes expectation is warranted. 


\section{REFERENCES}

Basch, C.E.; DeCicco, I.M.; and Malfetti, J.L. (1989). A focus group study on decision processes of young drivers: Reasons that may support a decision to drink and drive. Health Education Quarterly, 16(3), 389-396.

Basch, C.E. (1987). Focus group interview: An underutilized research technique for improving theory and practice in health education. Health Education Quarterly, 14, 441-448

Biddle, B.; Biddle, B.; and Bank, J. et al. (1980). Societal determinants of adolescent drinking. Journal of Studies on Alcohol, 41, 215-241.

Biddle, B.J.; Bank, B.J.; and Marlin, M.M. (1981). Social determinants of adolescent drinking. Journal of Studies on Alcohol, Vol 4.

Grey Advertising. (1975). Communication strategies on alcohol and highway safety. Washington, DC: U.S. Department of Transportation (Report No. DOT-HS-803-714).

Khron, M.; Ackers, R.; and Radosevich, M. et al. (1982). Norm qualities and adolescent driving and drug behavior. Journal of Drug Issues, 12, 343-359.

Klitzner, M.; Rossiter, C.; and Gruenwald, P.. (1987). Determinants of youth attitudes and skills towards which drinking/driving prevention programs should be directed (DOT HS 807 130). Washington, DC: NHTSA.

Lund, A.K. and Wolfe, A.C. (1989). Changes in the incidence of alcohol-impaired driving in the United States, 1973-1986. Arlington, VA: Insurance Institute for Highway Safety.

Marlatt, G.A. and Gordon, J.R. (1985). Relapse prevention: A self-control strategy for the maintenance of behavior change. New York, NY: Gulliford Press.

Milgram, G. (1982). Societal attitudes toward youthful drinking. Journal of Drug Education, 12(2).

National Highway Traffic Safety Administration (1987). Feasibility planning study for a behavioral database. Vol. III: Appendix B. Compendium of survey questions on drinking and driving and occupant restraints. National Highway Traffic Safety Administration. Report DOT HS 807 123. Washington, DC: U.S. Department of Transportation.

National Highway Traffic Safety Administration. (1993). Traffic Safety Facts, 1992. Washington, DC: NHTSA. Report No. DOT HS 808022.

Nusbaumer, M. and Zussman, M. (1981). Autos, alcohol, and adolescents: forgotten concerns and overlooked linkages. Journal of Driver Education, 11(2). 
Smith-Donals, L. and Klitzner, M. (1985). Self-reports of youthful drinking and driving: sensitivity analyses of sensitive data. Journal of Psychoactive Drugs. 17(3).

Thurman, Q.; Jackson, S.; and Zhao, J. (1993). Drunk-driving research and innovation: A factorial survey study of decisions to drink and drive. Social Science Research, Vol. 22(3), 245-264.

Vegaga, M.E. and Klitzner, M.D. (1989). Drinking and driving among youth: A study of situational risk factors. Health Education Quarterly, 16, 373-388.

Voas, R.B. (1990). Report on the Minnesota 1990 Roadside Survey. Landover, MD: National Public Services Research Institute. 